\title{
DECEPTIVE INTENT
}

Physiological reactions in different interpersonal contexts

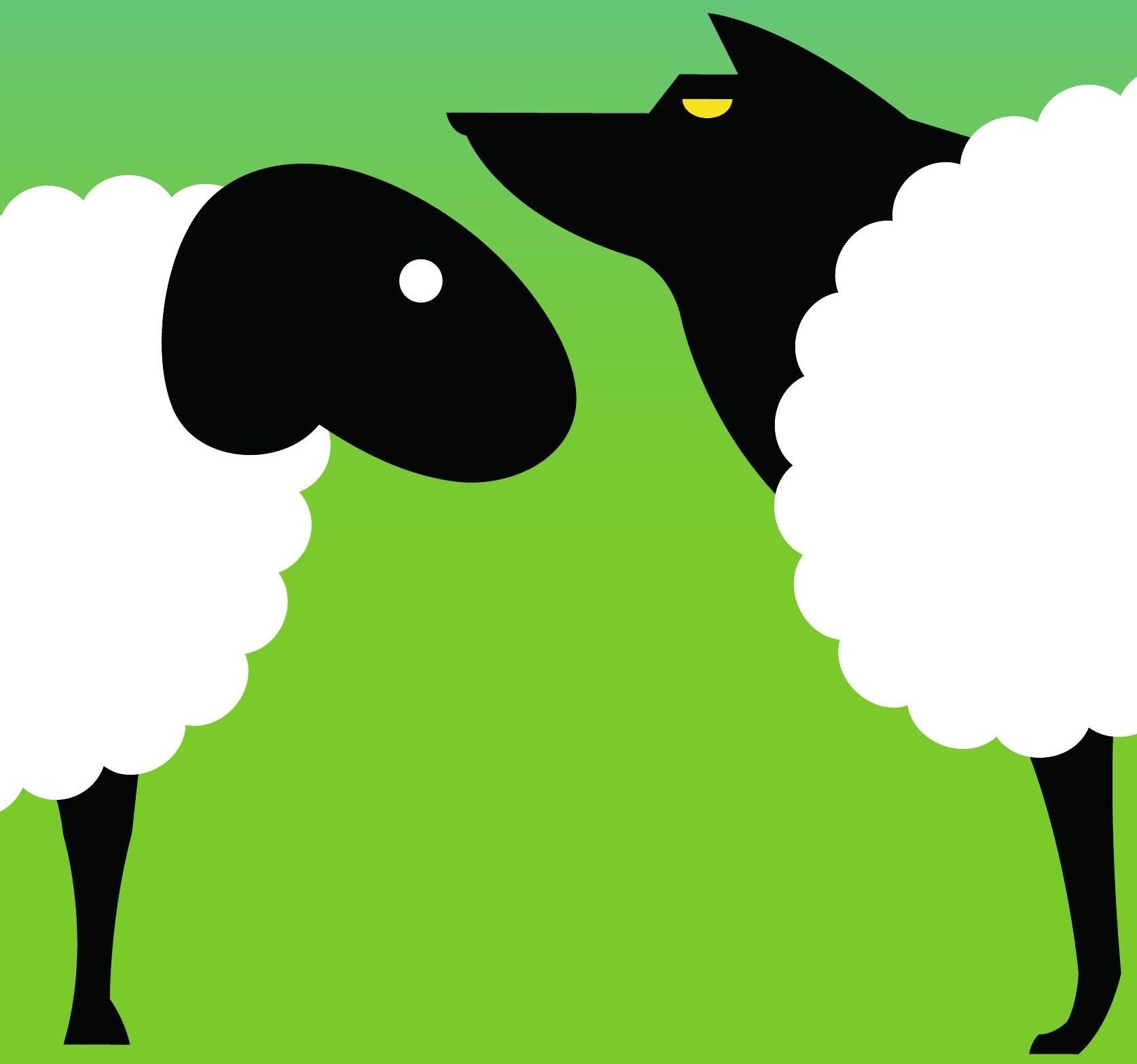

\section{Sabine Ströfer}


DECEPTIVE INTENT

Physiological reactions in different interpersonal contexts

Sabine Ströfer 
Thesis, University of Twente, 2016

(C) Sabine Ströfer

ISBN: 978-90-365-4030-8

DOI: $10.3990 / 1.9789036540308$

Cover by Floor Bakker

Bookdesign and printed by Gildeprint, Enschede, the Netherlands 


\title{
DECEPTIVE INTENT \\ PHYSIOLOGICAL REACTIONS IN DIFFERENT \\ INTERPERSONAL CONTEXTS
}

\author{
PROEFSCHRIFT \\ ter verkrijging van \\ de graad van doctor aan de Universiteit Twente, \\ op gezag van de rector magnificus, \\ prof. dr. H. Brinksma, \\ volgens besluit van het College voor Promoties \\ in het openbaar te verdedigen \\ op donderdag 18 februari 2016 om 16.45 uur
}

\author{
door \\ Sabine Ströfer \\ geboren op 6 augustus 1986 \\ te Beckum \\ Duitsland
}


Dit proefschrift is goedgekeurd door de promotor prof. dr. E. Giebels en de copromotoren dr. E. G. Ufkes en dr. M. L. Noordzij. 


\section{PROMOTIECOMMISSIE}

\section{Promotor}

Prof. dr. E. Giebels

\section{Copromotoren}

Dr. E. G. Ufkes

Dr. M. L. Noordzij

\section{Leden}

Prof. dr. P. J. Taylor

Prof. dr. D. K. J. Heylen

Prof. dr. J. M. C. Schraagen

Prof. dr. I. van Beest

Prof. dr. R. Volbert 



\section{Table of Contents}

Chapter 1: Introduction

Chapter 2: Deceptive intentions

Chapter 3: Catching a deceiver in the act

Chapter 4: Interviewing Suspects with Avatars

Chapter 5: Discussion

References

Summary

101

Samenvatting

Acknowledgements

KLI Dissertation Series 



\title{
Chapter 1
}

\author{
Introduction
}


10 | Chapter 1 
Perhaps one of the most well-known incidents involving deception is the Lewinsky scandal surrounding US president Bill Clinton in 1998. As there were increasing allegations of him having a sexual relationship with one of his employees, Monica Lewinsky, he denied having had a "sexual relationship": "Now, I have to go back to work on my State of the Union speech. And I worked on it until pretty late last night. But I want to say one thing to the American people. I want you to listen to me. I'm going to say this again: I did not have sexual relations with that woman, Miss Lewinsky." As the allegations increased and the evidence became stronger, Clinton defended himself by referring to the ordinary definition of the term "sexual relation", "[...] I'll bet the grand jurors, if they were talking about two people they know, and said they have a sexual relationship, they meant they were sleeping together; they meant they were having intercourse together." We know by now that Clinton has had an affair with Monika Lewinsky (Starr, 1998). But did Clinton lie? According to the definition of lyingmaking an untrue statement with the intent to deceive ("Lie", 2014)-he did not, because a "sexual relationship" literally refers to "Sexual intercourse" ("Sexual relations", 2015). Did Clinton deceive? He definitively did. He intentionally used the vague term sexual relationship (from which there is widespread disagreement in colloquial speech which sexual activities this term includes, see Tiersma, 2004) in a literal sense, knowing that people probably understanding the term sexual relationship as also including other sexual activities than intercourse (Tiersma, 2004).

Clinton's infamous attempt to deceive makes clear that having the intention to deceive is the defining factor of deception (Ambach, Stark, Peper, \& Vaitl, 2008). That is, literal lies or fabrications are not necessarily a requirement for deception (Sip, Roepstorff, McGregor, \& Frith, 2008). In this specific case, Clinton bent the truth, but deception may take a variety of other forms, ranging from direct lies to half-truths, vagueness, equivocations, and concealments (Carlson, George, Burgoon, Adkins, \& White, 2004). The essential point of successfully deceiving others is to intentionally control the information one is telling in order to create a false belief (Vrij, 2008). Even more so, in an attempt to create a false belief, deceivers generally stick to truth as close as possible (Leins, Fisher, \& Ross, 2013; Strömwall, Hartwig, \& Granhag, 2006). This is reflected in Clinton's statement, which started with a long truthful statement before he actually commented on the 'sexual relation' he pretended not to have. The reason why deceivers try to remain close to the truth is twofold: Staying close to truth is easier and costs less effort (Leins et al., 2013), and it reduces chances of being caught, for example because there is less chance one delivers contradicting information (Hartwig, Granhag, Strömwall, \& Doering, 2010). Thus, in order to create a coherent, believable but deceptive story, deceivers typically combine deliberate truth telling with specific moments where one diverges from the truth by for example using lies, vagueness or half-truths etc. However, until now, deception research has largely neglected such a more sophisticated conception of deception and has primarily focused on the strict comparison of lying with 
"sincere" truth telling (Gödert, Rill, \& Vossel, 2001; Jung \& Lee, 2012; Watson \& Sinha, 1993). The primary goal of this dissertation is to advance the deception field by examining the psychological processes associated with deceptive intent-truth telling with the intention to lie on a crucial aspect later in time.

In my approach I identified three areas of emphasis which contribute to theory formation as well as having applied relevance. First, and in line with the interpersonal deception theory (IDT) of Buller and Burgoon (1996), I consider deception as an interpersonal and interactive activity. Deception is defined as creating a false belief in another person ( $V$ rij, 2008) and therefore by definition is an interpersonal activity, including a deceiver and target to deceive. However, "deception has seldom been studied as a truly communicative activity" (Buller \& Burgoon, 1996, p. 203). As cues to deception may become more distinct under more interpersonal, interactive conditions, I examined deception in 4 empirical studies which differed in interpersonal contact and degree of interactivity, ranging from limited interpersonal contact and interactivity towards studies with high interpersonal contact and interactivity.

Second, I aimed to include studies with deception about transgressions that were committed on a voluntary basis. In many deception studies, participants are instructed by the research leaders to commit something unlawful (e.g., Gödert, Gamer, Rill, \& Vossel, 2005; Kircher, Horowitz, \& Raskin, 1988; Verschuere, Crombez, De Clercq, \& Koster, 2004) or envision committing such a crime (Beune, 2009). These studies are often criticized because participants may not feel "agency" and responsibility for their deed (DePaulo et al., 2003; Sip et al., 2008). Therefore, we developed and used a new paradigm where participants were "seduced" to commit a transgression and were merely advised about how to react when questioned (i.e., (when) to lie or not).

Third, I wanted to address the rapid recent developments in communication technology. Most deception theories are based on face-to-face encounters (Buller \& Burgoon, 1996; Zuckerman, DePaulo, \& Rosenthal, 1981), but nowadays a great deal of day-to-day deception takes place in computer-mediated communication settings (Hancock, Thom-Santelli, \& Ritchie, 2004). Furthermore, modern communication technologies not only create new deception settings (Hancock, 2007), they also offer new opportunities to detect deception. For example, autonomous interview systems (often embodied by virtual avatars) are increasingly considered as a first-level screening tools to detect cues to deception in interpersonal communications for crowded and vulnerable places such as airports (Derrick, Jenkins, \& Nunamaker Jr, 2011; Nunamaker, Derrick, Elkins, Burgoon, \& Patton, 2011; Twyman, Lowry, Burgoon, \& Nunamaker Jr, 2014). Considering that face-to-face communication has a different nature than communication with avatars (Schroeder, 2011) and although there is a lot of research on both deception and computer mediated communication separately, little research is done yet at their intersection (Carlson et al., 2004). Before I further elaborate on 
the specific studies conducted in this dissertation, I will go into the psychological processes underlying deception and how these can be measured, particularly on a physiological basis.

\section{Processes underlying deception}

Humans are bad lie detectors (Memon, Vrij, \& Bull, 2003; Vrij, 2000; Zuckerman et al., 1981) and there is no unique indicator of deception similar to Pinocchio's growing nose (Vrij, 2004b). Still, certain psychological processes are more likely to occur during deception than truth telling (Zuckerman et al., 1981). These processes in turn can result in behavioral and physiological cues to deception which may be observed and measured (DePaulo et al., 2003). In my dissertation I mainly focus on a physiological indicator-electrodermal activity (EDA), one of the most frequently used physiological measures by scholars and practitioners in the field of deception (Vrij, 2008).

According to Zuckerman et al.'s (1981) multi-factor model of deception, factors influencing cues to deception can be categorized into three categories: emotional stress, cognitive effort, and attempted behavioral control. Deception related emotional stress generally is caused by fear, guilt, and delight (Ekman, 1989). Deceivers might fear that their lie will be detected, feel guilty because they realize that what they do is wrong or simply be excited by the thrill of fooling someone.

Cognitive effort can either be related to the act of lying itself or to the deception process more in general. That is, during lying deceivers have to suppress the truth while coming up with a plausible alternative statement (Spence et al., 2001; Vrij, 2008). Previous research shows that during deception in general, and not restricted to the act of lying, deceivers are more inclined to monitor their behavior to appear honest (DePaulo, Kirkendol, Tang, \& O'Brien, 1988), monitor the person they deceive to check their believability (Buller \& Burgoon, 1996; Schweitzer, Brodt, \& Croson, 2002) and constantly remind themselves to appear honest (DePaulo et al., 2003).

The final category, the attempted behavioral control, describes cues to deception that indicate the deceiver's attempt to control his or her behavior (Buller \& Burgoon, 1996; Burgoon \& Buller, 1994). Deceivers are aware that attention is paid to their behavioral reactions to judge their credibility. Deceivers therefore try to show behaviors they believe make them appear credible (Hocking \& Leathers, 1980; Leary \& Kowalski, 1990) and this again should increase monitoring behavior and impression management. Cognitive effort and attempted behavioral control therefore share a cognitive origin whereas emotion related cues to deception are more 'stress' related. These two directions also can be seen back in the traditional emotional load approach of deception, focusing more on stress related cues, and the more innovative cognitive-load approach of deception, focusing more on cognitive cues (Vrij, 2008; Vrij, Fisher, Mann, \& Leal, 2006). 
In my dissertation I will argue that several aspects of emotional stress, cognitive effort as well as attempted behavioral control are present during the whole attempt to deceive, including the parts deceivers are not actually lying. Theoretically, deceivers should, for example, already be nervous or stressed at the foresight of lying. At the same time, deceivers already could be cognitively loaded by increased monitoring behavior even when they are not lying. For example, especially when switching between deceptive tactics it may be important to control the communication course, or monitor one's own appearance and that of the other to assure that the switching between telling the truth and lying remains unnoticed.

\section{Measuring cues to deception with electrodermal activity}

Physiological lie detection goes back till 1000 B.C. in the old China. Here, suspected liars were forced to chew rice powder and the spit it out. Suspects were judged as lying if the rice powder was dry (Vrij, 2008). The rationale behind this idea was that lying is associated with fear, and fear in turn is associated with decreased salivation and a dry mouth (Kleinmuntz \& Szucko, 1984). Today the techniques have become more sophisticated, but the basic premise of the Chinese survived in modern lie detection: using the idea that there are consistent differences in the physiological response of a person who is lying compared to someone who is telling the truth as basis for deception detection (Watson \& Sinha, 1993).

Most people can recall an occasion when, caught in a lie, our face flushed, our heart rate picked up and our hands became clammy (lacono, 2008). Modern polygraphs measure these changes in the sympathetic nervous system (SNS) by recording the physiological reactions to relevant and control questions. The magnitude of each type of physiological response can be compared and the likelihood calculated whether an examinee is lying or not (lacono, 2008). The most frequently used physiological measure in lie detection context is electrodermal activity (Vrij, 2008) which also forms the central measurement method in this dissertation. The mechanism behind measuring EDA is as follows: Various psychological processes such as cognitive load or stress activate the sympathetic branch of the nervous system (Engström, Johansson, \& Östlund, 2005; Hout, Jong, \& Kindt, 2000; Lacey, Kagan, Lacey, \& Moss, 1963; Nourbakhsh, Wang, Chen, \& Calvo, 2012; Page \& Robson, 2007; Shi, Ruiz, Taib, Choi, \& Chen, 2007; Wilson, 2002). This results in more sweating and because sweat is an electrolyte solution, the skin conductivity increases. Increased skin conductivity in turn can be measured by placing two electrodes on a person's fingers and apply a small current. The amount of current that passes between the electrodes is defined as skin conductance (measures in Micro Siemens) and mirrors the underlying electrodermal activity (Figner \& Murphy, 2010). 


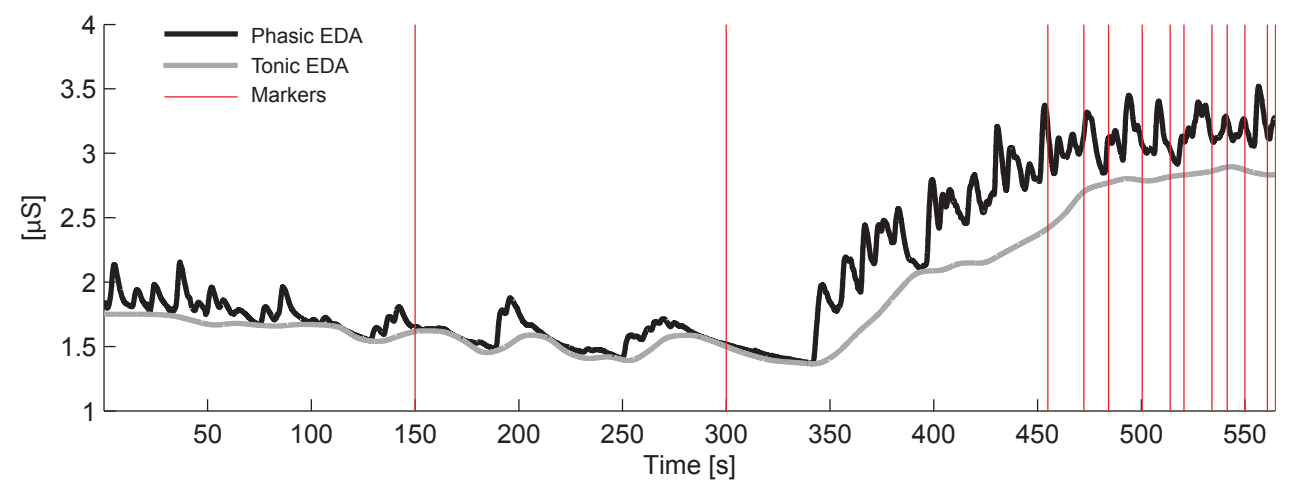

Figure 1.1. Electrodermal Activity (EDA). Illustrative example of measured EDA of one participant during an experiment interview. The markers indicate events in the experiments. The first two markers indicate the baseline measurement of the participant about 5 minutes. The remaining markers mark the start of a new question in the interview.

The advantage of EDA is that it directly indicates SNS activity and can be measured within one single measurement (Boucsein, 2012; Dawson, Schell, \& Filion, 2007). Generally, an EDA measurement over time consists of an overall, slow drifting signal, overlaid by phasic fluctuations, called skin conductance responses (SCRs; Boucsein, 2012), see Figure 1.1. In our studies we were interested in both more general SNS levels across for example deceptive interview and SNS activity changes on question levels. The former can best be measured via tonic EDA, which describes the overall level of EDA across time windows of ten or more seconds (Figner \& Murphy, 2010). Tonic EDA either can be operationalized by taking the average EDA across a time window or by quantifying the SCRs over per time unit, for example the number of SCRs per minute (Boucsein, 2012). To look at changes in SNS activity on question levels, it is most useful to investigate local phasic EDA changes.

There are various methods to analyze EDA (for a review see Boucsein, 2012; Roth, Dawson, \& Filion, 2012). In this dissertation the Continuous Decomposition Analysis (CDA) by Benedek and Kaernbach (2010) is used to separate the skin conductance into continuous signals of tonic and phasic EDA activity by means of deconvolution. I use this method as the basis for examining the psychological processes associated with deception.

\section{Interpersonal deception}

According to the 'Interpersonal Deception Theory' (Buller \& Burgoon, 1996), individual processes underlying deception are moderated by the kind of interpersonal contact the deceiver has with the communication partner. Herewith they recognize the factors from Zuckerman and colleagues (1981)-emotional stress, cognitive effort and attempted behavioral control-as underlying reasons for cues to deception (Vrij, 2008) but emphasize that these are sensitive to the interpersonal context. 
Interpersonal contexts may differ on two dimensions: the level of interactivity and interpersonal contact. Face-to-face interactions usually scores high on both dimensions. As a result, deception during face-to-face interactions further add cognitive demands to the deceiver beyond those already associated with deception (Buller \& Burgoon, 1996). Deceivers continuously have to "attend to their conversation partner to find out whether they are still believed, while managing their emotions, keep dialogue running smoothly, responding appropriately to what the conversation partner says and be discreet about any intentions to deceive" (Vrij, 2008, p. 48). Also, interpersonal communication cannot be fully anticipated (Berger \& Battista, 1993) which might be extra stressful for the deceiver. Interpersonal deception therefore is qualitatively different from non-interactive deception.

In my dissertation I examined deception by varying interpersonal contact as well as by the degree of interactivity. In Study 2.1 and 2.2 (Chapter 2), interpersonal contact was kept at a minimum and interactivity was low. Participants believed that an expert in lie detection would observe their reactions through a camera. However, the conversation was unidirectional in that the participant deceived/told the truth in front of a PC and the 'expert' did not react to the participant. In Study 3 (Chapter 3) and Study 4 (Chapter 4) we created a situation where participants had to deceive in an interactive interview setting. I hereby could see whether cues to deception measured during lying and the mere intention to lie are different when embedded in an interactive context.

The context of deception not just differs in interactivity but also in the level of interpersonal contact. With the rise of new technology this aspect has gained in importance and relevance. Computer-mediated communication provides less access to social cues than a face-to-face conversation (Buller \& Burgoon, 1996). In order to examine whether this is important to evoke cues to deception, I set up two interview studies which differ in interpersonal contact. Both studies were exactly the same and only differed in terms of the type of interpersonal contact: In Study 3 the interview was conducted face-to-face whereas in Study 4 the interview was conducted via a virtual avatar.

By comparing Study 3 and 4 I can see whether interpersonal contact, independent from interactivity, may alter cues to deception. In addition to that, we strived to make both studies more realistic by implanting a new paradigm in which participants where "seduced" to commit a transgression and were merely advised about how to react when questioned about it. I hereby induce in the participant's "agency" for their deed.

Within the avatar study (Study 4), I also pay intention to an even more fundamental question underlying interpersonal deception: Namely whether a minimal requirement to elicit cues to deception is that the deceiver recognizes the communication partner as a "conscious" being. Naturally this is the case as deceivers interact with humans. Yet, with the latest development in the field of deception detection this issue becomes relevant in security contexts using automatic interview systems. As already mentioned above, more and more effort is spent in 
developing computer operated interview systems to cope with one of the biggest security challenges of the 21th century-automated deception detection at vulnerable and crowded locations such as airports (Aradau, 2015; Damos, Boyett, \& Gibbs, 2013; Lu et al., 2010). As in normal suspect interviews, the aim of these computer operated systems is to determine whether a suspect is lying (Horvath, Jayne, \& Buckley, 1994). However, the crucial difference compared to normal interviews is of course that the human interviewer is replaced by an artificial intelligence (Al). An Al obviously neither is a human nor has consciousness. The question therefore arises how such systems affect the deception process and which variables are determinant to the success of such systems in detecting deception. In other words, will deceivers show cues to deception knowing that they are just talking with a machine?

\section{Overview of the studies in the dissertation}

In the first two empirical studies reported in Chapter 2 the aim was to put our idea that the mere intention to lie already could increase cues to deception to a first test. Therefore, we compared participants' electrodermal activity when they had the intention to lie and compared this with the more traditional conditions of pure lying and pure truth telling. The goal of these studies was to use a paradigm with high internal validity and low interpersonal variance. For this reasons we employed a within-subject design and let participants lie in front of a computer screen. The rationale behind this approach was to first investigate deception in a clean controllable environment to see whether the intention to lie can be measured at all. Moreover, adding double-tasks is known to increase cues to deception (Vrij, Fisher, et al., 2006). In Study 2.1 we therefore let participants conduct an emotion recognition double-task and in Study 2.2 a traditional arithmetic double-task while telling the truth and deceiving.

In Chapter 3, we investigated the three veracity conditions: Truth telling with the intention to lie, lying and truth telling, in a much more realistic between-subject design. We "seduced" participants to commit a transgression and to subsequently tell the truth about it or deceive about it by either lying on one crucial question or on all questions. In this study we wanted to test whether we could replicate our findings in a more interactive setting. To gain more insight into the processes underlying deception, this time, we combined measurements of electrodermal activity with self-reports of stress and cognitive load.

In Chapter 4, the study design was exactly the same as that used in Chapter 3 with the only difference that the human interviewer was replaced by virtual avatar. To resemble this as closely as possible, the avatars voice was taken from the human interviewer from Study 3. Next to examining whether cues to deception also appear when using an avatar, a virtual presentation of a human (Galanxhi-Janaqi \& Nah, 2004), we were also interested to see whether 'believing' such an avatar is human or computer operated is a vital ingredient that makes such automated lie detection work. See Table 1.1 for a schematic overview of the chapters. 
Table 1.1. Schematic Overview of Empirical Chapters.

\begin{tabular}{lllll}
\hline & $\begin{array}{l}\text { Interpersonal } \\
\text { contact }\end{array}$ & $\begin{array}{l}\text { Degree of } \\
\text { interactivity }\end{array}$ & "Agency" & Focus \\
\hline Chapter 2 & Low & Low & Low & $\begin{array}{l}\text { Controlled lab-environment, focus on } \\
\text { whether the mere intention to deceive can be } \\
\text { measured at all. }\end{array}$ \\
Chapter 3 & High & High & High & $\begin{array}{l}\text { Interactive face-to-face interview, focus on } \\
\text { processes underlying deception. } \\
\text { Interactive interview conducted by a virtual } \\
\text { avatar, focus on whether 'belief' that avatar is } \\
\text { human or computer operated influence cues } \\
\text { to deception. }\end{array}$ \\
\hline
\end{tabular}

Note: In all chapters we measure the physiological response while participants tell the truth while having the intention to lie, lie or tell the 'sincere' truth. 


\section{Chapter 2}

\section{Deceptive intentions}

Can cues to deception be measured before a lie is even stated?

This chapter is based on:

Ströfer, S., Noordzij, M. L., Ufkes, E. G., \& Giebels, E. (2015)

Deceptive intentions: Can cues to deception be measured before a lie is even stated? PlosOne, 1-17.

We would like to thank Marije Hoogeboom, Tom Jansen and Paul van der Zijden for conducting the experiment and Paul van der Zijden for developing the study paradigm. 
20 | Chapter 2 
Most of the research on physiological detection of deception has focused on the act of lying, and contrasts specific statements that are either truths or lies (Hartwig \& Bond Jr, 2011; Watson \& Sinha, 1993). These studies build on the fact that there are consistent differences in the physiological response of the sympathetic nervous system when lying or when telling the truth (Cunha et al., 2010; Jung \& Lee, 2012; Watson \& Sinha, 1993). However, categorizing statements as either truths or lies neglects that deception may take a variety of forms, ranging from its most direct form, fabrication, to more subtle forms including half-truths, vagueness, equivocations, and concealments (Carlson et al., 2004). This implies that deception and lying, although used interchangeably, reflect essentially different constructs. Deception refers to "[...] a deliberate attempt to create in another a belief which the communicator considers to be untrue" (Vrij, 2008). A lie is defined as intentionally making a false statement ("Lie", 2014). Thus, whereas deception refers to a process, lying refers to a specific strategy that can be used during this process. This is an important notion because deceivers tend to stick to the truth as much as possible (Leins et al., 2013) and to only lie on crucial aspects (Sip et al., 2008; Strömwall \& Willén, 2011).

Theory and empirical data emphasize that lying is cognitively and emotionally taxing (Zuckerman et al., 1981). Previous work demonstrated, for instance, that brain areas associated with cognitive processes such as working memory and executive control are more active when lying compared to telling the truth (Abe, Suzuki, Mori, Itoh, \& Fujii, 2007; Christ, Van Essen, Watson, Brubaker, \& McDermott, 2009; Ganis, Kosslyn, Stose, Thompson, \& YurgelunTodd, 2003; Nunez, Casey, Egner, Hare, \& Hirsch, 2005). Also, feelings of nervousness and stress may accompany lying (Burgoon \& Buller, 1994; Vrij, Ennis, Farman, \& Mann, 2010), which can be related to different emotions (Ekman, 1989). These differences are reflected in increased sympathetic nervous system (SNS) activity (Cunha et al., 2010; Jung \& Lee, 2012; Watson \& Sinha, 1993).

The aim of the current chapter is twofold: First we examine whether SNS activity, associated with deception, already can be observed in stages wherein one is telling the truth but does have the intention to lie at a later moment. Second, we examine how SNS activity is affected by moving from a mere intention to deceive to a stage wherein one-in order to keep up their deceptive intentions-actually will be required to lie.

\section{Truth telling with the intention to lie: Can SNS activity, related to deception, be detected before a lie is stated?}

Previous work consistently demonstrated that lying is cognitively and emotionally taxing (Zuckerman et al., 1981). Research shows that brain areas associated with cognitive processes such as self- and other monitoring, working memory, and executive control, are more active when lying compared to telling the truth (Abe et al., 2007; Christ et al., 2009; Ganis et al., 2003; Nunez et al., 2005). Also, feelings of nervousness and stress frequently accompany 
lying (Burgoon \& Buller, 1994; Vrij, Ennis, et al., 2010). Based on earlier research (Gödert et al., 2001; Jung \& Lee, 2012; Pennebaker \& Chew, 1985; Podlesny \& Raskin, 1977; Vincent \& Furedy, 1992; Watson \& Sinha, 1993), we therefore expect SNS activity to be higher during lying compared to truth telling (Hypothesis 1).

Moreover, SNS activity may already rise before lying, when having the intention to deceive. Intention refers to a mental representation of planned actions (in this case the aim to deceive others), based on some amount of reasoning and planning (Malle, Moses, \& Baldwin, 2001). Therefore, many of the cognitive processes needed for lying may already be active during the intention to deceive. This may, for example, reflect monitoring processes related to concerns to appear consistently honest and not to give away cues to deception when switching from truth telling to lying (Aikins, Martin, \& Morgan, 2010; DePaulo et al., 2003). Also, arguably, people may already feel nervous and stressed in the foresight of lying and not just at the moment of lying itself.

Some first evidence that the intention to deceive can be measured, can be found in studies which have tried to separate the 'act' of deception from the 'intention' to deceive by using a delay in subjects' answers (Dawson, 1980; Furedy \& Ben-Shakhar, 1991; Furedy, Davis, \& Gurevich, 1988; Gödert et al., 2001). These studies monitored SNS activity while people gave honest and deceptive answers to questions. SNS activity was increased during deceptive answers compared to truthful ones. Even more importantly, SNS activity already increased in the time interval between the question and the answer. In the short moment between question and lying, arousal thus already increased when anticipating lying.

This previous work, however, focused on a single snapshot of the specific moment that people are lying. The current research goes above and beyond these findings by approaching deception as an ongoing process. To do this we make a distinction between the anticipation and action stage during the process of deception. That is, deceptive interactions for a part exist of an action stage in which one has the intention to deceive others but is telling the truth because the content of the interaction does not require lying yet. Only a specific part of the interactions exists of an action stage involving interactions that require straightforward lies in order to deceive the other. We predict that increased SNS activity due to the intention to deceive already can be detected in such anticipation stages wherein one is telling the truth but has the intention to deceive when necessary (Hypothesis 2).

Moreover, cognitive load and stress caused by preparing to lie should become most taxing when moving to the action stage-when the necessity for lying increases. Also, switching between tasks in itself is known to cost effort (Monsell, 2003). Therefore, we assume that the switch from the anticipation stage toward the action stage especially increases SNS activity (Hypothesis 3). 


\section{The current research}

We developed a new paradigm to examine the entire process of deception, contrasting the mere intention to deceive with pure truth telling and lying. Traditionally studies investigating deception contrasted specific truthful statements with lies (Gödert et al., 2001; Jung \& Lee, 2012; Watson \& Sinha, 1993). However, such an approach makes it impossible to capture the processes associated with the mere intention to deceive, because intention related processes occur simultaneously with lying processes. In the current work we therefore not just compare SNS activity during lying and truth telling, but also during truth telling with the intention to lie at a later moment.

Moreover, previous studies demonstrated that adding a double task significantly improves the chances of observing cues to deception due to cognitive processes associated with deception (Vrij, Fisher, et al., 2006; Vrij, Granhag, Mann, \& Leal, 2011; Vrij, Mann, Leal, \& Fisher, 2010; Vrij et al., 2008). A secondary task increases participants' cognitive demand and impedes the act of deceiving which is also cognitively demanding. This leads to a poorer deception performance and hence more cues to deception (Vrij, Fisher, et al., 2006). Although studies in the field of deception detection used a variety of double tasks (Vrij, Fisher, et al., 2006; Vrij et al., 2011; Vrij, Mann, et al., 2010; Vrij et al., 2008), studies studying cognitive processes in general use arithmetic double tasks more often (Horrey, Lesch, \& Garabet, 2009; Park et al., 2011; Van Impe, Coxon, Goble, Wenderoth, \& Swinnen, 2011). In Study 2.1 we used an emotion recognition task, because, while deceiving, people constantly had to read facial expressions to assess whether they were believed or not (Buller \& Burgoon, 1996; Schweitzer et al., 2002). In Study 2.2 we used a more traditional, arithmetic double task.

In both studies, we measured electrodermal activity (EDA) as an indicator for SNS activity (Boucsein, 2012; Dawson et al., 2007). EDA is an index for both stress (Hout et al., 2000; Page \& Robson, 2007; Peter Bankart \& Elliott, 1974) and cognitive load (Engström et al., 2005; Nourbakhsh et al., 2012; Shi et al., 2007; Wilson, 2002)1. An important advantage of using EDA is that its signal is discriminable, meaning that changes in sympathetic nervous system activity can be detected with one single measurement (Dawson et al., 2007). Therefore, it is an often-used measure method in field studies with applied relevance (Dotsch \& Wigboldus, 2008; Kuikkaniemi et al., 2010; Schmeichel, Demaree, Robinson, \& Pu, 2006; Seitz, Daun, Zimmermann, \& Lienkamp, 2013), and the most frequently used physiological measure by scholars and practitioners in the field of deception (Vrij, 2000). An EDA signal measured over time consists of an overall, slow drifting signal, overlaid by short fluctuations, called skin conductance responses (Boucsein, 2012). The slow drifting signal is called tonic EDA and indicates the overall conductivity of the skin over long time intervals of about ten or more seconds (Figner \& Murphy, 2010). The overlaying fluctuations are referred to as phasic

\footnotetext{
${ }^{1}$ Please note that some studies tried to discriminate stress from cognitive load in EDA (e.g., Setz et al., 2010). However, usually stress and cognitive load are correlated (McEwen \& Sapolsky, 1995) and difficult tasks (such as deceiving) can induce both (Howells, Stein, \& Russell, 2010).
} 
EDA, and are particularly sensitive for short local fluctuations in SNS activity (Boucsein, 2012; Figner \& Murphy, 2010). It is therefore likely that tonic EDA will be most suited for comparing longer stages of truth telling-with and without the intention to lie-with those of constantly lying (Hypothesis 1 and 2). Phasic EDA in turn will be especially sensitive to brief changes in arousal, and therefore to measure the switch from anticipation toward action stage (Hypothesis 3).

\section{Study 2.1}

\section{Method}

\section{Participants.}

Fifty students from a Dutch University participated in the experiment. All subjects provided written informed consent and the Ethics Committee of the Faculty of Behavioral Sciences of the University of Twente approved the experimental protocol. Due to technical failures in measuring skin conductance, three participants were removed, leaving 47 participants for statistical analyses (mean age $=21.01$ years, $S D=2.28$, range $=18-29$ years; 21 women) .

\section{Experimental design.}

Blocks. The experiment consisted of three within-subject conditions (lie/truth/intention to lie), and was built up from nine successive blocks (3 lie blocks, 3 truth blocks and 3 intention blocks), presented in a random order. We used three different sequence versions to control for habituation effects. Every block was divided into an anticipation and an action stage, each consisting of three trials with a question (therefore each block consisted of six trials). In the action stage one of the three questions was colored blue (the order of the blue questions was counter-balanced).

In the truth blocks participants were instructed to answer truthfully on all six trials, and in the lie blocks participants had to lie on all six trials. In the intention blocks, participants were instructed to answer truthfully on all trials except for the critical trial (with the blue colored question). Because the blue question never occurred in the anticipation stage, this stage served as basis to measure truth telling with the intention to lie. The blue question always occurred in one of the final three question trials of the block, hence this stage is referred to as action stage.

Important to note is that in the truth and lie blocks participants additionally were instructed to say 'blue question' when the blue colored question appeared. This instruction created an expectation regarding the blue questions in all blocks, not just the intention blocks. Electrodermal activity (EDA) differences between the intention, lie and truth blocks therefore are not simply due to anticipation or occurrence of a neutral event (the blue question), but 
can be attributed to the anticipation of lying. The trial position of the blue question was unknown to the participant.

Trials. Participants first saw the stimulus window for 5 seconds, containing a face, a related Yes/No question to that face and a double task. The face stimuli were selected from the Radboud Faces Database (Langner et al., 2010). In order to increase external validity, we randomly used faces from males and females, Caucasian and non-Caucasians, as well as from adults and children. The question always referred to a face characteristic (e.g., "Does this person have blue eyes?"). Next, the answer window appeared for 6 seconds. During these 6 seconds participants were asked first to give a full verbal answer to the question (which could be a lie or truth, depending on the block) and then to give the solution to the double task. After the answer window, a white screen appeared for 9 seconds before a new trial began. A trial included a stimulus, a response and a pause (see Figure 2.1).

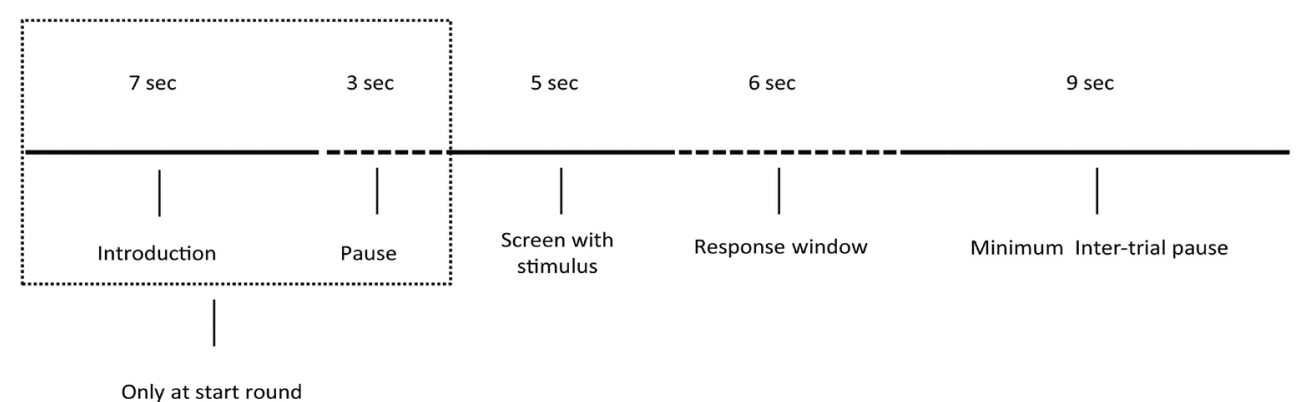

Figure 2.1. Trial structure. Every trial lasted for 20 seconds. During the first 5 seconds (Screen with stimulus) three objects were shown: a face, a Yes/No question about a face-characteristic and a double task. Then a response window was shown for 6 seconds. In these seconds participants first answered the question and then solved the double task, both orally. Finally, a white screen appeared for 9 seconds before a new trial started.

Double task. Monitoring others' emotional expressions is an important aspect during deceiving in order to assess whether one is believed or not (Buller \& Burgoon, 1996; Schweitzer et al., 2002). We constructed the task as such that the face stimuli expressed one of the most recognized emotions across cultures: anger, fear, sadness, disgust, happiness, contempt or surprise (Ekman, 1992). In six blocks, an emotion occurred only once. However, to prevent learning effects, in two blocks one emotion occurred twice and in one block one emotion occurred three times. Across all 54 trials, sadness occurred nine times, happiness and anger eight times, fear six times, disgust eleven times and contempt four times. Participants were instructed to say aloud the emotion that they saw. An example of these trials can be found in Figure 2.2 (Panel A). In half of the blocks, the facial expression to be recognized was morphed with the neutral face expression of the same face ${ }^{2}$.

\footnotetext{
${ }^{2}$ The original design also contained a between-subject factor, task difficulty. However, analyses with this variable did not render any significant main or interaction effects. We suspect that the difference between the conditions was not strong enough and we therefore eliminated this factor from further analyses.
} 

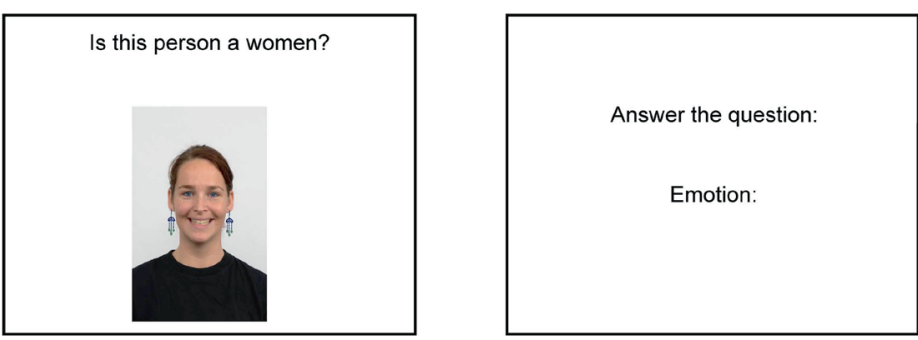

A
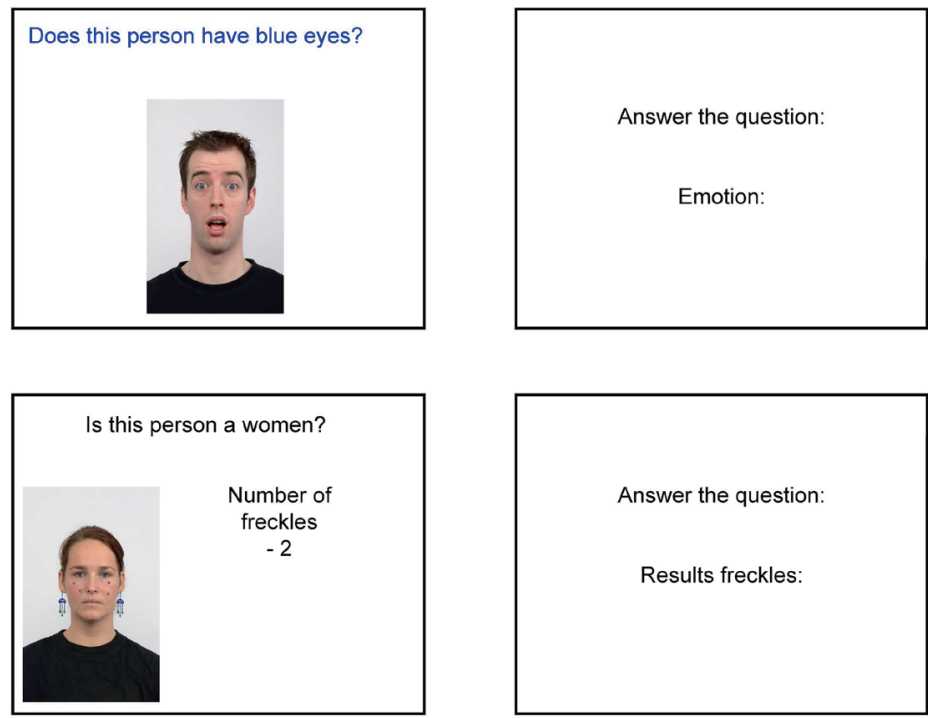

B
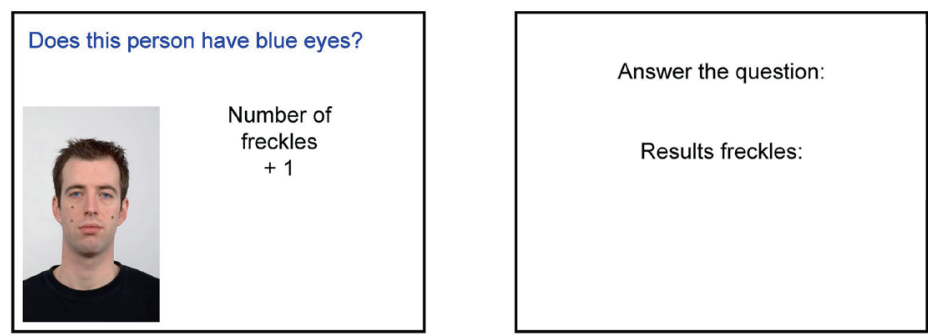

Figure 2.2. Double task example. Panel A shows an excerpt from Study 2.1 and panel B shows an excerpt from Study 2.2. Both contain two trials, consisting respectively of a question window (duration: 5 seconds) and answer window (duration: 6 seconds). At total each block consisted of 6 such successive trials from which one is colored blue. Whether participants responded with lying or saying 'blue question' on the blue question depended on the condition (lying, truth, intention). The two studies differed with respect to their double task. The double task in Study 2.1 consisted of an emotion recognition task. In the excerpt from panel A, participants were expected to say aloud 'Happy' and 'Surprised', after having answered the question (e.g., 'Yes, this person is a woman. Happy'). The double task in Study 2.2 consisted of an arithmetic task. In the excerpt from panel B, participants were expected to say aloud ' 2 ' and ' 4 ' after having answered the question in the answer window (e.g., 'Yes, this person is a woman. Two'). 
Procedure. Participants were instructed to answer blocks of six questions. We informed them that with each question a face would be shown to which the questions would be related, for instance a question about hair color. We told them that preceding each block they would get the instruction to lie, tell the truth on all questions, or just to lie on the blue colored question. We informed them that in case they got the instruction to tell the truth or lie on all questions, they had to say aloud 'blue question' as soon as they encountered a blue question. We also instructed them to say aloud the emotion they recognized in that face after they had answered the question.

Participants completed one practice block consisting of six trials in the presence of the experimenter who ensured that participants followed the instructions. Then the experimenter left the room and the experiment started. Participants received no feedback about their performance, neither on the double tasks, nor on truth telling and lying. The experiment lasted 26 minutes. To increase the participants' motivation and involvement in the task, we awarded a prize money of $100 €$ and $50 €$ respectively to the 'best and second best liar'. We also told participants that an expert in lie detection observing their responses via a webcam (a camera was placed next to the monitor so it was visible for the participants) would make this judgment ${ }^{3}$.

\section{Measures.}

Electrodermal activity as indicator for sympathetic nervous system activity. Using EDA has several advantages over other physiological measures: It directly reflects activity of the sympathetic nervous system (SNS) without being affected by parasympathetic activity (Boucsein, 2012; Wallin, 1981). Its signal is distinctive, can be measured unobtrusively and can be detected after one measurement (Dawson et al., 2007). Because we were interested in long lasting processes (monitoring and preparing) as well as short lasting events (the switching between a stage of truth telling and a stage where a lie takes place), we chose to base our analyses on tonic as well as phasic EDA.

Tonic versus Phasic EDA. In EDA research, differences are made between tonic and phasic EDA, which both can be extracted from the raw EDA data (Boucsein, 2012; Roth et al., 2012). EDA measured over a period of time consists of an overall and relatively slow drifting signal on which there are short fluctuations, called skin conductance responses (SCRs) (Benedek \& Kaernbach, 2010; Lykken \& Venables, 1971; Roth et al., 2012). The slow drifting signal is called tonic EDA and indicates a more general level of arousal over a longer time interval (Figner \& Murphy, 2010). The SCRs are sensitive for short phasic localized fluctuations in arousal (Boucsein, 2012).

Tonic EDA. Tonic EDA is modulated by chronic stimuli over a longer time interval (Dawson et al., 2007). Traditionally there are two ways of computing tonic EDA. First, one can average

\footnotetext{
${ }^{3}$ In reality, the money was allotted among the participants after the experiment.
} 
all measurements points distributed across the time window of interest, leaving out the measurement points during the SCRs (Boucsein, 2012). By omitting the SCRs, a stable and slowly adapting/changing signal is left, not distorted by spontaneous events. Another method is to measure characteristics of the SCRs observed in the time window of interest, for example the frequency or total amplitude of the SCRs (Roth et al., 2012). SCRs reflect the higher-frequency variability of the entire signal (Figner \& Murphy, 2010).

Because we are interested in SNS activity during longer time periods of truth telling and lying, tonic EDA is suitable for comparisons between the three conditions. Tonic EDA increases at any task performance. Even more important, the anticipation alone of any task will increase tonic EDA (Dawson et al., 2007). So, it can measure differences (if present) between truth telling with and without a deceptive intent, which do not differ in task (truth telling) but in anticipation (either lying or not on an upcoming question).

Phasic EDA. Since phasic EDA is based on SCRs, it is more sensitive to the abrupt, short-lived changes. This makes it a good candidate in our experiments to measure the switch from an anticipation stage (e.g., truth telling) to an action stage (where e.g., a lie takes place) within a condition.

Computing tonic EDA and phasic EDA. Establishing tonic and phasic EDA from one continuous EDA signal often bears difficulties. One of these difficulties is that SCRs often overlap and therefore lose their typical form of a sharp phasic peak. That makes it difficult to tear apart the slow changing tonic EDA from its overlaying SCRs (Boucsein, 2012). We used a method by Benedek and Kaernbach (Benedek \& Kaernbach, 2010) which controls for this problem, called the Continuous Decomposition Analysis (CDA). It returns the raw EDA data into a continuous tonic and phasic signal (the overlaying SCRs). Therefore, a multi-step deconvolution approach is applied, based upon a physiological model of the SCR shape. The continuous phasic signal is expressed as time integrated area under the SCR and measured in $\mu \mathrm{S}^{*} \mathrm{~s}$. The continuous tonic signal is measured in $\mu \mathrm{S}$.

Because of the slow fluctuations, tonic EDA is suitable for comparisons between the three conditions. Since phasic EDA is based on SCRs, it is more sensitive to the abrupt, short-lived changes when for example switching from anticipation (e.g., truth telling) to acting (e.g., lying) within a condition. Both hypotheses were tested on tonic and phasic EDA. Based on the nature of these two signals we expect to find a stronger pattern of effects for Hypotheses 1 and 2 (overall patterns) in tonic EDA and for Hypothesis 3 in phasic EDA (Dawson et al., 2007). Recording EDA. EDA was measured exodermal (constant voltage) using skin conductance sensors (Thought Technology Ltd., Montreal West, Quebec, Canada), attached to the distal phalanx of the right index and ring fingers (Roth et al., 2012). The signal was amplified and recorded using a ProCompInifiniti system (Thought Technology Ltd.). Continuous Decomposition analysis was executed using MATLAB custom code from Ledalab (Benedek \& Kaernbach, 2010). 
EDA Parameter settings. EDA was recorded at $256 \mathrm{~Hz}$ and down-sampled to $16 \mathrm{~Hz}$ (well above the $10 \mathrm{~Hz}$ after which increases in sample frequency do not significantly alter the EDA parameters) ${ }^{4}$. Parameters were computed with continuous decomposition analysis (CDA). We used a minimum amplitude threshold criterion of .01 $\mu \mathrm{S}$ (Boucsein, 2012) and iterated the parameter optimization three times. The skin conductance was separated into a continuous tonic and phasic signal, each containing 54 trials per subject.

EDA Time window. SCRs usually have a delay between one and four seconds (Roth et al., 2012). Figure 2.3 shows the mean course of raw EDA, phasic EDA and tonic EDA during a trial (20s) per condition. As can be seen, skin conductance rises about two seconds after stimulus onset. Therefore, we chose a time window ranging from 2 till 13 seconds after stimulus onset (the question), encompassing the moment the question is presented and the moment the answer has to be given. Our statistical analyses are based on tonic EDA ( $\mu S)$ and phasic EDA ( $\mu S^{*} s$ ) in this time window. As recommended by Boucsein (Boucsein, 2012), EDA was normalized by taking the natural logarithm. Statistical analyses were performed on logtransformed data, but the reported descriptive statistics were based on the raw data (phasic EDA in $\mu S^{*}$ s; tonic EDA in $\mu S$ ).

\section{Dependent Variables.}

In deception-detection paradigms it has been established that in a set of trials, the first trial results in atypical EDA fluctuations (e.g., the Guilty knowledge test; Vrij, 2000). Therefore, we removed the data of the first question trial in a block, leaving two question trials in the anticipation stage and three question trials in the action stage. We tested Hypotheses 1 and 2 on basis of the anticipation stage. The switch from the anticipation stage toward the action stage enabled us to examine the switch from a stage of truth telling with the intention to lie, toward a stage where a lie occurs. We let the blue question occur on a random trial position within the action stage to control for learning effects. Therefore, when contrasting the switch from the anticipation toward the action stage, we do not refer to the direct switch to a single trial with the blue question but to the switch to the stage that included the blue question. For the statistical analyses we report partial eta square $\left(\eta_{p}{ }^{2}\right)$ as effect size measure. This effect size measure usually is used in ANOVAs and explains the proportion of variance of an effect that is not explained by other variables in the analysis (Field, 2013).

\footnotetext{
${ }^{4}$ Benedek and Kaernbach (2010) proposed that EDA does not change above a sample rate of $16 \mathrm{~Hz}$. We verified their statement by analyzing the data with $64 \mathrm{~Hz}$. Our results however remained the same.
} 
Study 2.1

A)

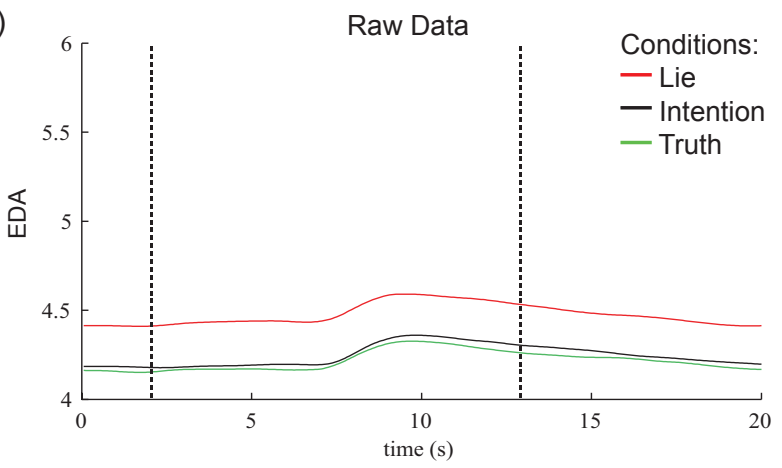

B)

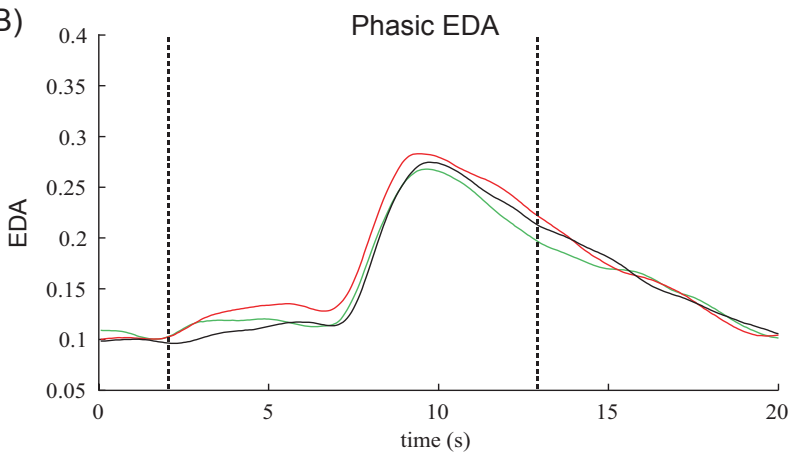

C)

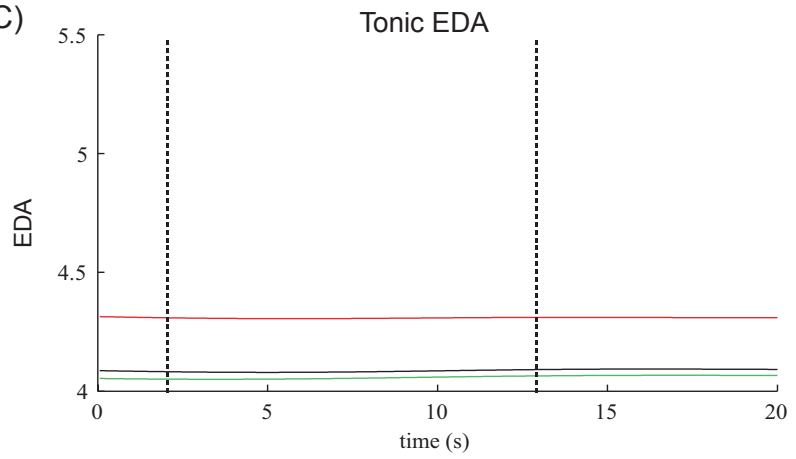

Figure 2.3. Mean EDA during a trial of study 2.1. We separated raw skin conductance data (A) into a continuous signal of phasic EDA (B) and tonic EDA (C). The graphs present the mean course of skin conductance during a trial (20 s) per condition. For the statistical analysis we used an interval from 2 till 13 seconds (dotted lines). To separate the raw signal into its components, continuous decomposition analysis (CDA) by Benedek and Kaernbach (2010) was used. It is important to note, that phasic EDA is mapped in $\mu \mathrm{S}$. However, the phasic EDA was time integrated in a later stadium of the CDA analysis. This means that the unit finally changes into $\mu \mathrm{S}^{*} \mathrm{~s}$. 


\section{Results}

\section{Cognitive load during the intention to lie.}

Our first aim was to compare truth telling with the intention to lie with 'honest' truth telling and lying on tonic EDA. Therefore we compared the anticipation stage, which spanned the time before the blue question occurred, between conditions. To test our hypotheses, we conducted a repeated measures analysis with within-subject factor condition (intention to lie/lie/truth) on tonic EDA (which should be especially sensitive for longer term changes in SNS activity) of the anticipation stage. In addition, we also report the results for the phasic EDA.

Supporting our prediction, we found a main effect of condition on tonic EDA for the anticipation stage, $F(2,92)=24.95, p<.001, \eta_{p}^{2}=.35$. Simple effect analyses revealed that EDA in the lie condition $(M=4.30, S E=.41)$ was significantly higher compared to the intention $(M=4.07, S E=.39), t(46)=5.85, p<.001$, and truth condition $(M=4.04, S E=.39), t(46)=$ $5.36, p<.001$. The difference between truth telling with and without the intention to lie was not significant, $t(46)=0.85, p=.399$. We repeated the same ANOVA analysis for phasic EDA within the anticipation stage and found no significant main effect of condition, $F(2,92)=0.66$, $p=.518, \eta_{p}^{2}=.01$.

These results supported Hypothesis 1: As expected, lying evoked higher tonic EDA than truth telling. Hypothesis 2, however, was not supported and EDA levels in the intention condition were comparable to the levels in the truth-telling condition. This implies that compared to straightforward truth telling, participants' SNS activity was not higher when telling the truth while preparing for lying. Lastly, we did not find reliable differences over conditions for phasic EDA levels. This is in accordance with the previously explained idea that phasic EDA is more sensitive to short-lived changes compared to ongoing processes.

\section{Cognitive load during the switch from the intention to lie toward lying.}

Our third prediction was that phasic EDA shows the largest increase from anticipating toward action stage in the intention condition. Here, participants switch from truth telling with the intention to lie toward a stage where a lie occurs. To rule out that this effect can be attributed to prospective memory (that is, remembering to do something at a particular time; Volle, Gonen-Yaacovi, de Lacy Costello, Gilbert, \& Burgess, 2011), we compared the switch from the anticipation toward the action stage between the three conditions. We conceptualized the rise in cognitive load as EDA difference between the anticipation and action stage. In line with this, we subtracted EDA activity of the anticipation stage from the action stage within all conditions. We conducted a repeated measures ANOVA using as within-subject factor EDA rise (Intention diff' Lie $_{\text {diff' }}$, Truth $_{\text {diff }}$ ) on phasic and tonic EDA. However, the effect of EDA rise on phasic EDA, $F(2,92)=1.87, p=.159, \eta_{p}^{2}=.04$, nor on tonic EDA, $F(2,92)=1.39, p=.255$, $\eta_{p}^{2}=.03$, were significant. The increase of phasic EDA thus did not differ between conditions and Hypothesis 3 therefore was not supported (see Figure 2.4). 


\section{$\mu S \times s \quad$ Study 2.1}

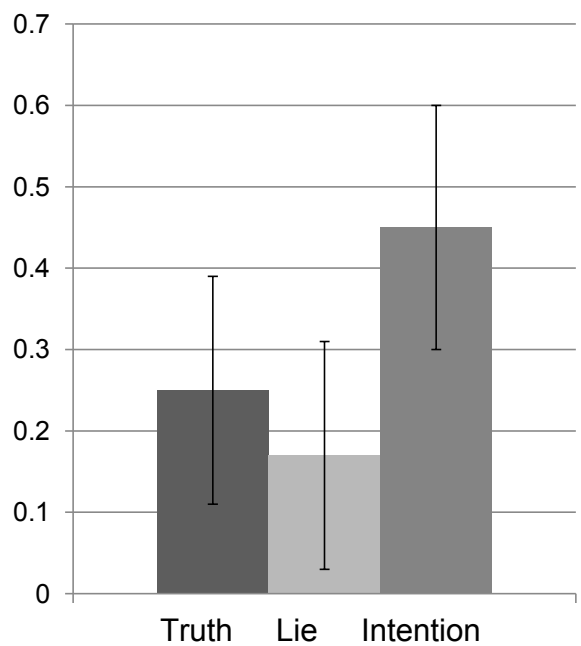

Figure 2.4. The switch from the anticipation to the action stage within Study 2.1. The figure displays the switch from the anticipation to the action stage. The mean rise in phasic EDA (with standard errors within parentheses) for the truth, lie and intention condition were $0.25(0.14), 0.17(0.14), 0.45(0.15)$ respectively.

\section{Discussion}

Using a new paradigm, we replicated earlier findings, demonstrating that lying evokes higher EDA than truth telling (Gödert et al., 2001; Jung \& Lee, 2012; Pennebaker \& Chew, 1985; Podlesny \& Raskin, 1977; Vincent \& Furedy, 1992; Watson \& Sinha, 1993). We found this effect on tonic EDA by comparing stages of constant lying with those of constant truth telling. This is in line with the notion that tonic EDA captures arousal over a long time interval whereas phasic EDA is sensitive to short localized fluctuations in SNS activity. However, we could not confirm our expectation that truth telling with the intention to lie evokes higher EDA than sincere truth telling. Also, the switch between the anticipation and action stage was not different for the three conditions.

The first aim of Study 2.2 was to replicate Study 2.1, using a different double task. Dual-task interference appears when there is not enough cognitive capacity to process a secondary task on top of the primary task (Tombu \& Jolicœur, 2003)-in our case lying and having the intention to lie. Recognizing expressions plays a role during deception (Buller \& Burgoon, 1996; Schweitzer et al., 2002), and hence an emotion recognition task could interfere with deceptive intent. However, in Study 2.1 we found no difference between the truth and intention conditions. For Study 2.2 we therefore chose a traditional arithmetic double task that has proven empirical ability to exacerbate (subtle) differences in cognitive processing 
demands of various experimental conditions (e.g., Horrey et al., 2009; Park et al., 2011; Van Impe et al., 2011). Instead of recognizing an emotion, participants had to solve a sum now. Except for the double task, the Method of Study 2.2 was precisely the same as that of Study 2.1.

\section{Study $\mathbf{2 . 2}$}

\section{Method}

\section{Participants.}

Forty-seven new students from a Dutch University participated in the experiment. All subjects provided written informed consent and the experimental protocol was approved by the Ethics Committee of the Faculty of Behavioral Sciences of the University of Twente. Due to technical failures in measuring skin conductance, one participant was removed, leaving 46 participants for statistical analyses (mean age $=20.88$ years, $S D=1.82$, range $=18$ through $27 ; 25$ women).

\section{Experimental design.}

Double task. For the arithmetic double tasks we chose the same face stimuli as in the emotion recognition task (Langner et al., 2010). However, this time the face stimuli had a neutral expression with 'printed' dots on it (range: 1 to 6 dots). The printed dots served as basis for the 'arithmetic' double task. In half of the blocks, these dots had to be added or subtracted with a number between one and six and in the other half of the blocks to be multiplied with a number between seven and 27 (see Figure 2.2, Panel B). Again, each time the correct answer had to be said out loud. Participants received no feedback about whether they solved the sum correctly.

Procedure. The same procedure as in Study 2.1 was applied with only one difference: The instruction about the double task. Participants completed one practice block consisting of six trials in the presence of the experimenter. We informed participants that the faces contained a number of "freckles". On basis of these freckles they would have to solve a sum, for instance "Number of freckles plus two". We instructed participants to say aloud the answer to the sum after they answered the question about the face.

\section{Measures.}

EDA was measured and analyzed the same way as in Study 2.1. Figure 2.5 shows the mean course of raw EDA, phasic EDA and tonic EDA during a trial (20s) per condition. As in Study 2.1 we chose a time window ranging from 2 till 13 seconds after stimulus onset and statistical analyses were performed on log-transformed data. Descriptive statistics were based on the raw data (phasic EDA in $\mu S^{*}$ s; tonic EDA in $\mu \mathrm{S}$ ). 


\section{Study 2.2}
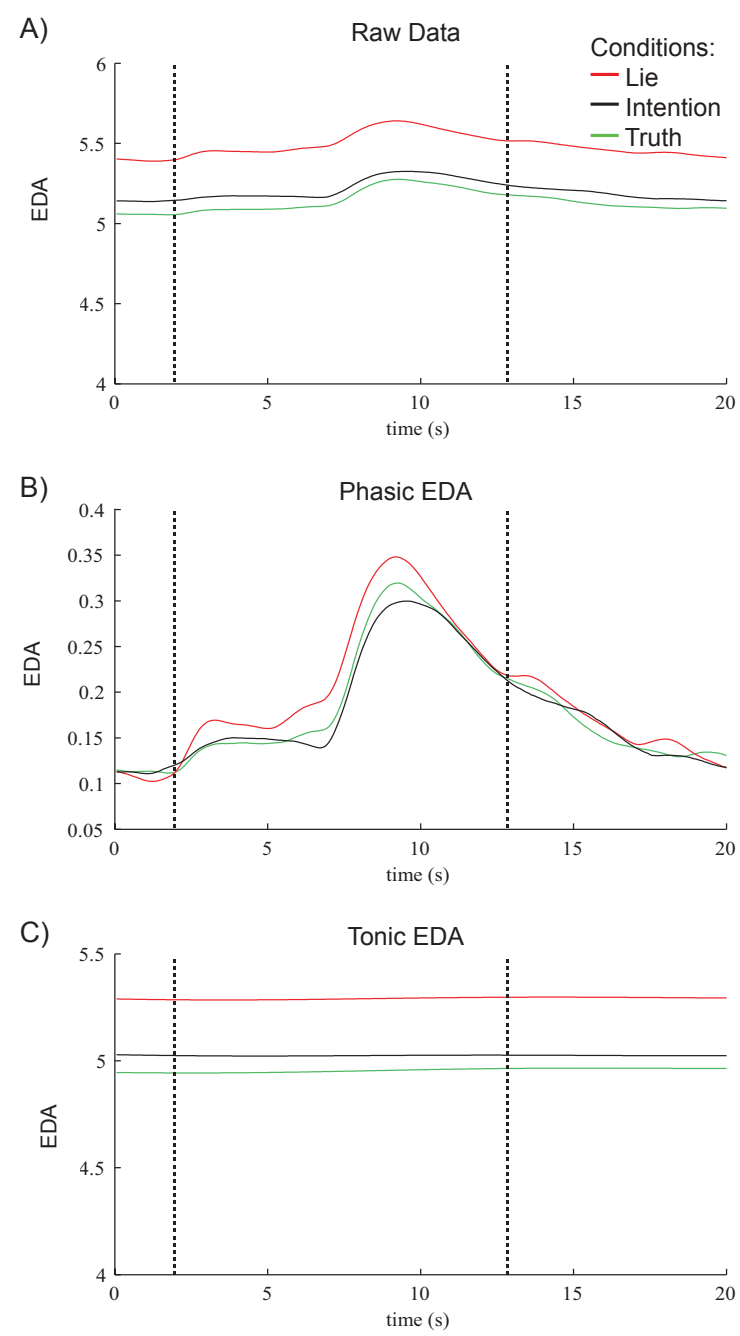

Figure 2.5. Mean EDA during a trial of study 2.2. We separated raw skin conductance data (A) into a continuous signal of phasic EDA (B) and tonic EDA (C). The graphs present the mean course of skin conductance during a trial (20 s) per condition. For the statistical analysis we used an interval from 2 till 13 seconds (dotted lines). To separate the raw signal into its components, continuous decomposition analysis (CDA) by Benedek and Kaernbach (2010) was used. It is important to note, that phasic EDA is mapped in $\mu \mathrm{S}$. However, the phasic EDA was time integrated in a later stadium of the CDA analysis. This means that the unit finally changes into $\mu S^{*} s$. 


\section{Results}

\section{Cognitive load during the intention to lie.}

An ANOVA with within-subject factor condition (intention to lie/lie/truth), showed, as in Study 2.1, a main effect of condition on tonic EDA for the anticipation stage, $F(2,90)=18.53$, $p<.001, \eta_{p}{ }^{2}=.29$. Simple effect analyses revealed that EDA in the lie condition $(M=5.28, S E$ $=.60)$ was significantly higher compared to the intention $(M=5.01, S E=.55), t(45)=3.73, p=$ .001 and truth condition $(M=4.93, S E=.55), t(45)=5.09, p<.001$. Moreover, different from the results of Study 2.1, but in line with Hypothesis 2 the results showed that, compared to the truth condition, EDA in the intention condition was significantly higher, $t(45)=2.69, p=$ 010 .

We repeated the ANOVA for phasic EDA within the anticipation stage and again found a main effect of condition, $F(2,90)=3.60, p=.031, \eta_{p}{ }^{2}=.07$. Simple effect analyses revealed that EDA was significantly higher in the lie $(M=2.98, S E=.40)$, compared to the intention condition $(M=2.61, S E=.35), t(45)=2.37, p=.022$, but not compared to truth condition $(M=2.80$, $S E=.38), t(45)=1.31, p=.196$. The difference of EDA between the intention and truth condition was not significant, $t(45)=1.64, p=.107$.

In line with Hypothesis 1, and the results of Study 2.1, we found that tonic EDA was highest during lying. Moreover, the results of Study 2.2 provided support for Hypothesis 2 as well. Compared to the truth telling condition, EDA was already elevated when participants had the intention to deceive, but were not required to lie yet. As expected, this difference was found when using the tonic but not the phasic EDA-data.

\section{Cognitive load during the switch from the intention to lie toward lying.}

Similar to Study 2.1, we conducted a repeated measures ANOVA using as within-subject factor EDA rise (Intention diff' Lie $_{\text {diff' }}$, Truth $_{\text {diff }}$ ) on phasic and tonic EDA to compare the switch from the anticipation toward the action stage between the three conditions. We found a main effect of EDA rise for phasic EDA, $F(2,90)=4.22, p=.018, \eta_{p}^{2}=.09$ (see Figure 2.6). In support of Hypothesis 3 , simple effect analyses following the ANOVA revealed that the EDA rise within the intention condition $(M=0.54, S E=.10)$ was significantly higher compared to that in the lie condition $(M=0.31, S E=.12), t(45)=2.13, p=.038$, and truth condition $(M=0.18, S E=.12), t(45)=2.50, p=.016$. EDA rise did not differ between the lie and truth condition, $t(45)=1.21, p=.232$.

For tonic EDA we found a marginal significant main effect of $\operatorname{EDA}$ rise, $F(2,90)=3.06$, $p=.051, \eta_{p}{ }^{2}=.06$. Simple-effect analyses revealed that the rise was highest in the intention to lie condition $(M=0.07, S E=.02)$, and that this significantly differed from the rise in the lie condition $(M=.03, S E=.01), t(45)=2.45, p=.018$, but not in the truth condition $(M=.07$, $S E=.02), t(45)=0.13, p=.896$. EDA rise did not significantly differ between the lie and truth condition, $t(45)=1.88, p=.066$. 


\section{$\mu \mathrm{S} \times \mathrm{S} \quad$ Study 2.2}

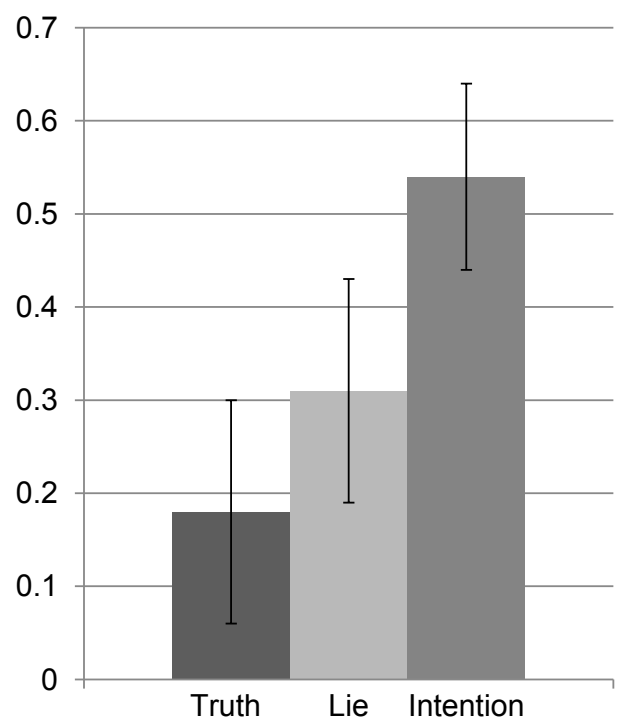

Figure 2.6. The switch from the anticipation to the action stage within Study 2.2. The figure displays the switch from the anticipation to the action stage. The mean rise in phasic EDA (with standard errors within parentheses) for the truth, lie and intention condition were $0.18(0.12), 0.31(0.12), 0.54(0.10)$ respectively.

We could support Hypothesis 3 for Study 2.2: The switch from anticipation toward action stage on phasic EDA was highest in the intention condition. For these results the patterns of the phasic EDA were clearer than those of the tonic EDA. This is in line with the notion that phasic EDA is sensitive for brief changes in SNS activity (Figner \& Murphy, 2010; Roth et al., 2012).

\section{General Discussion}

While over the past decades studies have been comparing lying and truth telling to detect cues to deception (DePaulo et al., 2003), our study is the first to find evidence that deceptive intent alone can contain cues in terms of increased SNS activity. In two experiments we tested whether the intention to deceive can be discriminated in terms of SNS activity from both truthful as well as entirely deceptive accounts. Using skin conductance (EDA) as an indicator for SNS activity, our results demonstrate that psychophysiological measures contain markers that may discriminate honest and deceitful intentions even before a lie is stated. 
Similarly to previous studies we have found higher SNS activity during lying than truth telling (Gödert et al., 2001; Jung \& Lee, 2012; Pennebaker \& Chew, 1985; Podlesny \& Raskin, 1977; Vincent \& Furedy, 1992; Watson \& Sinha, 1993). In reality deceivers often alternate between truth telling and lying in order to present a believable story, and stick to the truth most of the time (Leins et al., 2013; Sip et al., 2008; Strömwall \& Willén, 2011). This implies that a great part of deceptive attempts exists of truth telling with the intention to lie. The current study complements the field of deception detection by moving one step further than simply contrasting lies with truth, and showing that truth telling with the intention to deceive in itself may evoke higher SNS activity than 'sincere' truth telling. These findings are in line with earlier studies, which have shown that SNS activity already increased in the short interval between a question and given lie (Dawson, 1980; Furedy \& Ben-Shakhar, 1991; Furedy et al., 1988; Gödert et al., 2001). We, in contrast, focused on the intention to deceive before the need for a specific lie emerges. By doing so we were able to study deception as an ongoing process and demonstrate that lying is a crucial, but short element of the deception process. Furthermore, we found that particularly the switch from truth telling with deceptive intention toward an action stage involving a straightforward lie evokes higher EDA than switching toward an action stage requiring giving a non-deceptive statement.

We do have to note that the results from Study 2.1 and Study 2.2 differed to some extent. Specifically, the prediction that truth telling with the intention to deceive increases EDA compared to sincere truth telling was supported by the results of Study 2.2 but not by Study 2.1. Interestingly, EDA differences between the conditions seemed to become more in line with our predictions when using an arithmetic double task compared to an emotion recognition double task, especially with regard to truth telling with and without the intention to lie. Because we used these double tasks in two independent studies, we can only speculate why the arithmetic double task may have interfered more with the intention to lie and hence, increased the difference between truth telling with and without the intention to lie. A reason could be that, for instance, the mental operations needed to solve the equations are qualitatively different from emotion recognition. Solving an equation may need mental operations that are stretched in time whereas emotion recognition takes place within a brief moment. Also, an assignment to solve equations may be more concrete than emotion recognition, which could have led participants to focus more on solving the sum than on emotion recognition. Future research could systematically manipulate types of double tasks to further investigate which type of task is best suited to increase the chance of observing cues to deception during the intention to deceive.

It is most likely that the elevated EDA-levels during lying and the intention to lie observed in the present research are indicators for increased arousal, and are caused by stress and cognitive load. There is an abundance of research demonstrating that EDA rises with both stress/nervousness (Hout et al., 2000; Page \& Robson, 2007) and cognitive load (Engström et 
al., 2005; Lacey et al., 1963; Nourbakhsh et al., 2012; Shi et al., 2007; Wilson, 2002). Some studies found that EDA actually decreases with task difficulty (Ikehara \& Crosby, 2005; Leal, Vrij, Fisher, \& van Hooff, 2008). Ikehara and Crosby (2005) for instance, compared an easy and difficult task and found, contrary to their expectations, that the latter induced lower EDA. Interestingly they ascribed their findings to the task design and speculate that the easy task was too easy and tedious, and therefore could actually be more stressful than the difficult task. It is therefore likely that in these studies increased EDA was a result of increased emotional arousal rather than decreased cognitive load.

It is well-known that lying requires cognitive processes unique for lying, such as suppressing the truth while making a counterfactual statement (Spence et al., 2001; Walczyk et al., 2005). However, the current work suggests that SNS activity may already increase during the mere intention to lie. We therefore propose that some cognitive processes relevant to lying, such as self-monitoring and lie preparation, already may be relevant during truth telling with the intention to lie. An important avenue for future research therefore may be to investigate what kind of processes underlie the increase in SNS activity during lying and/or the intention to lie.

Research on the behavioral correlates of deception show that particularly high-stakes lies (often occurring in real-life) are associated with intense emotions (Porter \& Brinke, 2010), while relatively low-stakes lies (in experimental studies such as the current studies) are typically associated with cognitive load (DePaulo et al., 2003; Porter \& Brinke, 2010). On the one hand, because the topic of deception in the present research concerned relatively low-stakes, it may be less likely that strong emotions such as guilt or anxiety were aroused in the current paradigm. On the other hand, because participants were led to believe that a lie expert would judge them and that best two liars would receive a monetary prize, it is likely that deceiving was accompanied by excitement to fool the lie expert. This so called 'duping delight' (Ekman, 1985) could have resulted in elevated EDA during lying and the mere intention to lie compared to truth telling as a result of emotional arousal as well. It would be interesting to investigate how stakes moderate the type of processes (cognitive versus emotional) causing an increase in EDA.

\section{Limitations and future research}

When further developing the current paradigm, we advise to take into consideration several points. In the present work we decided to remove the first of six trials in a block, leaving two trials in the anticipation and three trials in the action stage. Herewith we aimed to prevent that atypical fluctuation commonly seen in the first trial of a set trials distorted our data (Vrij, 2000). Importantly, the different lengths of the two stages should not be problematic for the current findings. Both stages have the same lengths across the three conditions and also, we took the average of the trials within the stages. However, for follow-up studies we advise 
to expand on the number of trials in order to create anticipation and action stages of equal length. Also through adding more trials, a post action stage could be built in. The latter would be interesting in order to measure the reversed switch from lying toward truth telling.

We further should point out that the design of these studies was not optimized to examine the switch from truth telling toward lying within an attempt to deceive. Originally, the paradigm was designed to measure truth telling with the intention to lie. To be able to compare the anticipating stages for all three conditions, we took trial 1-3 as the anticipation stage, because the blue question never occurred before the 4 th trial. The blue question occurred on different trials within the action stage in order to prevent that the moment to lie would become predictable for participants. Ideally we would have analyzed the switch from the anticipation toward the blue question separately for the blocks on trial level. However, unfortunately our data set was too small to run these analyses while having sufficient statistical power. We therefore took the average of trial 4, 5 and 6 as the action stage. We realize that in some instances the blue question occurred at the very end of this phase. However, because it was clear that each block only had 6 trials, even in these cases participants would already be triggered and ready for action in the fifth trial. We therefore encourage future research to examine the switch from truth telling toward lying on trial level.

Generally, it would be interesting to design follow-up research that replaces the face stimuli with real humans to create a dynamic face-to-face interaction. This could generate more interpersonal monitoring processes, because the deceived person is the person checking one's credibility. Also, a real person's facial expression is not static and therefore monitoring a real person's face may induce more long-lasting interference with lying/the intention to lie than the face recognition of static faces (as this was the case at the emotion-recognition task in Study 2.1).

\section{Conclusion}

The present findings suggest that the current scientific discourse surrounding lie detection might have been approached too dichotomously. Lie detection research usually differentiates between lying and truth telling, which resonates in well-known deception detection methods. For instance, the Comparison Question Test (Honts, 2004) measures different physiological parameters and compares them on Yes/No answers that could either be a lie or the truth (Fiedler, Schmid, \& Stahl, 2002). Also, looking at lies and truths in isolation does insufficiently take into account that deception is a "process in which someone tries to create in another a belief which [...] is untrue" (Vrij, 2004a). Creating such a belief can be achieved through different means. Arguably crucial is the intention to deceive someone, which underlies the entire attempt to deceive (Sip et al., 2008), including lying and truth telling parts. And third, the findings add to an upcoming field in deception detection research: The ability to discover lies about future intentions (Granhag \& Hartwig, 2008). In line with the dichotomous focus 
40 | Chapter 2

on lying, most research in this new area examines whether a particular statement about the future is truthful or not (Granhag, 2010; Granhag \& Knieps, 2011; Warmelink, Vrij, Mann, Jundi, \& Granhag, 2012). We suggest that, also for this field, investigating deception as an ongoing process would provide a valuable alternative approach. 


\section{Chapter 3}

Catching a Deceiver in the Act

Processes underlying deception in an interview setting

This chapter is based on:

Ströfer, S., Ufkes, E. G., Noordzij, M. L., \& Giebels, E. (submitted). Catching a Deceiver in the Act: Processes underlying deception in an interview setting.

We would like to thank Dirk Berentsen, Niels Boele, Anna-Maria Bachmann, Ricarda Baumhof and Maren Bethke for their assistance in conducting the experiment. We would like to thank Ellen Giebels and Niels Boele for developing the assessment center test paradigm. 
42 I Chapter 3 
Previous studies showed that lying evokes more stress and is cognitively more challenging than truth telling (Caso, Gnisci, Vrij, \& Mann, 2005), and that this in turn increases physiological arousal (Jung \& Lee, 2012). Therefore, lying may activate both cognitive as well as emotional cues that can be used for deception detection (DePaulo et al., 2003). For example, studies reveal that people show higher sympathetic nervous system (SNS) activity when lying than when telling the truth (Vincent \& Furedy, 1992; Zuckerman et al., 1981). However, the crucial point of successfully deceiving others is to control the information one is telling in order to create a false belief ( $\mathrm{Vrij}, 2008)$. The operations to create a false belief therefore do not necessarily have to involve constant and explicit fabrications (Sip et al., 2008). For deception to take place, lying is often not even necessary. Deception may take a variety of forms, including half-truths, vagueness, equivocations, and concealments (Carlson et al., 2004). In fact, in natural situations deceivers stick to the truth as close as possible, and when they do mislead they seldom fabricate information but base deceptive accounts on previous experiences (Leins et al., 2013; Strömwall \& Willén, 2011).

Truth telling with the intention to lie thus makes up a great part of real-life deceptive attempts. This raises the question whether deceivers still have clearly diverging emotional and cognitive processes from truth tellers when only lying incidentally. The key question therefore may not be whether differences in cognitive and emotional load-and its reflection in the SNS activity - can be measured depending on whether a specific statement is truthful or not. The question rather should be whether cues to deception already can be measured at the mere intention to deceive-the crucial factor underlying deception (Ambach et al., 2008). The present study aims to answer this question by comparing interviews based on, respectively, fully deceptive and fully truthful accounts, with accounts wherein people largely tell the truth but have the aim to lie on crucial moments. Specifically, we tested in an interactive interview setting whether, compared to lying and truth telling, the intention to lie already increases self-reported stress levels and cognitive demands as well as physiological responses.

\section{Processes underlying deception}

Past work on deception processes demonstrated that lying is often accompanied by both increased stress levels and increased cognitive demand. Cognitive load is often higher during lying than during truth telling, because liars have to engage in more cognitive tasks when lying (Vrij, 2008). Examples of such tasks are suppressing the truth while coming up with a plausible alternative statement (Spence et al., 2001; Vrij, 2008), inferring what the other is thinking, 'keeping one's story straight' and monitoring and controlling one's own behavior to avoid creating the impression of lying (Vrij, Fisher, et al., 2006). Self-report studies indeed show that liars not just feel more nervous, less relaxed and calm than truth tellers but also find the task more strenuous, report being more concentrated, and indicate to monitor their non-verbal behavior more than truth tellers (Hartwig, Anders Granhag, \& Strömwall, 2007; Strömwall et al., 2006; Watson \& Sinha, 1993). 
The trend in more recent deception literature is to focus on cognitive cues above emotional cues in order to better distinguish deceivers from truth tellers (Vrij, Fisher, et al., 2006). The advantage of focusing on cognitive cues is that increased levels of cognitive load may exclusively be present during deception, whereas, in most interview settings, stress and tension may be present during lying as well as truth telling (US National Research Council, 2003; Vrij, 2008). Therefore, emotional indicators may be less reliable cues for detecting deception than cognitive cues (Vrij, Fisher, et al., 2006). Still, the notion that lying increases cognitive load was until now only supported by interview and free-recall studies in which participants either had to give fully deceptive or fully truthful accounts (Leal \& Vrij, 2008; Leal et al., 2008; Vrij, Leal, Mann, \& Fisher, 2012; Vrij, Mann, \& Fisher, 2006). Considering that in real-life situations, deceivers carefully mix truth and lies, it is important to validate the cognitive load approach in an interview setting, wherein deceivers most of the time stick to the truth and only lie incidentally.

\section{Processes potentially underlying the intention to deceive}

Arguably, both cognitive and emotional load are not just higher during the act of lying, but already during the mere intention to deceive. That is, several mental processes associated with deception are likely to be active during the entire deceptive attempt, including when telling the truth with the intention to deceive. People for example can be nervous to mislead the other person, or be afraid that their attempt to deceive will be discovered (Vrij, 2008), even when no lie has been told yet. But also cognitive processes, not directly related to literally lying, may play a role. For instance, deceivers continuously attempt to control their behavior to appear honest and avoid giving away cues to deception (Buller \& Burgoon, 1996). Such a motivation can already be present when having the mere intention to deceive but not lying yet. In addition, people with an intention to lie need to monitor the conversation more closely because they constantly have to decide whether they can tell the truth or should lie. This may be especially important when switching from truth telling towards lying, because during lying deceivers are even more aware that the observer pays attention to their behavior (Buller \& Burgoon, 1996). Because managing these processes involves cognitive effort, we predict that the mere intention to deceive already increases cognitive load.

\section{Testing the intention to deceive in an interactive interview setting}

Previous experimental studies showed that, compared to truth telling, the physiological response-measured with electrodermal activity (EDA)-already is higher during truth telling with the intention to lie and that the switch from intention to lie toward lying evoked a peak in SNS activity (Ströfer, Noordzij, Ufkes, \& Giebels, 2015). However, a disadvantage of physiological processes is that it remains unclear whether increased SNS activity may be due to increased cognitive load, emotional stress, or both (Zuckerman et al., 1981). In the 
present work we therefore also included self-report measures aimed at making a distinction between how deceivers subjectively experience cognitive load and emotional stress during truth telling with the intention to lie compared to consistent lying or consistent truth-telling. So far, studies looking at processes underlying deception in interview studies did not combine self-reports with physiological measures (Caso et al., 2005; Vrij, Mann, et al., 2006).

Moreover, previous interview and free-recall studies surrounding deception did not focus on more realistic deceptions wherein deceivers tell the truth most the time but have the intention to lie on crucial moments. Those studies which did investigate the physiology of deception were of a more experimental nature, having participants responding to (often unrelated) questions, prompted on a computer screen where they either lied or told the truth on specific trials or in blocks of questions (Dionisio, Granholm, Hillix, \& Perrine, 2001; Ganis et al., 2003; Ströfer et al., 2015).

Deception, however, is inherently an interactive process of which person-to-person communication is a fundamental part. In real interrogations for example, police officers determine the number and type of questions, ask follow-up questions and demand elaborations and clarifications (Hartwig, Granhag, Strömwall, \& Vrij, 2004). For instance, deception in an interactive setting requires deceivers to be prepared for (unexpected) questions and monitor the other person's reactions. Together with keeping the dialogue running, this should reveal more natural cues to deception (Miller \& Stiff, 1993). According to Buller and Burgoon's (1996) Interpersonal Deception Theory, face-to-face interactions force deceivers to process several tasks simultaneously: For instance, impression management on verbal and non-verbal behavior, and attending their conversation partner to check whether they were believed and managing their emotions while keeping the conversation running smoothly. Hence, researchers must come up with designs that mirror interactive processes at play in real-life interviews (Granhag \& Hartwig, 2008). The current study adds to the literature by answering this call and testing our hypotheses in such an interactive interview setting.

\section{The current study}

The aim of the current study was to examine underlying cognitive and emotional load processes during deception when the deceiver has the intention to deceive but only lies incidentally. To do this we created a paradigm, in which deceivers for a great part were required to stick to the truth and combine self-reports with a physiological measure. As cover story for the present study served the testing of an ostensible newly developed assessment center test (ACT; Sackett \& Dreher, 1982). The ACT contained an assignment in which participants had to solve several tasks. In one of the tasks participants were enticed to sign a document which could be seen as fraud. Hereby, a situation was created in which committing a transgression within the ACT was the participant's own decision and responsibility. We then interviewed participants about this transgression. The study was based on three veracity conditions: In 
the intention condition, participants were advised that the best strategy to approach the interview would be to tell the truth on all questions but to lie about signing the document-a question appearing at the end of the standardized interview. We contrasted this condition with a truth and lie condition wherein participants were respectively nudged toward telling the truth or lying on all questions.

The interview had the same structure as police interviews that build up with the aim to determine whether a suspect is lying or not (Horvath et al., 1994). As such, the interview followed a prescribed script with standard questions. It started broadly, and became continuously more specific regarding the transgression and disclosed the evidence against the participant not until late in the interview (Hartwig, 2005; Hartwig, Granhag, Strömwall, \& Kronkvist, 2006). We employed an information gathering interview style, a method based upon rapport and respect, in which interviewers request suspects to give detailed statements about their activities through open questions (Kelly, Miller, Redlich, \& Kleinman, 2013; Vrij, Mann, Kristen, \& Fisher, 2007).

During the interview we measured the physiological response of the sympathetic nervous system in form of electrodermal activity (EDA). EDA is an indicator for stress and cognitive load (Engström, Johansson, \& Östlund, 2005; Hout, Jong, \& Kindt, 2000; Nourbakhsh, Wang, Chen, \& Calvo, 2012; Page \& Robson, 2007; Peter Bankart \& Elliott, 1974; Shi, Ruiz, Taib, Choi, \& Chen, 2007; Wilson, 2002) and forms the most frequently used physiological measure by scholars and practitioners in the field of deception (Vrij, 2000). EDA has several advantages over other physiological measures: It directly reflects SNS activity and can be measured unobtrusively within one measurement (Boucsein, 2012; Dawson et al., 2007; Wallin, 1981). Participants' subjectively experienced cognitive and emotional load during the interview was assessed with self-reports. We took the self-reports directly after the interview, because concurrent assessments during the interview could be obtrusive and influence the behavior under investigation (Kazdin, 1979). Also, research has shown that momentary emotion experiences correlate highly with recall-based ratings of emotions (Barrett, 1997).

\section{Hypotheses}

In line with earlier studies examining cognitive load during lying (Caso et al., 2005; Vrij, Mann, et al., 2006), we expected that the self-reported cognitive load would be higher in the lie compared to the truth condition (Hypothesis 1a). In the lie condition, participants continuously had to make up a false story and come up with deceptive answers. The content of the questions was related, which meant that the deceptive answers had to form a coherent story which should be easier in the truth than in the deception condition, because the truth comes to mind automatically (Walczyk, Roper, Seemann, \& Humphrey, 2003; Walczyk et al., 2005). 
Similarly, we expected self-reported stress to be higher in the lie than in the truth condition (Hypothesis 1b). Participants should be more nervous during lying, both, because they are afraid of not being believed or being excited to mislead the interviewer (a money prize was promised to the three best interviewees). Since both, stress and cognitive load lead to an increase in EDA (Engström et al., 2005; Hout et al., 2000; Nourbakhsh et al., 2012; Page \& Robson, 2007; Peter Bankart \& Elliott, 1974; Shi et al., 2007; Wilson, 2002), we expect EDA to be higher during the lie compared to the truth condition (Hypothesis 1c).

Considering that deceivers only lie incidentally in an attempt to deceive, we additionally wanted to test whether the mere intention to lie can be differentiated on self-reported cognitive load, stress and/or physiological responses from truth telling. Theoretically, there are reasons to assume that both, cognitive load and stress are already increased at the foresight of lying. During truth telling with the intention to lie, participants have to decide whether to lie or not, prepare to lie, monitor oneself, the other and their story. They also could be stressed before the actual lie takes place (Ströfer et al., 2015). The more the participants progress through the interview, the more the questions are related to the relevant question 'Is this your signature?' (which was the question revealing the evidence). It therefore could be expected that nervousness already increases at these questions, because of the anticipation of the relevant question. Therefore, we expected both self-reported cognitive load and stress to be higher in the intention than in the truth condition (Hypothesis $2 a$ and $2 b$ ).

In line with these assumptions and previous findings (Ströfer et al., 2015), we expected that truth telling with the intention to lie evokes higher EDA than 'honest' truth telling in the truth condition (Hypothesis 2c). Above that, cognitive load and stress caused by preparing to lie should become most taxing when switching from truth telling to actual lying. We therefore expected that switching from the truth telling toward lying in the intention condition would induce a higher EDA response than switching to the same question in the other two conditions (Hypothesis 3).

\section{Method}

\section{Participants}

We conducted an experiment with 86 graduate students participating in exchange for course credit. Nineteen participants refused to sign the document that served as basis for the experiment and therefore were excluded from the experiment. The data of four participants who did not follow the instructions of the experiment were removed as well, leaving 63 participants for statistical analyses of the self-report data (mean age $=20.77, S D=2.47$, range = 18-29 years; 44 women $)^{5}$. Due to technical failures we failed to record EDA data for another 7 participants, therefore analyses for physiological responses are based on 56 participants which were equally distributed across conditions (mean age $=20.71, S D=2.56$, range $=18$ -

\footnotetext{
${ }^{5}$ Participants sometimes accidently skipped a self-report question. For this reason the degrees of freedom reported in the results section sometimes differ between analyses.
} 
29 years; 38 women). Participants provided written informed consent, and the institutional review board approved the experimental protocol.

\section{Experimental design}

The experiment consisted of a 3 (veracity condition: truth, lie or intention) $x 8$ (question type: 1-8) mixed design ${ }^{6}$. Veracity condition was a between subject-factor to which participants were randomly assigned, and question type a within-subject factor. We assessed phasic and tonic electrodermal activity, and self-reported stress and cognitive load as dependent variables.

\section{Procedure}

Participants ostensibly took part as test person for a newly developed assessment center test (ACT; Sackett \& Dreher, 1982). We used this cover story to create the opportunity of deception in a more realistic situation. At the start of the experiment we explained to the participants that the assessment center test (ACT) consisted of several exercises and that the three best participants completing these exercises each would win $50 €^{7}$. We further explained that all tasks of the session were relevant for the money prize and that we would clearly state when the experiment was finished. On average, the experimental sessions lasted for 1.5 hours $^{8}$. Each session was run by an experiment leader and two confederates: one acting as 'experiment assistant' and the other as 'interviewer'.

\section{In-basket exercise.}

The experiment started with an in-basket exercise, which often is part of an assessment center test (Dukerich, Milliken, \& Cowan, 1990). Participants were invited to assume the role of a manager of a transport company and to substitute a regular employee who currently was on sick leave. Participants were required to complete four tasks normally executed by the sick employee in 15 minutes. In the third task participants read a contract that had to be signed by the sick employee-as was indicated by the name of the employee that was already printed on the contract. A note explained that the contract was important for the company and had to be signed urgently. Most of the participants (79\%) signed the contract ${ }^{9}$,

\footnotetext{
${ }^{6}$ The original design also contained the number of interviewers as an additional between-subject factor. In half of the interviews a second interviewer was present while merely making notes and actively participating in the interview. Analyses with this factor did not render any significant main or interaction effects. We therefore eliminated number of interviewers from further analyses.

${ }^{7}$ In reality, the money was allotted among the participants after the experiment.

${ }^{8}$ Not all parts of the experiment eventually were used for the article. In the experiment participants also filled in a personality questionnaire right at the beginning and did a Stroop-task after the interview. Both datasets were not used in this article.

${ }^{9} 18$ of the 86 participants did not sign the document in first instance. In this case the experiment assistant tried to convince the participant to still sign the document directly after the ACT task by telling that he himself would sign the document, because this would increase the chance of the money price. Participants who after this reminder continued resisting signing the document were excluded from the experiment.
} 
since this is an easy and fast solvable problem, and continued with the fourth task. However, signing a document under a wrong name is legally not allowed. This transgression served as input for our deception experiment.

\section{EDA baseline measurement and confrontation.}

After finishing the in-basket exercise, participants were brought to the interview room. In order to get an EDA baseline, we attached the participant to skin conductance sensors and asked them to sit down 5 minutes and relax and wait for the next task of the experiment. We informed participants that this measure assessed the difficulty of the in-basket test. After 5 minutes the experiment leader entered the room again, stating that she reviewed the participant's output of the in-basket tasks, but that a problem occurred regarding one of the documents. The experiment leader then confronted the participant with the fact that (s)he signed a document (s)he was legally not allowed to sign, and informed that (s)he therefore would be interviewed about this incident.

\section{Experimental manipulation.}

All participants received a letter advising on the best approach to behave in the upcoming interview about the transgression. This letter formed the experimental manipulation consisting of three veracity conditions: a truth, a lie and an intention to lie condition. In the truth condition, the letter advised participants to tell the truth on all questions, including questions about whether one signed the document. In the lie condition, the letter advised to lie on all questions, including questions about whether one signed the document. Finally, in the intention condition, the letter advised to tell the truth on all questions but to lie on questions whether one signed the document. We also highlighted the question regarding the signature in the truth and lie condition to prevent that the question about the signature would get special meaning in the intention condition only. Hereby we aimed to prevent differences in prospective memory demands between conditions. Finally, we reminded participants that how well they followed the advice would affect their chances for the prize money.

\section{Interview and follow-up questionnaire.}

After the participant finished reading the letter the experiment leader left and the interviewer entered the room. The interview was fully standardized, with the interviewer asking a total of 10 questions in a fixed order (see Table 3.1). Furthermore, the interviewer was trained to behave similarly in each interview and to ask each question using a neutral intonation. Each interview started with a number of general questions and worked its way up to the key question revealing the evidence: 'Is this your signature on this document?' (Question 8). Thereafter the interview ended with two closing questions. During the interview, participants' EDA was recorded. After the interview the experiment leader entered the room again and asked participants to fill in a final questionnaire assessing their self-reported cognitive load and stress. 
Table 3.1. The interview

\begin{tabular}{ll}
\hline Question & Content \\
\hline 1 & $\begin{array}{l}\text { Can you tell about your link with the university? How often and why you are here, } \\
\text { what exactly are you doing here? }\end{array}$ \\
3 & Why did you come to University today? \\
4 & Can you describe step by step what you have done after your arrival? \\
5 & Did you encounter other people? Who? \\
6 & Can you give other additional information? \\
7 & Did you participate in an assessment center test? \\
8 & In front of you lies a map. Please open it. Have you seen this document before? \\
9 & Is this your signature? \\
10 & Do you want to add something? \\
\hline
\end{tabular}

Note: The interview consisted of 10 questions. Questions 9 and 10 were not included in the statistical analyses, since these form the closing part of the interview and were contently not relevant for our experimental manipulation.

\section{Measures}

\section{Self-reports.}

Cognitive load. We assessed a cognitive load scale, consisting of 5 items, $\alpha=.84$. Two items, 'How difficult was the interview?' and 'To what extent did you have to concentrate during the interview?' were based on items used in a study by Cierniak, Scheiter, and Gerjets (2009). The other three items, 'How much mental effort did the interview require?', 'To what degree was the interview was mentally demanding?' and 'To what extent did you have to think about the answer of the questions?' were based on items used in a study by Caso et al. (2005). Participants answered these questions on a 5-point scale ranging from 1 (very little) to 5 (very much). We created a cognitive load score by aggregating the scores on these 5 items. An explorative factor analysis on these five items (method: maximum likelihood, based on Eigenvalues greater than 1) revealed one underlying factor, explaining $62.82 \%$ of the variance. Stress. Stress was measured with four items, $\alpha=.88$, derived from the Perceived Stress Scale (Cohen, Kamarck, \& Mermelstein, 1983). We adjusted the items to the interview situation in our study. The items were 'To which extent did you feel upset during, or directly after the interview?', 'To which extent did you feel nervous during, or directly after the interview?', 'To which extent did you feel that the stress during, or directly after, the interview increased to such high levels that you could not let go of it?' and 'To which extent did you feel tension during, or directly after the interview?' (e.g., Giebels \& Janssen, 2005). All items were measured on 7-point Likert scales ranging from 1 (not at all) to 7 (to a great extent). We created a stress score by aggregating the scores on these 4 items. An explorative factor analysis on these four items (method: maximum likelihood, based on Eigenvalues greater than 1) revealed one underlying factor, explaining $73.49 \%$ of the variance. 


\section{Skin conductance.}

Recording EDA. EDA was recorded at $256 \mathrm{~Hz}$ and down-sampled to $16 \mathrm{~Hz}$. EDA was measured exodermal (constant voltage) via skin conductance using skin conductance sensors (Thought Technology Ltd., Montreal West, Quebec, Canada), attached to the distal phalanx of the right index and ring fingers (Boucsein, 2012). The signal was amplified using ProComplnifiniti amplifier (Thought Technology Ltd.) and was recorded in $\mu \mathrm{S}$.

Range correction. Preliminary analyses of the data showed high between-subject variation on tonic EDA recordings due to differences in interview length ${ }^{10}$. To adjust for the inter-individual variance in EDA, we applied a range correction by correcting every recorded data point into proportion (between 0 and 1 ) to the intra-individual range, using a person's recorded EDA maximum and minimum (Lykken, Rose, Luther, \& Maley, 1966). To assess participants' maximum and minimum values we used the recorded data from the baseline through the accusation till the interview end. Since phasic EDA is not time dependent, analyses for phasic EDA were based on the raw data. Our reported descriptive statistics were based on raw data for both, tonic as well as phasic EDA (in $\mu \mathrm{S}$ ).

Tonic and Phasic EDA. In EDA research, a distinction can be made between tonic and phasic EDA, which both can be extracted from the raw EDA data (Boucsein, 2012). EDA measured over a period of time consists of an overall and relatively slowly drifting signal on which there are short fluctuations, called skin conductance responses (SCRs or phasic EDA; seen as sharp peaks). SCRs are sensitive for short 'phasic' and localized fluctuations in arousal. The slowly drifting signal is called 'tonic' EDA and indicates a more general level of arousal over a longer time interval (Figner \& Murphy, 2010). Both tonic and phasic measures are interesting with regard to the present study. Tonic EDA can indicate which of our experimental conditions evoked highest arousal generally summarized over all individual questions. Phasic EDA on the other side is more sensitive to abrupt, local, short-living changes. This makes it suitable to indicate how arousal changed through the interview between questions (See Ströfer et al., 2015 for a similar argument).

Continuous Decomposition Analysis (CDA). In order to extract the phasic and tonic data from the raw EDA data, we executed a Continuous Decomposition Analysis using Ledalab (Benedek \& Kaernbach, 2010) which is an algorithm written in MATLAB. We iterated the parameter optimization three times, which is above the minimal iteration of two recommended by Benedek and Kaernbach (2010). This multi-step deconvolution approach is based upon a physiological model of the SCR shape. The algorithm has several outputs but most importantly reports the continuous phasic and tonic component of the signal.

\footnotetext{
${ }^{10}$ Generally, EDA increases at stimulation (Dawson et al., 2007) and shows a drift with time. We therefore conducted an ANOVA with veracity condition (intention to lie/lie/truth) as a between-subject factor on interview length (in seconds). Veracity condition had a marginal significant effect on interview length, $F(2,51)$ $=2.86, p=.066$, showing that interview length was longer in the truth $(M=462.47, S E=11.87)$ compared to lie condition, $(M=425.76, S E=12.03), t(34)=2.91, p=0.024$ whereas there was no difference between the intention $(M=453.71, S E=11.69)$ with either the lie, $t(33)=1.58, p=0.102$, or truth condition, $t(35)=0.59$, $p=0.517$.
} 
EDA Time segments. After the CDA analysis we separated the signal into time segments, based on the interview questions. Each segment respectively contained the EDA of a question and the corresponding answer. There is variation in the lengths of each segment, which also differed between persons. To compare EDA between segments the average phasic and tonic EDA activity was calculated for each segment. From this we subtracted the average phasic and tonic EDA activity we respectively measured at the baseline.

\section{Results}

\section{Self-reported cognitive load and stress}

Our first aim was to assess differences in self-reported cognitive load and stress between the conditions (see Figure 3.1). To analyze these differences we conducted two ANOVAs with veracity condition (intention to lie/lie/truth) as a between-subject factor on, respectively, selfreported cognitive load and stress. The results revealed a significant main effect of veracity condition on cognitive load $F(2,60)=5.65, p=.006, \eta_{p}^{2}=.16$, as well as stress, $F(2,58)=6.67$, $p=.002, \eta_{p}^{2}=.19$. Subsequent simple effect analyses showed that, in line with our predictions, participants reported the lie condition $(M=3.65, S E=.17)$ to be more cognitively demanding than the truth condition $(M=2.94, \mathrm{SE}=.17), t(37)=3.53, p=.005$. In the lie condition, self-reported cognitive load was also significantly higher than in the intention condition $(M=3.00, S E=.15), t(41)=2.62, p=.012$, whereas the intention and truth conditions did not differ significantly, $t(42)=0.26, p=.794$. Similarly, we found that self-reported stress was significantly higher in the lie condition $(M=4.26, S E=.30)$ than in the truth condition $(M=2.80, S E=.28), t(36)=3.62, p=.001$. However, self-reported stress was also significantly higher in the intention than in the truth condition, $t(41)=2.50, p=.017$, with no significant difference between the lie and intention condition $(M=3.78, S E=.26), t(39)=1.22, p=.231$. These results revealed that in the lie condition participants reported the highest levels of cognitive load as well as stress. For the intention condition, in turn, the results showed that participants report relative low levels of cognitive load (comparable to cognitive load in the truth condition) but still higher levels of stress (comparable to the lie condition). Thus whereas participants in the intention to lie condition did not experience the interview as particularly cognitively demanding, they did experience elevated emotional stress up to the level of participants lying consistently. 


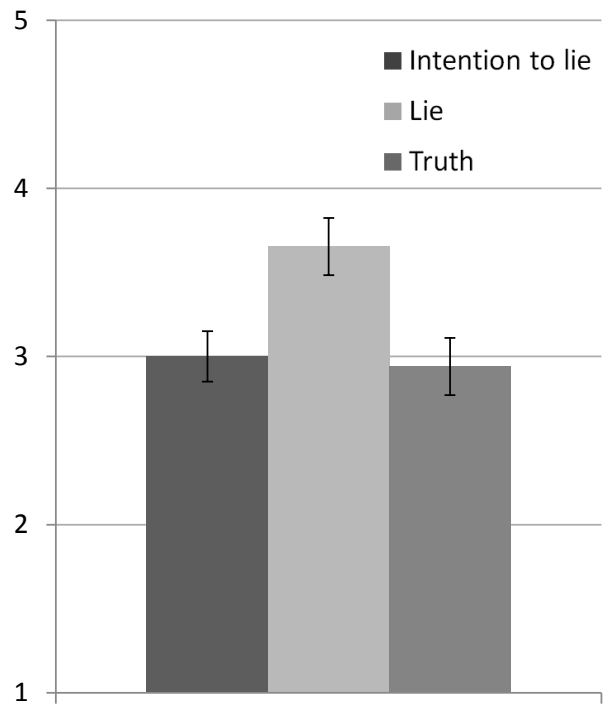

Self-reported cognitive load

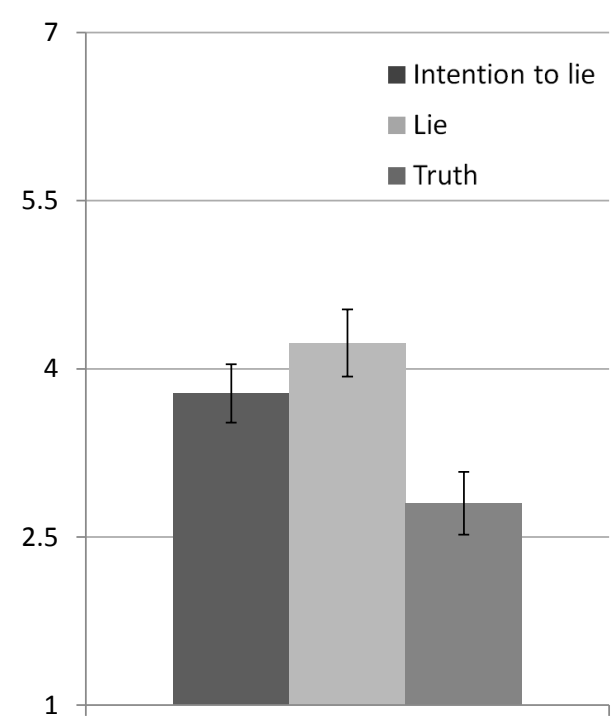

Self-reported stress

Figure 3.1. Mean self-reported cognitive load and stress (+ SE) for the three veracity condition (Intention to lie, lie, truth). Cognitive load was measured on a 5-point Likert scale and stress on a 7-point Likert.

\section{Physiological responses across interviews for tonic EDA}

Our second aim was to investigate the course of the physiological response in SNS activity of someone lying, telling the truth and telling the truth with the intention to lie. We focused on question one to eight, which comprises the questions where participants had to tell the truth (1-7) and had to lie in the intention condition (8). We conducted two mixed factorial ANOVAs with veracity condition (intention to lie/lie/truth) as between-subject factor and question type (1-8) as within-subject factor on tonic and phasic EDA.

For tonic EDA, we found a significant main effect of veracity condition, $F(2,53)=5.72, p=$ $.006, \eta_{p}^{2}=.18$ and question type, $F(7,371)=10.91, p<.001, \eta_{p}^{2}=.17$. The interaction effect between veracity and question was not significant, $F(14,371)=0.84, p=.622, \eta_{p}^{2}=.03$. Simple effect analyses for the main effect of veracity condition revealed that tonic EDA was marginal significantly higher in the lie $(M=3.01, S E=0.68)$ than in the truth $(M=1.84, S E=$ $0.67), t(35)=1.74, p=.059$ and significantly higher than in the intention condition $(M=1.44$, $S E=0.67), t(35)=4.80, p=.001$. There was however no difference in tonic EDA between the intention and truth condition, $t(36)=1.30, p=.15$. The pattern for tonic EDA therefore is similar to the pattern we found for self-reported cognitive load.

Simple effect analyses following the main effect of question type, showed that when moving chronologically through the interview, tonic EDA significantly rises from question 1 to $2 t(55)$ $=2.54, p=.013$, remains constant from question 2 to $4, t s(55)<1.30, p s>.207$, and then rises again through question $8, t s(55)>1.93, p s<.054$. 


\section{Physiological responses across interviews for phasic EDA}

In line with the premise that phasic EDA can better discriminate on question level, we found for phasic EDA no significant main effect of veracity condition, $F(2,53)=.48, p=.621, \eta_{p}^{2}$ $=.018$, but a significant main effect of question type, $F(7,371)=8.97, p<.001, \eta_{p}{ }^{2}=.145$. Subsequent simple effect analyses revealed that across all three veracity conditions, question 1,7 and 8 induced the highest peak in EDA. While all three do not differ significantly mutually, $t s(55)<0.42 ; p s>.706$, they do differ from all other questions, at least marginal significantly, $t s(55)>1.79 ; p s<.084$. Only on question 8 , the relevant question wherein participants were confronted with the evidence, the pattern of phasic EDA between the questions was different within the conditions, which was supported by a significant interaction effect between condition and question type, $F(14,371)=2.02, p=.015, \eta_{p}^{2}=.071$. Phasic EDA showed a sharp increase at question 8 in the intention $(M=0.21, S E=0.04)$ and truth condition $(M=$ $0.21, S E=0.04)$ but not in the lie condition $(M=0.09, S E=0.04)$. No significant difference was found between the truth and intention condition, $t(36)=0.08, p=.933$. Phasic EDA was higher in both than in the lie condition, $t s(35)>2.43, p s<.035$ (see Figure 3.2).

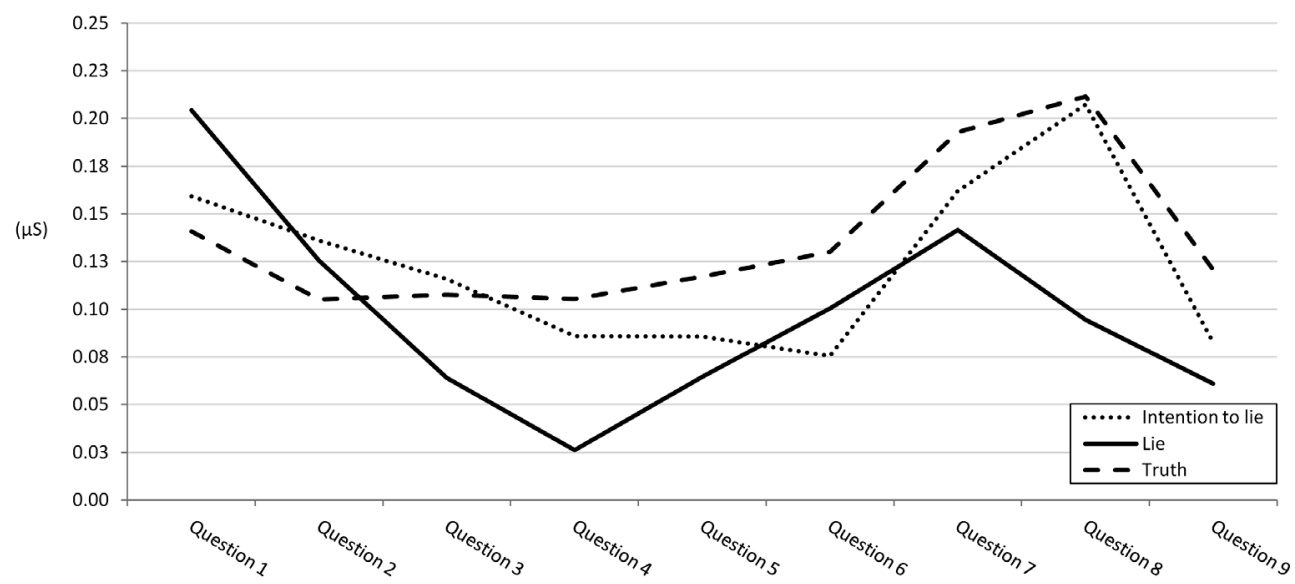

Figure 3.2. The course of phasic EDA during the interview. Mean phasic EDA from question 1 to 9 (with standard error in parentheses) for the lie condition were 0.20 (0.04), $0.13(0.04), 0.06(0.03), 0.03$ (0.03), $0.06(0.04), 0.10(0.03), 0.14(0.04), 0.09(0.04) 0.06(0.03)$, for the Intention condition 0.16 $(0.04), 0.14(0.03), 0.12(0.03), 0.09(0.03), 0.09(0.04), 0.08(0.03), 0.16(0.04), 0.21(0.04), 0.08(0.03)$ and for the truth condition $0.14(0.04), 0.11(0.03), 0.11(0.03), 0.11(0.03), 0.12(0.04), 0.13(0.03), 0.19$ (0.04), 0.21 (0.04), $0.12(0.03)$.

\section{Relationship between tonic EDA and self-reported stress and cognitive load}

Our third goal was to gain more insight into the relationship between the self-reported experiences by participants and their physiological responses across the interviews. For this purpose, we took the mean tonic EDA from question one to eight and correlated these with 
self-reported stress and cognitive load. These analyses revealed a correlation between both, tonic EDA and self-reported cognitive load, $r(54)=.50, p<.001$ but also between tonic EDA and self-reported stress, $r(54)=.30, p=.030$. In addition, the correlation between tonic EDA and cognitive load was significantly stronger than that between tonic EDA and stress, $z=1.962$, $p=.05$ (Lee \& Preacher, 2013; see also Steiger, 1980). This suggests that the physiological response of the participants was more strongly related to their subjective experience of how cognitively demanding than of how stressful they experienced the interview.

When looking at the positive relationship between EDA and self-reported cognitive load in more detail (see Figure 3.3, panel A) we see that participants of the lie condition formed a cluster, all scoring high on tonic EDA as well as on self-reported cognitive load. Such a cluster was not present in the other two conditions or for the relation between EDA and stress (see Figure 3.3, panel B), where participants showed more variation on both their physiological as well as self-reported responses. This suggests that lying affected all participants in a unique way: it increases both the physiological as well subjective experience of cognitive load during the interview. Truth telling and intention to lie, however, did not have this effect, resulting in more inter-individual variation on how they responded to these measures.

\section{A}

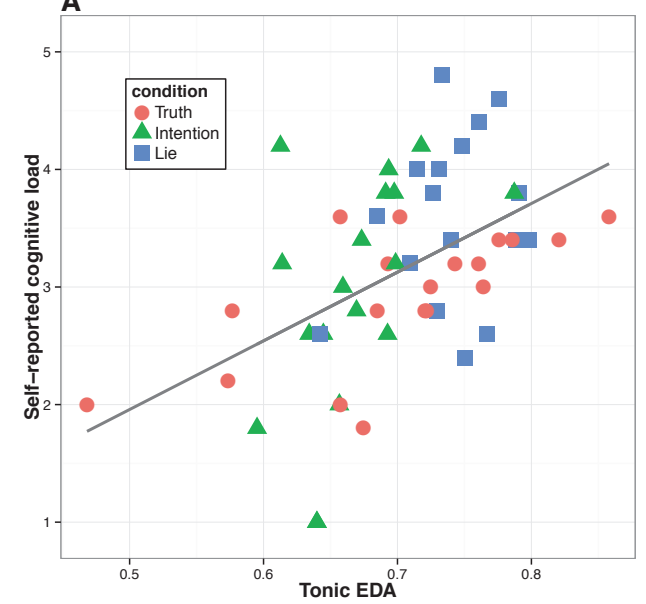

B

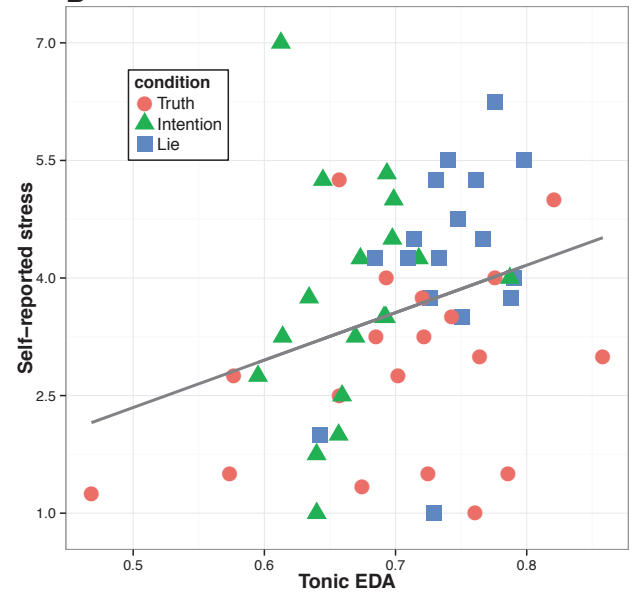

Figure 3.3. Relationship between tonic EDA (range corrected) and self-reports across all interviews. Panel A shows the relationship between tonic EDA and self-reported cognitive load (measured on a 5-point Likert scale) and panel B the relationship between tonic EDA and self-reported stress (measured on a 7-point Likert scale). 


\section{Discussion}

The current study investigated cognitive and affective processes during deception in an interactive interview setting. Although previous research demonstrated that deception induces high levels of both cognitive load and stress (Caso et al., 2005; Hartwig et al., 2007; Spence et al., 2001; Strömwall et al., 2006; Vrij, Fisher, et al., 2006; Vrij et al., 2008; Watson \& Sinha, 1993), the trend in the field of deception detection is to focus on cognitive load to discriminate deceivers from truth tellers (Vrij, Fisher, et al., 2006). The interview studies supporting this cognitive load approach, however, have all focused on the strict comparison of fully deceptive with fully truthful accounts (Caso et al., 2005; Vrij et al., 2011; Vrij et al., 2012; Vrij, Mann, et al., 2006; Vrij et al., 2008; Vrij, Semin, \& Bull, 1996; Warmelink, Vrij, Mann, Leal, \& Poletiek, 2013). When deceiving in real life though, people most of the time stick to the truth and only lie incidentally (Leins et al., 2013; Strömwall \& Willén, 2011). The question therefore arises whether more realistic deceptive attempts, consisting mostly of truth telling and only a few literal lies, still diverge from fully truthful accounts in terms of cognitive load and stress.

To provide an answer to this question, we investigated people who committed a transgression and, in a subsequent interview, either consistently told the truth, consistently lied, or told the truth but lied on one critical question about the transgression. In addition to self-reported cognitive load and stress, we also assessed the interviewee's sympathetic nervous system (SNS) activity in the form of EDA. Increased SNS and EDA activity is typically associated with deception/lying (e.g., Vincent \& Furedy, 1992; Watson \& Sinha, 1993) and even forms the basis of the polygraph (Iacono, 2008; Vrij, 2008). However, theoretically it is not clear yet which psychological processes lead to increased EDA during deception. That is, increased EDA during deception can be explained by an increase in cognitive information processing activities, such as, paying attention, monitoring and solving complex tasks (Dawson et al., 2007; Iani, Gopher, \& Lavie, 2004; Wilson, 2002) as well as affective processes such as fear and stress (Boucsein, 2012; Dawson et al., 2007). The combination of self-reports with measures of EDA activity therefore offered us unique insights into how SNS activity and self-reported cognitive load and stress may be related in a deceptive attempt (Figner \& Murphy, 2010).

Specifically, in the current study participants who lied on all questions, showed higher physiological responses, and also reported to experience the interview as more stressful and cognitively demanding than truth-tellers. We assume that the higher self-reports of cognitive load probably were related to activities directly associated with literally lying, such as suppressing the truth while making up a believable story (Spence et al., 2001; Vrij, 2008), whereas the higher self-reported stress assumably was related to fear and nervousness of not being believed and/or excitement to deceive the other (Ekman, 1985; Vrij, 2008). It is generally assumed that the more deceivers experience one or more of these factors, the 
more likely cues to deception would occur (Zuckerman et al., 1981). In line with this, EDAknown to increase with cognitive load as well as stress (Engström et al., 2005; Hout et al., 2000; Nourbakhsh et al., 2012; Page \& Robson, 2007; Peter Bankart \& Elliott, 1974; Shi et al., 2007; Wilson, 2002) - was higher during lying than truth telling.

Our main interest however was the intention condition, which resembled real-life deceptionwherein truths and lies are mixed-much better. Interestingly, the intention condition could not be differentiated from the truth condition in terms of EDA. Truth telling with and without the intention to lie evoked an equal physiological response pattern. Moreover, we observed a high phasic EDA peak on the relevant question (where participants had to lie in the intention and tell the truth in the truth condition) in both conditions. In first instance, this is surprising, because in line with previous work we expected that the mere intention to lie could already evoke higher EDA (Ströfer et al., 2015). The premise was that mental processes associated with deception would be active during the whole deceptive attempt, including the truth telling parts. These could be stress related-for instance, being nervous in the foresight of lying (Vrij, 2008) - as well as having a more cognitive origin - for instance, caused by monitoring oneself, the other, or preparing to lie (Ströfer et al., 2015).

We think the reason for the similar physiological response pattern between the intention to lie and truth-telling conditions is not an absence of these processes in the intention condition. We rather assume that particularly stress related processes, present in the intention condition, underlie 'honest' truth telling in a more realistic deception setting as well. Unlike the criticism often ascribed to transgression studies, in the present study we compared liars with truth tellers who both transgressed (see for a review DePaulo et al., 2003). Truth telling in the truth condition therefore perhaps was not a neutral act, 'free' from feelings of stress. Participants in our truth condition therefore may have had as much stress answering the relevant question than those whose transgressions remained hidden by the lie. This reasoning matches the fact that whereas previous work did reveal a difference between truth telling with and without the intention to lie on EDA (Ströfer et al., 2015), the current study did not find this difference. That is, in the more experimental studies of Ströfer and colleagues (2015) participants did not commit a transgression, questions were contently unrelated, and neither had personal relevance nor were embedded in an interactive interview. However, even when innocent people tell the truth, questions about a transgression might evoke stress. Gudjonsson (1982) for instance, already found that the physiological response to interview questions is not just influenced by veracity alone, but also by how disturbing the questions are experienced.

Another reason for the similar physiological response pattern may be related to our study design. Differences in truth telling with and without the intention to deceive may be too subtle to be detected in interactive scenarios like ours with interpersonal variability. In our study, no interview was exactly the same as the other, even within conditions. It seems thus that in real-life, truth telling with and without the intention to deceive can elicit similar responses, at least on a physiological basis. 
Since stress is not unique for people being interviewed who deceive, but also common for people who tell the sincere truth, researchers indeed recently argued to focus on cognitive cues to deception instead (US National Research Council, 2003; Vrij, 2008). When Iying on all questions, the current work could differentiate liars based on their self-reported cognitive load and on tonic EDA. So far though, our results only support the cognitive load approach for fully deceptive accounts. In terms of self-reported cognitive load as well as EDA, deceivers who only lied incidentally could not be differentiated from truth tellers. Although tonic EDA may be sensitive to stress as well (Boucsein, 2012), in our specific study context, higher tonic EDA levels seemed to be more strongly related to self-reported cognitive load than emotional stress. That is, when comparing the experimental conditions we find similar patterns for selfreported cognitive load and tonic EDA, whereas the pattern for self-reported stress differs: cognitive load and EDA were higher only in the lie condition, while stress was higher in both the lie and intention condition. Moreover, when comparing the relation between tonic EDA and self-reported cognitive load and stress, we found that the correlation was significantly stronger than the correlation between tonic EDA and self-reported stress.

Cognitive load in the lie condition could directly be a result of suppressing the truth while making up a counterfactual statement (Spence et al., 2001; Vrij, 2008). Continuously making up a story may further indirectly affect cognitive load by increasing monitoring behavior, implanted by the deceiver to avoid creating the impression of lying (Buller \& Burgoon, 1996; Vrij, Fisher, et al., 2006). Previously we reasoned that these latter, indirect processes may not be unique for constant lying, but may be active during the intention to deceive as well. However, having in mind that in the present study the intention and truth condition neither differed in terms of cognitive load nor in EDA, we may conclude that whereas consistently lying is cognitively taxing, having the mere intention to deceive may not be.

Moreover, deception is about creating a belief in others which oneself considers to be untrue ( Vrij, 2000). How this belief is created should not matter, because the crucial factor underlying deception is the intention to deceive (Ambach et al., 2008) and this intention should be equally strong for people who consistently are lying and people with the mere intention to deceive. This is also reflected in the present study in terms of affective responses, since the lie and intention conditions were experienced as equally stressful, although in terms of content they were different. Thus, in contrast to the findings with respect to cognitive load, in terms of stress, accounts with the intention to deceive are more similar to accounts wherein people are consistently lying. Together these results illustrate the complex nature of cues to deception when deceivers have the intention to deceive but do not lie yet. That is, whereas accounts with the intention to deceive on the one hand may be more similar to truth telling accounts-in both accounts people largely tell the truth-on the other hand they may be more similar to deception accounts - in both type of accounts people have the intention to deceive. 
When zooming in on differences in EDA between the different questions, we found that the moment of the critical question triggering participants in the intention condition to lie did induce a high phasic EDA peak. In the lie condition in contrast, phasic EDA showed the opposite effect concerning the question with the signature, with decreased phasic EDA on the relevant question (see Figure 3.2). This may be explained by a habituation effect: Frequent lying makes lying easier and frequent truth telling (like in reality and resembled in our intention condition) makes lying more difficult (Hu, Chen, \& Fu, 2012; Verschuere, Spruyt, Meijer, \& Otgaar, 2011). Also, the preceding questions demanded much more elaborated answers than the relevant question concerning the signature. Therefore, it is imaginable that participants in the lie condition could have been more cognitively depleted during the interview and were relieved at the 'relatively' simple Yes/No question: 'Is this your signature?', pointing out the end of the interview.

Although the phasic physiological responses of people who consistently lied, and people who only lied on the relevant question were different, both groups did report to have experienced more stress during the interview than people who only told the truth. It may be possible that self-reported stress in the intention condition was caused by the lie moment itself, whereas in the lie condition stress was experienced across the whole interview. Future studies testing theories on deception processes should use paradigms where truths and lies are mixed to investigate these processes in more detail. Such paradigms may not just qualitatively differ in their underlying processes related to stress and cognitive load; they also reflect real-life interviews better than when participants constantly lie.

\section{Limitations and recommendations}

The aim of the present study was to find out whether deceivers already diverge from truth tellers when they merely have the aim to deceive but do not (have to) lie yet. The answer is yes: Deceptive accounts, consisting mainly of truth telling with only one (crucial) lie differed with truthful ones, but only on self-reported stress and not cognitive load or physiological responses. This supports the emotional load approach which aims to distinguish deceivers and truth tellers by signs of stress, resulting from concerns of being detected (Vrij, 2000). However, the practical gains from the present findings remain restricted as long as these stress differences cannot be measured using more unobtrusive measures than self-reports.

Previous studies surrounding the physiology of the intention to deceive were much more structured (Carrión, Keenan, \& Sebanz, 2010; Dawson, 1980; Furedy \& Ben-Shakhar, 1991; Furedy et al., 1988; Ströfer et al., 2015). For the present study we deliberately chose to embed deception in an interview setting resembling real-life interviews as closely as possible. Although this approach increases external validity, topical interviews (such as in the current study) bear other complications such as identifying the source of physiological changes (Cunha et al., 2010). We aimed to overcome this challenge by testing the relationship 
between self-reported stress and cognitive load and tonic EDA, and found relations between those measures. It remains however difficult to identify the source of physiological changes on question level (local phasic EDA changes) since they cannot be related to self-reports concerning the whole interview.

With regard to further validate the cognitive load approach we encourage future studies to increase the reality of the scenarios against the approach that is tested. The current study only found support for the cognitive load approach for fully deceptive accounts. Our findings do not imply that in real-life scenarios where truth and lies are mixed, cognitive load could not play a role at all. In real life, deceivers strategically choose themselves when to lie and when not in deceptive attempt. This factor could be cognitively demanding, because deceivers have to think when it makes sense to lie. To investigate this, we advise to further develop the paradigm and make it even more realistic. Participants could for instance be given a choice when to lie and when to tell the truth to build up a coherent deceptive story (Sip et al., 2008). Building in factors like 'free will' when to lie could make a deceptive attempt cognitively more demanding, even if the truth is told most of the time.

In conclusion, previous deception research mainly focused on finding cues to deception by investigating accounts wherein deceivers are lying consistently. Although these studies revealed important information on which cues to deception may be useful for deception detection in real-life, they have an important limitation: in real deceptive accounts people almost never consistently lie but stick to the truth as much as possible and only lie on relevant moments in the conversation. The current research shows that the psychological processes during such an intention to lie on the one hand may be similar to processes during lying itself: both create an intention to deceive others which may result in elevated stress levels. On the other hand, processes during accounts with the intention to lie were more similar to truthtelling accounts since both resulted in lower cognitive load than fully deceptive accounts. To discovering cues to deception in real-life conversations, research therefore should focus on both emotional and cognitive indicators of deception. 


\section{Chapter 4}

\section{Interviewing Suspects with Avatars}

Avatars are more effective when perceived as human

This chapter is based on:

Ströfer, S., Ufkes, E. G., Bruijnes, M., Giebels, E., \& Noordzij, M. L. (submitted). Interviewing Suspects with Avatars: Avatars are more effective when perceived as human.

We would like to thank Jaron Plochg, Theresa Angsmann and Laurèn Appelman for their assistance in conducting the experiment. We would like to thank Ellen Giebels and Niels Boele for developing the assessment center test paradigm. 
62 I Chapter 4 
Automated deception detection is one of the biggest security challenges for the $21^{\text {st }}$ century. More than ever, governments and border agencies are interested in fast, reliable and lowintrusive ways to detect deception in crowded and vulnerable places such as airports (Aradau, 2015; Damos et al., 2013; Lu et al., 2010). The main goal is to quickly filter out those who are low at risk and to flag bad intent. A promising approach to meet this goal is to use 'automated interview systems' (AIS), which conduct structured interviews and assess deviations in the interviewee's physiology and behavior via sensors (Burgoon \& Nunamaker, 2004; Nunamaker et al., 2011; Twyman et al., 2014).

Despite the variety in interfaces, AIS all share the underlying principle of physiological lie detection, that deception is accompanied by increases in sympathetic nervous system (SNS) activity. This increase is attributed to anxiety, negative emotional states, and cognitive demand (Ekman \& Friesen, 1969; Vrij, 2008; Zuckerman et al., 1981). By sensing and interpreting these increases in the interviewee's physiological response, AIS in security contexts already have shown promising first results in terms of detecting deception but the evidence is still mixed (Derrick et al., 2011; Nunamaker et al., 2011; Twyman et al., 2014). Without doubt therefore, AIS are technically advanced enough to sense increases in SNS activity but we do not know much yet about the underlying factors that makes AIS successful deception detectors.

A critical unanswered question is: Will deceivers' SNS activity increase, knowing they 'just' talk to a computer? From interpersonal deception theory (Buller \& Burgoon, 1996) we know that in real face-to-face encounters, pressure is put on the deceiver, because the deceiver continuously has to manage his expressions in response to suspicion. As a result emotional stress, cognitive load, and attempted behavior control increase during deception in interpersonal interactions (Zuckerman et al., 1981). However, these processes are arguably moderated by the type of interpersonal context in which they take place (Buller \& Burgoon, 1996). The question is whether AIS, operated by computer algorithms, induce similar interpersonal processes in the deceiver. Specifically, in a face-to-face encounter, deceivers likely experience fear of getting caught by the interviewer, and put much effort in acting convincingly and therefore often closely monitor themselves and the reactions of the person they deceive (Buller \& Burgoon, 1996; DePaulo et al., 1988; Schweitzer et al., 2002; Vrij, 2008). It is questionable whether deceivers exhibit such behavior, knowing their conversation-partner neither is human nor has consciousness. If this is the case, a crucial ingredient for AIS to induce cues to deception therefore might be that deceivers 'believe' they interact with a real human.

Research has shown that people are capable of believing they would interact with a human, even when they do not. Based on Milgram's 'cyranic illusion' paradigm (Milgram, 1992), participants in a human face-to-face interaction did not notice that their human conversation partners just voice the words of a computer algorithm in real-time (Corti \& Gillespie, 2015a, 2015b). With regards to the content therefore, computers seemingly are capable of being 
perceived as humans. AIS however, do not have to be embodied by a real human of flesh and blood to convince people of their humanness. Already Turing (1950, p. 434) concluded that when placing the conversation in a context that naturally prevents people to see and touch the 'other', there is "[...] little point in trying to make a 'thinking machine' more human by dressing it up [...]". Nowadays, such a context can simply be created using a computermediated-communication setting (Schroeder, 2011). Lucas, Gratch, King, and Morency (2014) demonstrated for instance that one could let individuals believe that they interacted with a real human or with a computer by either introducing a virtual avatar as human or computer operated. An avatar that 'looks' and 'talks' as a human to convince people might not even be necessary. A study by Morkes, Kernal, and Nass (1999) successfully led people to believe that they communicated with a real person in a text-based chat, which actually was a computer algorithm. Importantly, when providing no clear framing of the 'other' as either human or computer operated, people for the identical AIS strongly differ in the extent to which they believe they interact with a human or a computer (Schuetzler, Grimes, Giboney, \& Buckman, 2014).

There is first evidence that 'believing' a virtual avatar is human operated indeed alters the behavior towards the virtual avatar. This is shown by a study of Lucas et al. (2014) who tested the capability of virtual avatars in clinical screening interviews. Participants, who thought they interacted with a human instead of a computer, disclosed less information and showed higher impression management. According to the authors this can be explained by the feeling that responses are currently judged when talking to a human. Whereas in a clinical interview this is disadvantageous, in a deception detection context this may be beneficial in order to evoke cues to deception.

The deception study by Schuetzler et al. (2014) for instance showed that making an AIS's communication skills more human-like-by building in an adapting response model-not just increases perceived humanness but also induces faster responses in the deceiver and reduces speech pauses. The authors ascribed this to the fact that during deception, deceivers try to maintain their normal pattern of behavior (Buller \& Burgoon, 1996). When the interview system however is static and gives no indication of interpreting or understanding the response, deceivers may not feel judged and see no urge to response fast.

We state therefore that in order to induce physiological cues to deception, perceiving an AIS as human operated is crucial. The current study tested whether deceivers who perceive the AIS as computer operated would not differ with respect to SNS activity from truth-tellers, whereas deceivers who perceive the AIS as human operated would show an increase in SNS activity. 


\section{The current study}

The aim of the current study was to investigate whether perceiving an automated interview system as operated by a human or computer, influences cues to deception in the form of increased SNS activity. Therefore, we conducted an experiment, where participants were led to believe they participated as test person for a newly developed in-basket exercise to test management skills. During the exercise they were "seduced" to commit fraud by signing a document they were not allowed to. They were then interviewed about this transgression in a structured manner by a human-like avatar on a screen. When confronted with human-like avatars, people generally are uncertain to which degree the avatar really directly represents the actions and thoughts of the person controlling that avatar (Schroeder, 2011). During the interview we measured the participant's electrodermal activity (EDA), the most frequently used measure in the field of physiological lie detection (Vrij, 2000). EDA directly reflects SNS activity and can be measured unobtrusively within one measurement (Boucsein, 2012; Dawson et al., 2007; Wallin, 1981).

In a between-subject design we then let participants deceive the avatar by either lying on all questions or only on the crucial question regarding the signature (which was at the end of the interview). We included the latter condition, because it mirrors real-life deception more closely than when people constantly lie (see Ströfer et al., 2015 for an extended explanation of this issue). Both deception conditions were compared with a condition where participants told the truth. After the interview we asked participants to rate to which degree they believed they had interacted with a human or computer. We expected that EDA would be higher in the two deceptive conditions than in the truth condition and that these differences would become larger as participants believed they interacted with a human rather than a computer.

\section{Method}

\section{Participants}

We conducted an experiment with 107 graduate students participating in exchange for $5 €$. Thirteen participants refused to sign the document that served as basis for the experiment and therefore were excluded from the experiment. The data of 8 participants who did not follow the instructions of the experiment were removed as well, leaving 86 participants for statistical analyses of the self-report data (mean age $=21.94, S D=2.79$, range $=18-30$ years; 46 women). Due to technical problems we failed to record EDA data for another 7 participants, therefore analyses for physiological responses are based on $79^{11}$ participants (mean age $=21.88, S D=2.84$, range $=18-30$ years; 41 women). Participants provided written informed consent, and the institutional review board approved the experimental protocol.

\footnotetext{
${ }^{11}$ The 28 of 107 participants who had to be excluded were randomly divided across conditions.
} 


\section{Experimental design}

The experiment consisted of a one-factorial (veracity condition: truth, lie or intention to lie) between-subject design ${ }^{12}$. Participants were randomly assigned to the veracity condition, meaning that they either had to tell the truth, to lie, or to mislead by telling the truth but lie on one crucial question during the interview concerning the signature. We assessed electrodermal activity from which the parameters described below were taken as a dependent variable.

\section{Procedure}

Participants believed they would take part at a test session for an ostensible newly developed assessment center test (ACT; Sackett \& Dreher, 1982). We employed this cover story to allow for deception in a realistic setting. At the start of the experiment we explained to the participants that the assessment center test (ACT) consisted of several exercises and that the three best participants completing these exercises each would win $50 €^{13}$. We further explained that all tasks of the session were relevant for the prize and that we would clearly state when the experiment was finished. On average, the experimental sessions lasted for 1 hour. Each session was run by an experiment leader and two confederates: One acting as 'experiment assistant' and the other as 'interviewer'.

\section{In-basket exercise.}

The experiment started with an in-basket exercise, which often is part of an assessment center test (Dukerich et al., 1990). Participants were invited to assume the role of a manager of a transport company and to substitute a regular employee who currently was on sick leave. Participants were required to complete four tasks normally executed by the sick employee in 15 minutes. In the third task participants read a contract that had to be signed by the sick employee-as was indicated by the name of the employee that was already printed on the contract. A note explained that the contract was important for the company and had to be signed urgently. Most of the participants (88\%) signed the contract, since this is an easy and fast solvable problem, and continued with the fourth task. However, signing a document under a wrong name is legally not allowed. This transgression served as input for our deception experiment.

\section{EDA baseline measurement and confrontation.}

After finishing the in-basket exercise, participants were brought to the interview room. In order to get an EDA baseline, we attached the participant to skin conductance sensors and

\footnotetext{
12 The original design also contained interview style (information-gathering vs. accusatory style) as an additional between-subject factor. Analyses with this factor did not render any significant main or interaction effects. We therefore eliminated interview style from further analyses.

${ }^{13}$ In reality, the money was allotted among the participants after the experiment.
} 
asked them to sit down for 5 minutes and relax and wait for the next task of the experiment. We informed participants that this measure assessed the difficulty of the in-basket test. After 5 minutes the experiment leader entered the room again, stating that she reviewed the participant's output of the in-basket tasks, but that a problem occurred regarding one of the documents. The experiment leader then confronted the participant with the fact that (s)he signed a document (s)he was legally not allowed to sign, and informed that (s)he therefore would be interviewed about this incident by an intelligent virtual agent.

\section{Introduction of the virtual avatar.}

The virtual avatar (see Figure 4.1) was introduced as an intelligent agent who would appear on the screen (which was turned off during the baseline measurement) in front of the participant. The experiment leader stressed that the virtual agent could hear and see them and that they could talk to him in a normal way. Although in reality the avatar was operated by a human (the experiment confederate), it remained ambiguous to the participants whether or not the avatar acted autonomously or not.

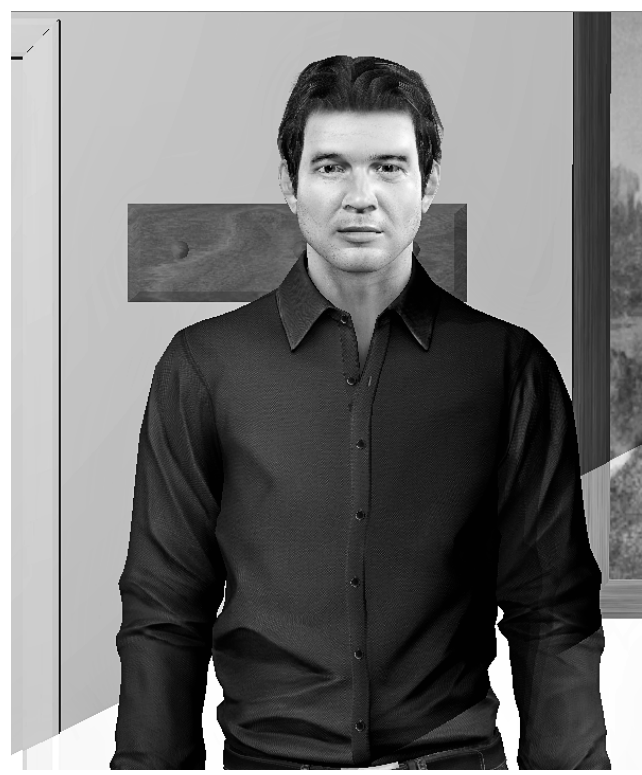

Figure 4.1. Avatar used in the experiment (Hartholt et al., 2013)

\section{Experimental manipulation.}

After introducing the virtual agent, participants received a letter advising on the best approach to behave in the upcoming interview about their transgression. This letter formed the experimental manipulation consisting of three veracity conditions: A truth, a lie and an intention to lie condition. In the truth condition, the letter advised participants to tell the 
truth on all questions, including questions about whether one signed the document. In the lie condition, the letter advised to lie on all questions, including questions about whether one signed the document. Finally, in the intention condition, the letter advised to tell the truth on all questions but to lie on questions whether one signed the document. We also highlighted the question regarding the signature in the truth and lie condition to prevent that the question about the signature would get special meaning in the intention condition only. Hereby we aimed to prevent differences in prospective memory demands between conditions. Finally, we reminded participants that how well they followed the advice would affect their chances for the prize money.

\section{The Interview with the virtual agent.}

Interview questions. After the participant finished reading the letter the experiment leader turned on the screen and the virtual agent emerged. Then the experiment leader left the room and the interview started. The interview was fully standardized, with the virtual agent asking a total of 10 questions in a fixed order (see Table 3.1). Each interview started with a number of general questions and worked its way up to the key question revealing the evidence: "Is this your signature on this document?" Thereafter the interview ended with two closing questions. During the interview, participants' EDA was recorded. After the interview the experiment leader entered the room again and asked participants to fill in a final questionnaire, including a short measure assessing the degree to which participants thought they interacted with a human or computer.

Operation of the virtual agent. The virtual agent was portrayed by VHToolkit avatar 'Brad' (Hartholt et al., 2013) and appeared on a screen in front of the participant. The virtual agent was operated out of eye shot of the participant from the experiment confederate. The operator of the virtual agent could hear and see the participant on a separate screen and therefore was able to react to the participant's speech in real-time. The operator let the avatar successively ask the 10 interview questions. A new question was selected whenever the participants finished the answer to the preceding one. In addition, the operator could choose to let the avatar display natural listening behavior while the participant was providing an answer. In normal conversations, listeners make short brief utterances such as 'M-mh', 'Yes' and 'Ok' while the conservation partner is talking (Krauss, Garlock, Bricker, \& McMahon, 1977). The listener hereby shows active listening and engagement in the conversation (Heylen et al., 2011). We had 3 versions of each utterance, which only slightly differenced in tone. While the operator chose the kind of utterance, an algorithm randomly chose one of the three versions. We did this to increase the impression of natural behavior and thus the credibility of the virtual agent. In addition to that the avatar displayed visual listening behavior as well (Krauss et al., 1977). While the participant was answering, the virtual agent recurrently shifted a little bit with his body posture, blinked with the eyes and displayed eye 
saccades. Also, the operator could choose unspecific answers to evade situations in case the participant asks back questions such as 'Do you want me to tell more?'. The operator could choose out of a set of answers such as 'Just go on' (see Table 4.1)

Table 4.1. Repertoire of evading answers the operator could give

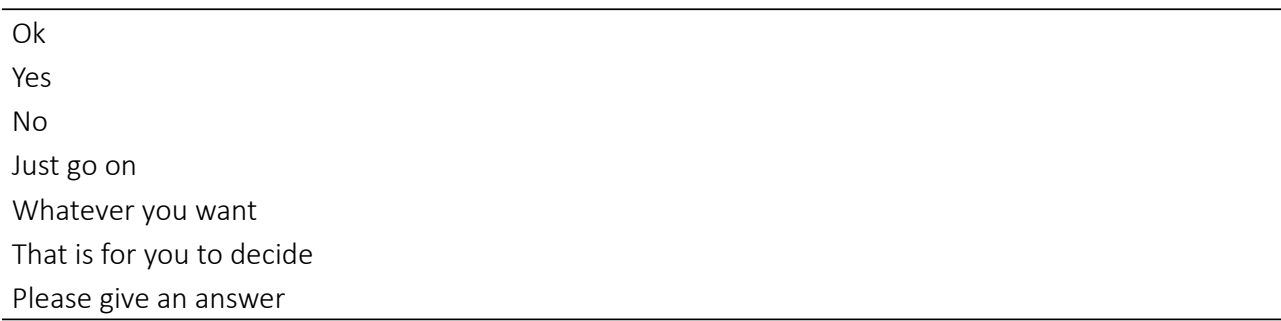

Note: The operator of the avatar used these options to evade counter question by the participant

\section{Measures}

\section{Perception of virtual agent.}

We assessed the degree to which participants perceived they interacted with a human or computer with a self-report measure. Participants completed 5 items such as "I think the virtual agent was controlled by [...]" or "I think the questions were selected by [...] on a 7-point Likert scales ranging from 1 (A human) to 7 (A computer), $\alpha=87$. An explorative factor analysis on these five items (method: maximum likelihood, based on Eigenvalues greater than 1) revealed one underlying factor, explaining $56.96 \%$ of the variance. We therefore created an overall score by computing the mean value for the scores on the 5 items. High scores indicate that participants perceived the avatar as more computer-operated and low scores as more human-operated (Distribution of scores across participant sample: $M=3.52$, $S D=1.59$, Range: 1 tot 7 ).

\section{Electrodermal activity (EDA).}

Recording. EDA was recorded continuously with $256 \mathrm{~Hz}$ from baseline till the end of the interview (down-sampled to $16 \mathrm{~Hz}$ during off-line analysis). EDA was recorded exodermal (constant voltage) via skin conductance using skin conductance sensors (Thought Technology Ltd., Montreal West, Quebec, Canada), attached to the distal phalanx of the right index and ring fingers (Boucsein, 2012). The signal was amplified using ProComplnifiniti amplifier (Thought Technology Ltd.) and was recorded in $\mu \mathrm{S}$.

Analyzing. To assess physiological arousal during the interview ${ }^{14}$, we executed a Continuous Decomposition Analysis using Ledalab (Benedek \& Kaernbach, 2010) which is an algorithm

\footnotetext{
${ }^{14}$ Unlike in Study 3, an ANOVA with veracity condition (intention to lie/lie/truth) as a between-subject factor on interview length (in seconds) revealed no difference between the conditions, $F(2,76)=0.429, p=.652$. The mean interview length (with standard error in parentheses) for the intention, lie and truth condition was $122.63,(7.15), 122.11(6.12)$ and 114.97 (6.45).
} 
written in MATLAB. We focused on tonic EDA which describes the overall conductivity of the skin over longer time intervals and can be operationalized by the skin conductance level (SCL; Figner \& Murphy, 2010). To assess EDA during the interview, we subtracted the SCL during the interview from the SCL during the baseline measurement.

\section{Results}

A multiple regression was conducted to test whether perceiving the avatar as human operated, increases cues to deception in form of tonic EDA ${ }^{15}$. We ran a regression model with the standardized scores of avatar perception, two dummy variables dummy coding the experimental conditions, and two interaction terms as predictors. For the dummy variables we used the truth condition as reference condition. Dummy 1 compared the lie condition (lying $=1$, intention $=0$, and truth $=0$ ) and dummy 2 the intention condition (lying $=0$, intention $=1$, truth $=0$ ) to the truth condition ${ }^{16}$.

In line with our hypothesis, we found a significant effect of dummy $1, \beta=.29, t(71)=2.34$, $p=.023$, revealing that $\mathrm{SCL}$ was higher in the lie $(M=2.29, S E=0.28)$ compared to truth condition ( $M=1.47, S E=0.29)$. This effect was qualified by a significant interaction effect of dummy 1 and avatar perceptions, $\beta=-.40, t(71)=-2.77, p=.007$. Simple slopes analyses (Aiken \& West, 1991; see Figure 4.2) revealed that for participants who perceived the avatar as relatively human operated (1SD from mean towards human anchor), SCL was significantly higher in the lie than in the truth condition, $\beta=0.65, t(71)=3.63, p=.001$. However, for participants perceiving the avatar as relatively computer operated ( 1 SD from mean towards computer anchor), the difference in $\mathrm{SCL}$ between the lie and truth condition disappeared, $\beta=-.06, t(71)=-0.35, p=.726$.

A similar pattern was found when comparing the intention with the truth condition. The main effect of dummy 2 was marginal significant, $\beta=.23, t(71)=1.85, p=.068$, showing that SCL was higher in the intention $(M=1.80, S E=0.32)$ compared to the truth condition $(M=$ $1.47, S E=0.29$ ). Again, this effect was qualified by a marginally significant interaction effect of dummy 2 with perceptions of the avatar, $\beta=-.25, t(71)=-1.74, p=.068$ (see Figure 4.2). That is, simple slopes analyses showed that for participants who perceived the avatar as more human operated (1 SD from mean towards human anchor) the difference in SCL between

\footnotetext{
${ }^{15}$ We verified the results by also using another way of calculating tonic EDA. Employing CDA analysis as proposed by Benedek and Kaernbach (2010), we used the average phasic driver activity across the interview as dependent variable in the regression model. This estimates the phasic activity of the electrodermal activity which overlays the skin conductance level (Figner \& Murphy, 2010). The same significant patterns were found using the phasic driver activity as using the SCL.

${ }^{16}$ We ran the same regression model using self-reported stress and cognitive load as dependent variables (both constructs were measured the same way as in Study 3 of Chapter 3). We only found a significant main effect of dummy $1, \beta=.29, t(78)=2.31, p=.02$. A subsequent ANOVA analysis revealed that cognitive load was significantly higher in the lie compared to the truth and the intention condition.
} 
the intention and truth condition was significant, $\beta=0.45, t(71)=2.58, p=.012$. However, for participants who perceived the avatar as computer operated (1 SD from mean towards computer anchor) there was no significant difference in $\mathrm{SCL}$ between the intention and truth condition, $\beta=.02, t(71)=0.10, p=.924$. As expected, the tonic EDA differences between the truth and respectively the lie and intention condition thus became larger when participants believed the avatar would be human instead of computer operated.

When participants believed the AIS was computer instead of human operated, simple slopes analyses within each veracity condition revealed that in the truth condition EDA significantly increased, $\beta=.37, t(71)=2.18, p=.003$, whereas in the lie condition, tonic EDA marginal significantly decreased, $\beta=-.35, t(71)=-1.77, p=.080$. In the intention condition, EDA was not influenced by the degree to which participants believed they interacted with a computer, $\beta=-.10, t(71)=-0.48, p=.633$.

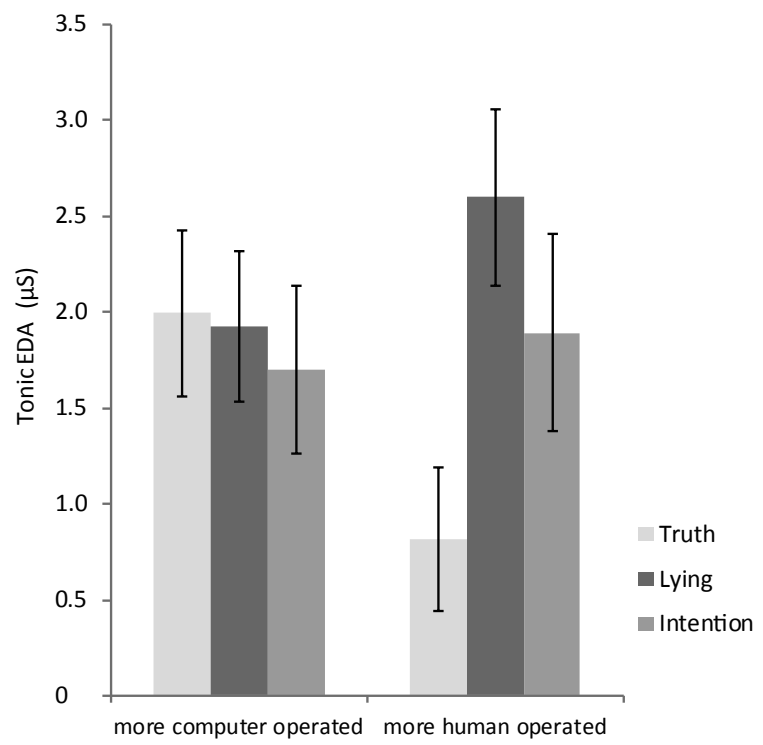

Figure 4.2. The interaction effect between condition and the perceived operation of the avatar on tonic EDA. The bars with standard error present the predicted tonic EDA value for people who score $1 S D$ from the mean towards the computer anchor and $1 S D$ towards the human anchor on the perceived avatar operation scale within the three veracity conditions.

\section{Discussion}

Automated physiological lie detection may work-but the results of our study suggest that it is crucial that deceivers believe that the system they are interacting with is controlled by another human and not by an intelligent computer. In the current study we examined 
deceivers who interacted with a virtual avatar about whom they were uncertain whether it was human or computer operated. We found that the degree to which participants perceived they interacted with a human intensifies cues to deception in the form of heightened skin conductance levels, a common marker for psychophysiological lie detection (Vrij, 2008). In line with our hypothesis, EDA differences between deceivers and truth tellers became significantly more pronounced when participants believed they interacted with a human operated avatar. When participants perceived the avatar as computer operated, there was no difference between truth tellers and deceivers. This difference in EDA between deceivers and truth-tellers was still present, even when deceivers only lied on one-crucial-question regarding the transgression. This last finding has important practical significance, because in reality deceivers tend to tell the truth as much as possible and only lie on crucial parts in a conversation (Leins et al., 2013; Strömwall et al., 2006).

As predicted, part of the decline in EDA differences between lying and truth telling when the avatar was perceived as more computer than human-operated, could be explained by a decrease in EDA when people perceived the avatar as being computer (versus human) operated and were lying. However, we also-rather unexpectedly-found that EDA increased when people perceived the avatar as computer instead of human-operated and were telling the truth.

Based on interpersonal deception theory (Buller \& Burgoon, 1996), we indeed predicted that a virtual avatar which is believed to be computer-operated might not elicit the typical psychological responses (such as an increase in monitoring processes) typical for deceivers compared to truth-tellers. In interpersonal interactions perceivers usually believe their lies shine through and therefore experience a greater sense of awareness with regard to their performance than truth tellers (Elaad, 2003; Gilovich, Savitsky, \& Medvec, 1998; Vrij, 2008). Despite the technical abilities of current Al systems to conduct an interview and to sense physiological arousal, today's Al systems however just "pretend to act like" humans instead of being one. AIS, for instance, have no consciousness in terms of noticing the presence of themselves in the world (Khanna et al., 2015), which may have important consequences for how people socially respond in interactions with Als. For example, a study by Schuetzler et al. (2014) demonstrated that deceivers exhibit shorter response latencies and pause lengths when deceiving a chatbot which was perceived as more human-operated compared to a chatbot that was perceived as computer-operated. The authors explained this by the fact that deceivers feel a greater sense of urgency to respond quickly due to their desire to appear truthful when interacting with a human-operated system.

Similarly, deceivers who assume to talk to an unconscious computer which does not 'understand' the conversation on a social level may feel less pressure to monitor the course of the deceptive conversation on a meta-level such as they would when talking to a real human (Buller \& Burgoon, 1996). Consequently, deceivers may be less engaged in monitoring 
behavior and feel no need to maintain a normal (unsuspicious) conversation while deceiving. Perceiving an Al system as computer rather than human-operated thus indeed should result in less demanding cognitive and affective processes and, consequently, lower EDA normally associated with deception (Spence et al., 2001; Vrij, 2008).

In addition, the present results revealed that truth tellers showed an opposite pattern: EDA increased to the extent to which truth-tellers believed the avatar was operated by a computer and decreased to the extent to which they believed the AIS was operated by a human. This result implies that also for truth-tellers' physiological reactions perceiving an AIS as a conscious social being versus a socially inapt computer may be crucial-and specifically so in the current setting. That is, truth tellers generally believe that their innocence automatically shines through (Gilovich et al., 1998; Vrij, 2008). In the present study truth tellers were in fact not innocent, because they did put an unauthorized signature on the document. Participants however did not commit the transgression on purpose, and may see it as minor transgression which would not be a big problem to admit when explained. It may be possible that truth tellers might have felt that an AIS controlled by a socially aware human would understand their good intentions, but that a computer directed system would completely miss this aspect of their transgression, and would judge them strictly on the basis of their actions.

\section{Recommendations and limitations}

With the rise of new technology, the findings of the current chapter not only have theoretical but also practical relevance. From a theoretical view, it supplements the Interpersonal Deception Theory (IDT) by Buller and Burgoon (1996) who emphasize the importance of interpersonal contact and interactivity in communication for cues to deception. We supplement these factors by adding 'believing' to communicate with a real human being as a third crucial factor for cues to deception. When using an AIS in a physiological lie detection context, it may be important to indicate to interviewees that the avatar is human controlledas this may help to better discriminate between honest and deceitful persons.

Moreover, we could also differentiate truth tellers from deceivers who only lied on one crucial question and for the rest of the interview stuck to the truth, but only given that the interviewees believed that a human operated the virtual interviewer. This finding is of great practical relevance as real-life deceptive attempts typically consist for a great part of truth telling (with the intention to lie) and only a few literal lies (Carlson et al., 2004; Leins et al., 2013; Strömwall \& Willén, 2011). The reason for this is twofold: Staying close to truth is easier and costs less effort (Leins et al., 2013), and it reduces chances of being caught by for instance delivering contradicting information (Hartwig et al., 2010).

The current as well as previous work (e.g., Schuetzler et al., 2014) show that people naturally differ in the extent to which they perceive an AIS as being human controlled or an autonomously computer controlled system. Having established that the 'mere belief' to 
communicate with a real human is crucial, we also recommend manipulating experimentally the actual operation of the avatar and belief of how the avatar is operated (see for example Lucas et al., 2014). Another interesting question for future research is why people differ in the perceptions of such systems. This may be correlated with certain personality traits such as emotional stability, or for instance tied to the level of experience someone has with how computer systems operate.

Our findings also have broader implications for the field of deception detection. Deception is defined as 'creating in another a belief which oneself considers to be untrue' (Vrij, 2008). This implicates that deception by definition is an interpersonal activity, including a deceiver and target to deceive. However, a lot of physiological deception studies neglect that deception takes place within a context of social interaction and study deception in isolation. By placing the emphasis on a clean and controlled study environment, it often is neglected that deception by definition is socially rooted (Sip et al., 2008). The deceptive activity howeverwhether it is literary lying, bluffing, or omitting facts (Carlson et al., 2004) - by its own nature is associated with mentalizing what the target to deceive knows and thinks to anticipate the deceptive course of action. Therefore the target to deceive plays a crucial role for the psychological processes underlying deception. Hence, it should be beneficial for detecting cues to deception to let the suspect communicate with-or at least believe to communicate with - a real human being.

\section{Conclusion}

One of the challenges of the 21st century is automated deception detection. The current study discovered a crucial ingredient that makes such systems work-the belief that one is talking to a human instead of an autonomous computer-operated system. We advise research and security industry to take this into account when putting the results of experimental studies into real-life applications such as an automated interview system for deception detection. Already existing automated interview systems are technically sophisticated and even 'look' human-like by means of an avatar interface (Derrick et al., 2011; Nunamaker et al., 2011). The crux of the matter however may be not that these systems look human-like, but that they are perceived as human-operated. In other words, the suspects have to have the belief that they talk to a conscious human through the virtual avatar and not a machine. 


\title{
Chapter 5
}

\author{
Discussion
}


76 | Chapter 5 
The aim of this dissertation was to examine the intention to deceive: The unifying factor underlying all deceptive activities. The crucial point of deception is to intentionally create a false belief in another (Vrij, 2000). This however can be done by many different strategies, ranging from literally lying, bluffing, half-truths, and concealments (Carlson et al., 2004). There are in fact many more ways to mislead, yet it is the intention to deceive that matters and underlies all deceptive attempts. Deceivers in real-life do try to stick to the truth as close as possible. With the aim to tell a coherent but deceptive story, they tend to diverge from truth telling as little as possible (Leins et al., 2013; Sip et al., 2008; Strömwall et al., 2006). As a result, truth telling with the intention to deceive takes up a large part of the time and psychological efforts within a deceptive attempt.

To 'capture' the mere intention to deceive, in this dissertation I examined the process of truth telling with the intention to lie on a crucial aspect later on. I contrasted this advanced condition with two conditions, traditionally compared in the field of deception: 'sincere' truth telling and consistently lying. Across four empirical studies, I compared the physiological response while people tell the truth with the intention to lie, constantly lie or sincerely tell the truth. On a behavioral basis, truth telling with the intention to lie is very similar to 'sincere' truth telling. Both involve truth telling but they diverge in the underlying intention people have while doing so. Also, deception is about creating a false belief in another and therefore by definition an interpersonal activity, including a deceiver and a target to deceive. Therefore, I examined the intention to deceive in different interpersonal contexts in the current doctoral dissertation.

In my dissertation I varied interpersonal contact and interactivity of the conversation across four empirical studies. The main focus of the first two studies, presented in Chapter 2, was to see whether the intention to lie can be measured at all. We tested the intention to deceive in a controlled setting with no interactivity and low interpersonal contact. For this purpose participants assumed that an expert in lie detection would observe them via a camera. In the studies of Chapters 3 and 4 we tested the intention to deceive in an interview context with high interactivity. Both studies were identical but differed in interpersonal contact the participant had with the interviewer: In Study 3 the interview was conducted face-to-face by a human interviewer and in Study 4 by a virtual interviewer on a computer screen.

In the current chapter, I will discuss the empirical findings of the current dissertation, comparing the outcomes of the different chapters and relating these to a broader theoretical context. I will focus on the commonalities and differences of the findings, what we can learn from these findings and which issues (yet) remain unanswered. Emphasis will be placed on the processes underlying deception and the role of the interpersonal context in detecting physiological cues to deception. I will start this chapter with a short summary of the findings and conclude with the practical implications as well as potential directions for future research. 


\section{Summary of the main findings}

Deceptive intentions: Measuring cues to deception before a lie is even stated.

In Chapter 2, we presented two studies in which we put the idea that already the mere intention to lie could be measured to a first test. Previous work consistently showed that sympathetic nervous system (SNS) activity is higher during lying than truth telling (Cunha et al., 2010; Jung \& Lee, 2012; Watson \& Sinha, 1993). This can be related to stress and cognitive load, both accompanying lying (Zuckerman et al., 1981) and both inducing an increase in SNS (Engström et al., 2005; Hout et al., 2000; Lacey et al., 1963; Nourbakhsh et al., 2012; Page \& Robson, 2007; Shi et al., 2007; Wilson, 2002). We hypothesized that SNS activity already rises during intentions to lie and, consequently, physiological cues to deception can be detected for deceivers who did not lie yet. In two studies, controlling for prospective memory, we monitored SNS activity during lying, truth telling, and truth telling with the aim of lying at a later instance.

We used electrodermal activity (EDA) as an indicator of SNS activity (Boucsein, 2012; Dawson et al., 2007). We found that EDA was highest during lying (Study 2.1 and 2.2), and compared to the truth condition, EDA was also raised during the intention to deceive (Study 2.2). Moreover, the switch from truth telling towards lying in the intention condition evoked higher EDA than switching towards non-deception related tasks in the lie or truth condition (Study 2.2). These results provide some first empirical evidence that physiological cues to deception in the form of increased EDA are already present during the mere intention to lie.

\section{Processes underlying deception in an interactive interview setting.}

Having established in Chapter 2 that the mere intention to deceive can lead to physiological cues to deception, we examined deception in a more natural situation in Chapter 3. Our aim was threefold: First, we aimed to replicate our findings from study one in a face-toface interview. Second, we aimed to get more insight into the mechanisms underlying psychological changes caused by deception. Third, we aimed to increase "agency" by seducing the participants to commit a transgression which they later on were interviewed about. Increases in EDA alone tell us to which degree a subject is physiologically aroused (Boucsein, 2012; Dawson et al., 2007). To get a first idea of the origin and nature of the increases we therefore added self-reports of cognitive load and stress to our EDA measurements. Both are known to be higher during deception (Zuckerman et al., 1981) and leading to increases in SNS activity (Engström et al., 2005; Hout et al., 2000; Lacey et al., 1963; Nourbakhsh et al., 2012; Page \& Robson, 2007; Shi et al., 2007; Wilson, 2002). Again we compared three veracity conditions: Intention to lie, lying and truth telling.

We either gave participants the instruction to deceive the interviewer by telling the truth but to lie on only one single crucial question (intention to lie condition), lying on all questions (lie condition) or to be honest and tell the truth on all questions (truth condition). We found that 
deceivers who lied constantly diverge from truth tellers in EDA, self-reported cognitive load and stress. Additionally, despite the fact that deceivers experienced the intention condition as more stressful than the truth condition, we found no difference in EDA or self-reported cognitive load. Across all interviews, EDA correlated stronger with self-reports of cognitive load than stress. Together these results suggest that whereas lying clearly diverges from truth telling-physiologically and on self-reports-the intention to deceive seemed to be more difficult to capture in an interpersonal face-to-face communication with high interactivity.

\section{Interviewing Suspects with Avatars.}

The aim of the fourth and final study was to examine cues to deception in an interview setting where we replaced the human interviewer with a virtual avatar (displayed on a screen). This enabled us to discover whether deceivers still would reveal physiological cues to deception (EDA) when being interviewed by a virtual avatar. Importantly, participants were naïve to how the virtual avatar was operated. The main hypothesis was that the difference between truth telling and deception would be moderated by the degree to which people actually 'believed' that the avatar was operated by a human versus a computer. Again, we measured EDA (and afterwards assessed self-reports) while participants deceived the interviewer by telling the truth but lying on only one single crucial question (intention to lie condition) or lying on all questions (lie condition), and compared these to the truth condition where the truth was told on all questions (truth condition). This time EDA was not only higher in the lie but also in the intention compared to the truth condition (as we found in Study 2.2). These effects were qualified by whether people believed that the avatar was human versus computer-operated. Cues to deception in the form of EDA increased as people 'believed' they talked to a human operated instead of to a computer operated system. However, the 'belief' of the 'other' as either human or computer operated had no effect on self-reported stress and cognitive load. We only found a main effect of veracity condition on self-reported cognitive load which was rated highest in the lie condition.

\section{Fully deceptive versus fully truthful accounts.}

Across all 4 empirical studies we successfully could differentiate liars from truth tellers on a physiological basis: that is, independent of the study paradigm EDA levels were consistently higher during lying compared to during truth telling, which vows for the stability of this effect. This finding is in line with traditional research which compared truth telling and lying on a physiological basis (Gödert et al., 2001; Jung \& Lee, 2012; Pennebaker \& Chew, 1985; Podlesny \& Raskin, 1977; Vincent \& Furedy, 1992; Watson \& Sinha, 1993).

I went one step further and added self-reports to the traditional physiological differentiation of deception in Study 3 and 4. These revealed unique insights into what might have caused this constant difference in EDA between the lie and truth condition. Next to the stable EDA 
differences we found across all empirical studies, in Study 3 and 4, fully deceptive accounts also differed from truthful ones in terms of self-reported cognitive load. Both strongly correlated in Study 3. In contrast, self-reported stress showed a weaker correlation with EDA and was only rated higher in the lie condition using a human interviewer (Study 3). Experienced stress therefore seems to be more sensitive to the social context (i.e., the presence of another individual) than cognitive load.

The finding that lying has a more stable effect on cognitive load than experienced stress is relevant for the debate in the deception literature whether to focus more on cognitive or emotional cues to differentiate liars from truth tellers (Vrij, Fisher, et al., 2006). Concerning the comparison of fully deceptive with fully truthful accounts, the current dissertation's results support the cognitive load approach. The act of lying in itself is difficult, because one has to suppress the truth while making up a counter-factual statement (Spence et al., 2001; Vrij, 2008). Above this rather intrapersonal aspect comes an aspect on an interpersonal level: Liars actively have to engage in impression management, that is, they have to make sure to appear honest and therefore have to control themselves and monitor the reaction of the other.

In real life, fully deceptive accounts are scarce, since they cost effort and increase the chance of delivering contradicting information (Hartwig et al., 2010; Leins et al., 2013). Instead, deceivers mostly stick to the truth as close as possible. Hence, a real-life deceptive attempt usually contains a mixture of truths and lies but for the greatest part exist of truths. Deception paradigms therefore must recognize that a great part of the deception attempt occurs in the absence of lying and the crucial factor underlying deception is the intention to deceive (Sip et al., 2008). This puts forward two questions: "Is it possible to measure the mere intention to deceive?" and "How does a deceptive attempt where truth and lies are mixed affect one's physiological reactions?". The following section discusses the insights provided by this dissertation.

\section{The intention to deceive}

\section{Processes underlying truth telling with the intention to deceive.}

We hypothesized that similar to lying, truth telling with the mere intention to lie already could induce increased EDA. Theoretically, deception related processes should already be present during truth telling with the intention to lie. For instance, deception typically can be paired with increased stress and cognitive load levels. One could however argue that such processes are present during the whole deceptive attempt, including lie as well as truth moments.

On a behavioral level, the intention condition is more similar to the truth condition: Neither the truth needs to be suppressed nor a statement has to be fabricated. However, conceptually seen, the intention and lie condition are more similar: In both situations, deceivers have the intention to deceive and may engage in impression-management to, for example make sure their deceptive intentions do not shine through. 
In this dissertation we therefore aimed to find out whether EDA levels during the intention to lie resemble EDA levels during sincere truth telling or lying. Findings across this dissertation are mixed and may depend on the interpersonal context.

\section{Can the intention to deceive be measured? It depends on the context.}

In Chapter 2 we found some first evidence that the mere intention to deceive evokes higher EDA than 'sincere' truth telling ${ }^{17}$ in a controlled lab setting with no interactivity between the deceiver and the target to deceive (an expert in lie detection who observed the participants passively via a camera ${ }^{18}$ ). We concluded that some processes related to monitoring and liepreparation probably were already present during truth telling with the intention to lie.

In Chapter 3 we then tested whether we could replicate these findings in a face-to-face interview setting. We hypothesized that in a setting with high interpersonal contact and interactivity, monitoring behavior would be even more stressed because the conversation pattern is rather dynamic and cannot be fully anticipated (Berger \& Battista, 1993). However, inconsistent with our hypothesis, EDA levels were the same in the intention and truth condition.

A reason for this could be that the effect of truth telling with the intention to lie is very subtle and cannot (yet) be reliably detected in studies with high variance. In Chapter 2, employing a within-subject design, participants went through veracity conditions several times and the answers were restricted by the experiment, which led to lower inter-personal variability than in the study reported in Chapter 3. In Chapter 3, interpersonal variance between the participants was higher, because no interview was exactly alike (for an argumentation see 'Measuring electrodermal activity', p.110). This could have overshadowed the effect of the intention to deceive on EDA.

In Study 4, using a virtual avatar as the interviewer, we again did find a difference in EDA level between the intention and truth condition, but only when participants believed the avatar was human instead of computer operated. In first instance this is surprising, because both Studies 3 and 4 were highly similar and only differed in interpersonal contact: In Study 3 the interview was conducted face-to-face by a human and in Study 4 by a virtual avatar. The fact that we found no difference in EDA level between the intention and truth condition in Study 3 therefore could not be solely explained by interpersonal variance overshadowing the subtle effect, because interactivity was the same across these interview studies.

A possible explanation might therefore lie in the degree of interpersonal contact, especially access to the other person's reaction. Interpersonal contact was low in Studies 2.1, 2.2 and 4. In Chapter 2 (Studies 2.1 and 2.2) participants assumed that they deceived someone who

\footnotetext{
${ }^{17}$ An EDA difference between truth telling with and without the intention to lie was only found in Study 2.2, when using a traditional arithmetic double-task but not in Study 2.1, using a non-traditional emotionrecognition double-task. For an argumentation of why some double-task work and others not see 'The use of double-tasks to increase cues to deception' (p.109).

${ }^{18}$ In reality we only let participants believe that they would be observed by an expert and there was no real expert in lie detection present.
} 
watched them via a camera. Ergo, they could not 'read' the other's face. This was similar in Chapter 4, because participants only saw a virtual avatar and not the human they assumed operating it. The absence of relevant social information therefore might heavily affect the deceiver (Culnan \& Markus, 1987).

Interpersonal deception theory states that deceiving face-to-face is initially difficult but that these difficulties typically dissipate over time as participants acquire more feedback about the target to deceive (Buller \& Burgoon, 1996). The crucial point is that the deceivers only could acquire ongoing feedback about the other side in the face-to-face interaction in Study 3. The non-access to reactions of the target to deceive in Studies 2.2 and 4 could have made the monitoring of the other more difficult and thus kept them in the dark about the success of their impression management attempts. Participants knew that someone else would see them but they in turn could not check the 'other's' reaction. This might have induced additional pressure on the deceiver. In Chapter 3 however, deceivers had full access to the facial reactions of the interviewer and as such- they may have felt better able to monitor the interaction.

For the differentiation between lying and 'sincere' truth telling, having access to the other's reaction wasn't a constraining requirement. Across all studies the lie and truth condition could de differentiated, independent of the interpersonal contact. During lying, impression management is coupled with making counterfactual statements. Making a counterfactual statement in itself is already demanding, independent from the context. This would explain why the effect of the intention to deceive (for which only impression management is relevant) depends on the amount/type of the interpersonal contact. On the basis of this discussion, we therefore conclude that to increase the chance of measuring cues to deception at the mere intention to deceive, withholding the deceiver from reactions on the part of the target to deceive can be beneficial.

In the current dissertation we only found one interpersonal context wherein we measured no cues to deception at all: When participants believed they interacted with a virtual avatar operated by a computer instead of a human (Study 4). All preceding studies shared on a minimal basis that the deceivers 'believed' they would be monitored by a real human. So we may conclude that a requirement to evoke physiological cues to deception is that the suspect believes to be monitored by a 'sentient' other. A reason might be that deceivers perceive no need to engage in impression-management at all, when an unconscious computer cannot 'understand' the conversation such as a human would.

\section{The switch from truth telling towards lying.}

Another way to look at the intention to deceive is to examine the switch from truth telling towards lying within a deceptive attempt. The focus here is shifted from measuring the intention to deceive in itself towards the effect the intention to deceive might have on the 
upcoming lie moments. In Study 2.2 and Study 3 we found that switching from truth telling with the intention to lie towards lying on the relevant question evokes a peak in EDA. An explanation for this finding may be that cognitive load and stress related to deception, become most taxing when making the switch towards lying.

In contrast, in fully deceptive accounts no such increase was seen when switching to the corresponding question which might be explained by a habituation effect (Hu et al., 2012; Verschuere et al., 2011). In fully deceptive accounts, stress and cognitive load might be more uniformly spread across the deceptive attempt. This again provides evidence that fully deceptive accouts qualitatively differ from deceptive accounts where truth and lies are mixed. Interestingly, we saw such an increase in EDA also in the truth condition of interview Study 3 (Chapter 3$)^{19}$ but not in Study 2.2 (Chapter 2). Since the corresponding question in the truth condition was highlighted as relevant question across all studies, differences cannot be fully explained by an automatic orientation response (Sokolov, 1963; Verschuere et al., 2004). We rather explain this discrepancy between Study 2.2 on the one hand and Study 3 on the other by a so called automatic defensive response: A reaction to stimuli perceived as aversive or threatening might induce a peak in physiological arousal (Campbell, Wood, \& McBride, 1997; Roelofs, Hagenaars, \& Stins, 2010). Participants in the interview studies deliberately signed a document which afterwards appeared not to be allowed. This transgression formed the basis for the interview. Truth tellers may have found answering the question "Is this your signature?" as disturbing as deceivers in the intention condition (who lied on this question). In Chapter 2 on the other side, participants did not commit a transgression and the relevant questions might not have been disturbing. This could explain why in interview Study 3 we detected an increase in EDA in the truth condition as well.

\section{Limitations and recommendations \\ Conceptualizing the intention to deceive.}

Whereas lying could successfully be measured, 'capturing' the mere intention to lie turned out to be much more complex. In order to 'purely' measure the mere intention to deceive we focused our research on truth telling with the intention to deceive. To realize this and make deceptive attempts comparable we instructed participants on which moments to lie. In this way we were able to secure that the lie moment is proceeded by a period of truth telling with the intention to deceive. In real-life however there are no external cues for the deceiver when and whether to utter a lie. Therefore, Sip and colleagues (2008) state that prescribing when to lie eliminates the voluntary intention to deceive and its deliberate execution. We tried to take these considerations into account as far as possible while taking care that

\footnotetext{
${ }^{19}$ In Chapter 4 we did not calculate the switch towards the relevant question, because the focus of this chapter was on whether the belief to interact with a human or computer-operated avatar can modulate cues to deception. Further analyses are needed to analyze whether the switch can also be seen here, dependent on the veracity condition and participants' belief.
} 
the experimental conditions remained comparable. In our interview studies, participants committed the transgressions themselves whereas in a lot of mock-crime studies the experiment leader prescribes the participant to commit a transgression and to subsequently lie about it (e.g., Gödert et al., 2005; Kircher et al., 1988; Verschuere et al., 2004). We 'only' gave the participants an advice to tell the truth or deceive about this transgression in an upcoming interview, meaning that it still was their own decision to deceive. Of course this bears the danger that some participants will not commit the transgression or follow the advice, as we also experienced in our studies. However, deceptive attempts became more realistic, because those who committed the transgression and decided to lie, had voluntarily settled on the intention to deceive (Sip et al., 2008).

How the deceptive attempt looks like was prescribed in our studies (lying on all questions or only on one single relevant question). Participants thus chose to deceive but not the manner how to deceive. For future studies we recommend letting deceivers carefully and strategically consider themselves when and how to deceive (e.g., through lying, bluffing, concealing) to make a deceptive attempt even more realistic. This might make a deceptive attempt more demanding and make it subsequently easier to measure difference between truth telling with and without the intention to lie.

A final remark has to be made on the set-up of our three veracity conditions in the interview studies. Our aim was to make these conditions realistic in that the interview topic-a transgression committed within the experiment-was relevant to the participants. To make the veracity condition comparable, truth tellers in our studies had to commit the transgression to prevent that conditions would differ in the stakes. However, it has to be acknowledged that in real-life, most of the time deceivers have to be differentiated from 'innocent' truth tellers. It would therefore be insightful to add to our study design a second truth condition in which participants do not commit the transgression. In our studies such a group evolved in a natural manner out of participants who refused to sign the document and those we actively assigned to the truth condition. These falsely accused truth tellers however were not included in our analysis because of two reasons: First, there was a self-selection bias in that those persons who refused to sign probably differ significantly from the rest of the sample in other characteristics. Second, these persons were not randomly assigned to the truth condition. Also, including such a group was not within the scope of this dissertation. We however encourage future research to also compare truth tellers who are falsely accused with deceivers, to further study the knowledge surrounding processes underlying deception.

\section{Inconsistent findings regarding EDA and self-reports measures.}

Throughout the dissertation we saw that lying was accompanied by the highest EDA levels and highest self-ratings in cognitive load. For self-reported stress, results were mixed: Findings on EDA and self-reported stress showed opposite patterns across the face-to-face interview 
(Study 3) and the virtual avatar study (Study 4). In Study 3 the intention and truth condition differed on self-reported stress but not EDA and in Study 4 vice versa. A weak or even no relationship between the human's subjective experience and physiological response system occurs often (e.g., Hodgson \& Rachman, 1974; Johannes \& Gaillard, 2014; Mauss, Wilhelm, $\&$ Gross, 2004). This could have several reasons. Subjective experiences and physiological responses may be based on qualitatively different response systems. Evers et al. (2014) for example propose a dual-process perspective in which subjective experiences are based on a reflective (relatively conscious, deliberate, and effortful) and physiological responses on an automatic (relatively unconscious, fast, and efficient) response system. Also, humans differ in their physiological reactivity and/or awareness of emotional responding, leading to varying degrees of experience-physiology associations among people (Brosschot \& Janssen, 1998; Cacioppo, Berntson, \& Klein, 1992).

But detecting no relationship can also have methodological reasons as suggested by Mauss, Levenson, McCarter, Wilhelm, and Gross (2005). Between-subject designs generally weaken the relationship because of between-individual variance. But also, aggregating measures across mixed emotional contexts can obscure relationships. With regard to our studies, the virtual avatar for example might have elicited more mixed emotions across the interview than the human interviewer. The avatar might have left the participants not just stressed but also puzzled (most people did not encounter a virtual avatar before). Figuring out why under some circumstances, subjective and objective measures correlate and sometimes not is an interesting question that follow-up research might look further into (see e.g., Evers et al., 2014).

\section{The use of double-tasks to increase cues to deception.}

Whereas lying can be measured on a group-level, measuring the mere intention to lie appears more difficult. For future research we have several recommendations: We found an effect of the intention to deceive in a controlled experiment setting when using an arithmetic double-task. Normally, double-tasks are known to increase cues to deception (Vrij, Fisher, et al., 2006; Vrij et al., 2011; Vrij, Mann, et al., 2010; Vrij et al., 2008). It seemed however that double-tasks not always work, at least not for differentiating intention and truth conditions (see Study 2.1 using an emotion-recognition double-task). Also, we used an 'easy' and 'difficult' version of each double-task in Study 2.1 and Study 2.2. Unlike our expectations, we found no interaction-effect between veracity condition and double-task difficulty. There are several reasons why double-tasks could not work: They do not necessarily interfere with deception related processes, they might be too difficult or they are not executed seriously. The reason that our difficulty manipulation did not work may be explained by a mismatch of task-difficulty and task-engagement. Most of the times both are correlated but when a task becomes too difficult or unsolvable, the person disengages from the task and EDA actually 
decreases (Pecchinenda, 1996). Therefore, for future studies we recommend testing prior to the deception experiment the impact of non-traditional double-tasks and difficulty levels on physiology and self reported cognitive demand.

\section{Measuring electrodermal activity.}

Some practical remarks have to be made with regard to the EDA analyses across the studies. All EDA analyses of the empirical chapters were based on the continuous decomposition analysis by Benedek and Kaernbach (2010). However, there are some small differences between the studies which I will explain and elaborate on. First, in Chapter 2, we reported the integrated skin conductance response (ISCR) as indicator for phasic EDA whereas in Chapter 3 and 4 we report the average phasic driver activity. Both contain the same information, since the ISCR is the time integral of the phasic driver, it equals the average phasic driver activity multiplied by the size of the response window ( $\mu S^{*} s$, for more details see Benedek and Kaernbach, 2010). In the first and second study (Chapter 2), the time window of interest was restricted by the experiment-all time windows for the analysis had the same length-whereas in Study 3 and 4 , the length of the time window varied between participants since each interview was different. Therefore, a measurement unit which is time dependent would not be useful and we chose to use the average phasic driver activity.

However, the fact that the length of the time windows of interests were not fixed in Study 3 and 4 also had another consequence for the EDA analysis: Handling the EDA drift in time. Usually, the skin conductance level (SCL) gradually decreases (at a rest period) but steadily increases at stimulation (Dawson et al., 2007). With regard to our interview studies, it follows that participants who talked longer to the interviewer also were exposed longer to stimulation. Hence, they could have an overall higher EDA level, simply because the conversation lasted longer. High interpersonal variance in time therefore can form a great source for noise and in the worst case overshadow the effects caused by the experimental manipulation. Because in Study 3, interview length seemed to differ between veracity conditions and variance in interview lengths was much higher than in Study 4, we decided to apply a range correction. We corrected every recorded data point into proportion to the intra individual range, using a person's recorded EDA maximum and minimum (Lykken et al., 1966). Through this, effects on EDA caused by the veracity manipulation (e.g., a fast steep rise in EDA compared to baseline) remain visible and artifacts caused by time drift become extenuated. For future studies we recommend incorporating variance in interview lengths. We also recommend corroborating EDA results with other physiological measures common in deception experiments, such as vocal pitch and tense or pupil dilation (for a review see DePaulo et al., 2003). 


\section{Conclusion}

Across the dissertation, lying could be reliably differentiated from 'sincere' truth telling in terms of EDA and self-reported cognitive load. Importantly, deceivers actually stick to truth as close as possible and intend to only lie on some aspects. That is why realistic deceptive attempts exist for the largest part of truth telling with the intention to lie.

We provided some first evidence that the mere intention to lie already can induce an increase in the physiological response of deceivers. We showed this by comparing deceptive accounts, which exist for the largest part of truth telling with the intention to lie, with fully truthful accounts. However, measuring cues to deception at the mere intention to deceive highly depends on the interpersonal contact. To be more precise, depriving the deceiver of the ongoing reactions of the target to deceive, seem to be necessary to evoke cues to deception. The reason might be that impression management to appear honest, typically seen for deceivers, is more difficult when having no access to the other's reactions.

Finally, we identified one situation under which we could detect no cues to deception at all: That is when the participants communicated with a virtual interviewer that they 'believed' to be operated by a computer. We conclude that in order to evoke (physiological) cues to deception it is important to let the deceiver communicate or at least believe to communicate with a real human. Furthermore, depriving the deceiver from seeing the other may benefit detecting subtle difference between truth telling with and without the intention to deceive. 



\section{References}


90 | References 
Lie (n.d.) In The Oxford English Dictionary. Retrieved from http://oxforddictionaries.com/words/theoxford-english-dictionary

Abe, N., Suzuki, M., Mori, E., Itoh, M., \& Fujii, T. (2007). Deceiving others: distinct neural responses of the prefrontal cortex and amygdala in simple fabrication and deception with social interactions. Journal of Cognitive Neuroscience, 19(2), 287-295.

Aiken, L. S., West, S. G., \& Reno, R. R. (1991). Multiple regression: Testing and interpreting interactions. Newbury Park, CA: Sage.

Aikins, D. E., Martin, D. J., \& Morgan, C. (2010). Decreased respiratory sinus arrhythmia in individuals with deceptive intent. Psychophysiology, 47(4), 633-636.

Ambach, W., Stark, R., Peper, M., \& Vaitl, D. (2008). Separating deceptive and orienting components in a Concealed Information Test. International Journal of Psychophysiology, 70(2), 95-104. doi: 10.1016/j.ijpsycho.2008.07.002

Aradau, C. (2015). 'Crowded Places Are Everywhere We Go': Crowds, Emergency, Politics. Theory, Culture \& Society, 1-21.

Barrett, L. F. (1997). The relationships among momentary emotion experiences, personality descrptions, and retrospective ratings of emotion. Personality \& Social Psychology Bulletin, 23(10), 1100.

Benedek, M., \& Kaernbach, C. (2010). A continuous measure of phasic electrodermal activity. Journal of Neuroscience Methods, 190(1), 80-91. doi: 10.1016/j.jneumeth.2010.04.028

Berger, C. R., \& Battista, P. d. (1993). Communication failure and plan adaptation: If at first you don't succeed, say it louder and slower. Communications Monographs, 60(3), 220-238.

Beune, K. (2009). Talking Heads: Interviewing Suspects from a Cultural Perspective. Doctoral thesis, University of Twente, Enschede, The Netherlands.

Boucsein, W. (2012). Electrodermal Activity. New York: Springer.

Brosschot, J. F., \& Janssen, E. (1998). Continuous monitoring of affective-autonomic response dissociation in repressers during negative emotional stimulation. Personality and Individual Differences, 25(1), 69-84.

Buller, D. B., \& Burgoon, J. K. (1996). Interpersonal Deception Theory. Communication Theory, 6(3), 203242. doi: 10.1111/j.1468-2885.1996.tb00127.x

Burgoon, J., \& Nunamaker, J. (2004). Toward computer-aided support for the detection of deception. Group Decision and Negotiation, 13(1), 1-4.

Burgoon, J. K., \& Buller, D. B. (1994). Interpersonal deception: III. Effects of deceit on perceived communication and nonverbal behavior dynamics. Journal of Nonverbal Behavior, 18(2), 155-184. doi: 10.1007/BF02170076

Cacioppo, J. T., Berntson, G. G., \& Klein, D. J. (1992). What is an emotion? The role of somatovisceral afference, with special emphasis on somatovisceral "illusions". In M. S. Clark (Ed.), Emotion and Social Behavior (pp. 63-89). Thousand Oaks, CA: Sage.

Campbell, B. A., Wood, G., \& McBride, T. (1997). Origins of Orienting and Defensive Responses: An Evolutionary Perspective. In P. J. Lang, R. F. Simons \& M. T. Balaban (Eds.), Attention and Orienting: Sensory and Motivational Processes (pp. 41-67). Mahwah, NJ: Lawrence Erlbaum.

Carlson, J. R., George, J. F., Burgoon, J. K., Adkins, M., \& White, C. H. (2004). Deception in computer-mediated communication. Group Decision and Negotiation, 13(1), 5-28. doi: 10.1023/B:GRUP.0000011942.31158.d8

Carrión, R. E., Keenan, J. P., \& Sebanz, N. (2010). A truth that's told with bad intent: an ERP study of deception. Cognition, 114(1), 105-110. doi: 10.1016/j.cognition.2009.05.014 
Caso, L., Gnisci, A., Vrij, A., \& Mann, S. (2005). Processes underlying deception: an empirical analysis of truth and lies when manipulating the stakes. Journal of Investigative Psychology and Offender Profiling, 2(3), 195-202. doi: 10.1002/jip.32

Christ, S. E., Van Essen, D. C., Watson, J. M., Brubaker, L. E., \& McDermott, K. B. (2009). The contributions of prefrontal cortex and executive control to deception: evidence from activation likelihood estimate meta-analyses. Cerebral Cortex, 19(7), 1557-1566.

Cierniak, G., Scheiter, K., \& Gerjets, P. (2009). Explaining the split-attention effect: Is the reduction of extraneous cognitive load accompanied by an increase in germane cognitive load? Computers in Human Behavior, 25(2), 315-324. doi: 10.1016/j.chb.2008.12.020

Cohen, S., Kamarck, T., \& Mermelstein, R. (1983). A global measure of perceived stress. Journal of Health and Social Behavior, 385-396.

Corti, K., \& Gillespie, A. (2015a). Revisiting Milgram's cyranoid method: experimenting with hybrid human agents. The Journal of Social Psychology, 155(1), 30-56.

Corti, K., \& Gillespie, A. (2015b). A truly human interface: interacting face-to-face with someone whose words are determined by a computer program. Frontiers in Psychology, 6, 634.

Culnan, M. J., \& Markus, M. L. (1987). Information technologies: Electronic media and intraorganizational communication. In F. M. Jablin, L. L. Putnam, K. H. Roberts \& L. W. Porter (Eds.), Handbook of Organizational Communication: An Interdisciplinary Perspective (pp. 420-444). Newbury Park, CA: Sage.

Cunha, M. G., Clarke, A. C., Martin, J. Z., Beauregard, J. R., Webb, A. K., Hensley, A. A., . . Martin, D. J. (2010). Detection of deception in structured interviews using sensors and algorithms. Paper presented at the SPIE Defense, Security, and Sensing, Orlando, FL, United States.

Damos, D. L., Boyett, K. S., \& Gibbs, P. (2013). Safety versus passenger service: The flight attendants' dilemma. The International Journal of Aviation Psychology, 23(2), 91-112.

Dawson, M. E. (1980). Physiological detection of deception: Measurement of responses to questions and answers during countermeasure maneuvers. Psychophysiology, 17(1), 8-17. doi: 10.1111/ j.1469-8986.1980.tb02452.x

Dawson, M. E., Schell, A. M., \& Filion, D. L. (2007). The Electrodermal System. In J. Cacioppo, L. G. Tassinary \& G. G. Berntson (Eds.), Handbook of Psychophysiology (pp. 159-181). New York.: Cambridge University Press.

DePaulo, B. M., Kirkendol, S. E., Tang, J., \& O’Brien, T. P. (1988). The motivational impairment effect in the communication of deception: Replications and extensions. Journal of Nonverbal Behavior, 12(3), 177-202.

DePaulo, B. M., Lindsay, J. J., Malone, B. E., Muhlenbruck, L., Charlton, K., \& Cooper, H. (2003). Cues to deception. Psychological Bulletin, 129(1), 74-118. doi: 10.1037/0033-2909.129.1.74

Derrick, D. C., Jenkins, J. L., \& Nunamaker Jr, J. F. (2011). Design principles for special purpose, embodied, conversational intelligence with environmental sensors (SPECIES) agents. AIS Transactions on Human-Computer Interaction, 3(2), 62-81.

Dionisio, D. P., Granholm, E., Hillix, W. A., \& Perrine, W. F. (2001). Differentiation of deception using pupillary responses as an index of cognitive processing. Psychophysiology, 38(2), 205-211. doi: 10.1111/1469-8986.3820205

Dotsch, R., \& Wigboldus, D. H. (2008). Virtual prejudice. Journal of experimental social psychology, 44(4), 1194-1198. doi: 10.1016/j.jesp.2008.03.003

Dukerich, J. M., Milliken, F. J., \& Cowan, D. A. (1990). In-basket exercises as a methodology for studying information processing. Simulation \& Gaming, 21(4), 397-410. doi: 10.1177/104687819002100404 
Ekman, P. (1985). Telling lies: Clues to deceit in the marketplace, politics and marriage. New York: W. W. Norton \& Company

Ekman, P. (1989). Why lies fail and what behaviors betray a lie. In J. C. Yuille (Ed.), Credibility assessment (pp. 71-81). New York: Springer + Business Media LLC.

Ekman, P. (1992). Are there basic emotions? Psychological Review, 99, 550-553.

Ekman, P., \& Friesen, W. V. (1969). Nonverbal leakage and clues to deception. Psychiatry, 32(1), 88-106.

Elaad, E. (2003). Effects of feedback on the overestimated capacity to detect lies and the underestimated ability to tell lies. Applied Cognitive Psychology, 17(3), 349-363.

Engström, J., Johansson, E., \& Östlund, J. (2005). Effects of visual and cognitive load in real and simulated motorway driving. Transportation Research Part F: Traffic Psychology and Behaviour, 8(2), 97-120. doi: 10.1016/j.trf.2005.04.012

Evers, C., Hopp, H., Gross, J. J., Fischer, A. H., Manstead, A. S., \& Mauss, I. B. (2014). Emotion response coherence: A dual-process perspective. Biological Psychology, 98, 43-49.

Fiedler, K., Schmid, J., \& Stahl, T. (2002). What is the current truth about polygraph lie detection? Basic and Applied Social Psychology, 24(4), 313-324.

Field, A. (2013). Discovering statistics using IBM SPSS statistics. London: Sage Publications Ltd.

Figner, B., \& Murphy, R. O. (2010). Using skin conductance in judgment and decision making research. In M. Schulte-Mecklenburg, A. Kuehberger \& R. Ranyard (Eds.), A handbook of process tracing methods for decision research: A critical review and user's guide (pp. 163-184). New York: Psychology Press.

Furedy, J. J., \& Ben-Shakhar, G. (1991). The roles of deception, intention to deceive, and motivation to avoid detection in the psychophysiological detection of guilty knowledge. Psychophysiology, 28(2), 163-171. doi: 10.1111/j.1469-8986.1991.tb00407.x

Furedy, J. J., Davis, C., \& Gurevich, M. (1988). Differentiation of deception as a psychological process: A psychophysiological approach. Psychophysiology, 25(6), 683-688. doi: 10.1111/j.1469-8986.1988. tb01908.x

Galanxhi-Janaqi, H., \& Nah, F. (2004). Investigating Deception in Cyberspace. Paper presented at the Americas Conference on Information Systems, New York.

Ganis, G., Kosslyn, S. M., Stose, S., Thompson, W., \& Yurgelun-Todd, D. A. (2003). Neural correlates of different types of deception: an fMRI investigation. Cerebral Cortex, 13(8), 830-836. doi: 10.1093/ cercor/13.8.830

Giebels, E., \& Janssen, O. (2005). Conflict stress and reduced well-being at work: The buffering effect of third-party help. European Journal of Work and Organizational Psychology, 14(2), 137-155. doi: 10.1080/13594320444000236

Gilovich, T., Savitsky, K., \& Medvec, V. H. (1998). The illusion of transparency: biased assessments of others' ability to read one's emotional states. Journal of Personality and Social Psychology, 75(2), 332.

Gödert, H. W., Gamer, M., Rill, H.-G., \& Vossel, G. (2005). Statement validity assessment: Inter-rater reliability of criteria-based content analysis in the mock-crime paradigm. Legal and Criminological Psychology, 10(2), 225-245.

Gödert, H. W., Rill, H.-G., \& Vossel, G. (2001). Psychophysiological differentiation of deception: the effects of electrodermal lability and mode of responding on skin conductance and heart rate. International Journal of Psychophysiology, 40(1), 61-75.

Granhag, P. A. (2010). On the psycho-legal study of true and false intentions: Dangerous waters and some stepping stones. The Open Criminology Journal, 3, 37-43. 
Granhag, P. A., \& Hartwig, M. (2008). Detecting Deception. In G. Davies, C. Holling \& R. Bull (Eds.), Forensic Psychology. West Sussex: John Wiley \& Sons.

Granhag, P. A., \& Knieps, M. (2011). Episodic future thought: Illuminating the trademarks of forming true and false intentions. Applied Cognitive Psychology, 25(2), 274-280.

Gudjonsson, G. H. (1982). Electrodermal responsivity to interrogation questions and its relation to self-reported emotional disturbance. Biological Psychology, 14(3), 213-218. doi: 10.1016/03010511(82)90002-3

Hancock, J. T. (2007). Digital deception: Why, when and how people lie online. In A. N. Joinson, K. Y. A. McKenna, T. Postmes \& U.-D. Reips (Eds.), Oxford Handbook of Internet Psychology (pp. 289-301). Oxford: Oxford University Press.

Hancock, J. T., Thom-Santelli, J., \& Ritchie, T. (2004). Deception and design: The impact of communication technology on lying behavior. Paper presented at the SIGCHI conference on Human Factors in Computing Systems, Vienna, Austria.

Hartholt, A., Traum, D., Marsella, S. C., Shapiro, A., Stratou, G., Leuski, A., . . Gratch, J. (2013). All together now: Introducing the Virtual Human Toolkit. Paper presented at the Intelligent Virtual Agents, Edinburgh, UK.

Hartwig, M. (2005). Interrogating to detect deception and truth: Effects of strategic use of evidence.

Hartwig, M., Anders Granhag, P., \& Strömwall, L. A. (2007). Guilty and innocent suspects' strategies during police interrogations. Psychology, Crime \& Law, 13(2), 213-227. doi: 10.1080/10683160600750264

Hartwig, M., \& Bond Jr, C. F. (2011). Why do lie-catchers fail? A lens model meta-analysis of human lie judgments. Psychological bulletin, 137(4), 643-659.

Hartwig, M., Granhag, P. A., Strömwall, L. A., \& Doering, N. (2010). Impression and information management: On the strategic self-regulation of innocent and guilty suspects. The Open Criminology Journal, 3, 10-16.

Hartwig, M., Granhag, P. A., Strömwall, L. A., \& Kronkvist, O. (2006). Strategic use of evidence during police interviews: when training to detect deception works. Law and Human Behavior, 30(5), 603619. doi: 10.1007/s10979-006-9053-9

Hartwig, M., Granhag, P. A., Strömwall, L. A., \& Vrij, A. (2004). Police officers' lie detection accuracy: Interrogating freely versus observing video. Police Quarterly, 7(4), 429-456. doi: 10.1177/1098611104264748

Heylen, D., Bevacqua, E., Pelachaud, C., Poggi, I., Gratch, J., \& Schröder, M. (2011). Generating listening behaviour. In P. Petta, C. Pelachaud \& R. Cowie (Eds.), Emotion-Oriented Systems. The Humaine Handbook. New York: Springer.

Hocking, J. E., \& Leathers, D. G. (1980). Nonverbal indicators of deception: A new theoretical perspective. Communications Monographs, 47(2), 119-131.

Hodgson, R., \& Rachman, S. (1974). Desynchrony in measures of fear. Behaviour Research and Therapy, 12(4), 319-326.

Honts, C. R. (2004). The psychophysiological detection of deception. In P. A. Granhag \& L. A. Strömwall (Eds.), The detection of deception in forensic contexts (pp. 103-126). Cambridge: Cambridge University Press.

Horrey, W. J., Lesch, M. F., \& Garabet, A. (2009). Dissociation between driving performance and drivers' subjective estimates of performance and workload in dual-task conditions. Journal of safety research, 40(1), 7-12.

Horvath, F., Jayne, B., \& Buckley, J. (1994). Differentiation of truthful and deceptive criminal suspects in Behavior Analysis Interviews. Journal of Forensic Sciences, 39(3), 793-807. 
Hout, M., Jong, P., \& Kindt, M. (2000). Masked fear words produce increased SCRs: An anomaly for Öhman's theory of pre-attentive processing in anxiety. Psychophysiology, 37(3), 283-288. doi: 10.1111/1469-8986.3730283

Howells, F. M., Stein, D. J., \& Russell, V. A. (2010). Research Perceived mental effort correlates with changes in tonic arousal during attentional tasks. Behavioral and Brain Functions, 6, 1-15.

Hu, X., Chen, H., \& Fu, G. (2012). A repeated lie becomes a truth? The effect of intentional control and training on deception. Frontiers in Psychology, 3, 1-7. doi: 10.3389/fpsyg.2012.00488

Iacono, W. G. (2008). Effective policing understanding how polygraph tests work and are used. Criminal Justice and Behavior, 35(10), 1295-1308. doi: 10.1177/0093854808321529

Iani, C., Gopher, D., \& Lavie, P. (2004). Effects of task difficulty and invested mental effort on peripheral vasoconstriction. Psychophysiology, 41(5), 789-798. doi: 10.1111/j.1469-8986.2004.00200.x

Ikehara, C. S., \& Crosby, M. E. (2005). Assessing cognitive load with physiological sensors. Paper presented at the Proceedings of the 38th Annual Hawaii International Conference on System Sciences, Waikoloa Village, HI, USA.

Johannes, B., \& Gaillard, A. W. (2014). A methodology to compensate for individual differences in psychophysiological assessment. Biological Psychology, 96, 77-85.

Jung, K. H., \& Lee, J. H. (2012). Cognitive and emotional correlates of different types of deception. Social Behavior and Personality: an international journal, 40(4), 575-584. doi: http://dx.doi.org/10.2224/ sbp.2012.40.4.575

Kazdin, A. E. (1979). Unobtrusive measures in behavioral assessment. Journal of Applied Behavior Analysis, 12(4), 713-724.

Kelly, C. E., Miller, J. C., Redlich, A. D., \& Kleinman, S. M. (2013). A taxonomy of interrogation methods. Psychology, Public Policy, and Law, 19(2), 165-178. doi: http://dx.doi.org/10.1037/a0030310

Khanna, A., Pandey, B., Vashishta, K., Kalia, K., Pradeepkumar, B., \& Das, T. (2015). A Study of Today's Al through Chatbots and Rediscovery of Machine Intelligence. International Journal of u-and e-Service, Science and Technology, 8(7), 277-284.

Kircher, J. C., Horowitz, S. W., \& Raskin, D. C. (1988). Meta-analysis of mock crime studies of the control question polygraph technique. Law and Human Behavior, 12(1), 79.

Kleinmuntz, B., \& Szucko, J. J. (1984). Lie detection in ancient and modern times: A call for contemporary scientific study. American Psychologist, 39(7), 766.

Krauss, R. M., Garlock, C. M., Bricker, P. D., \& McMahon, L. E. (1977). The role of audible and visible backchannel responses in interpersonal communication. Journal of Personality and Social Psychology, 35(7), 523.

Kuikkaniemi, K., Laitinen, T., Turpeinen, M., Saari, T., Kosunen, I., \& Ravaja, N. (2010). The influence of implicit and explicit biofeedback in first-person shooter games. Paper presented at the Proceedings of the SIGCHI Conference on Human Factors in Computing Systems, Atlanta, GA, USA.

Lacey, J. I., Kagan, J., Lacey, B. C., \& Moss, H. A. (1963). The visceral level: Situational determinants and behavioral correlates of automatic response patterns. In P. H. Knapp (Ed.), Expression of Emotion in Man (pp. 161-196). New York International University Press.

Langner, O., Dotsch, R., Bijlstra, G., Wigboldus, D. H., Hawk, S. T., \& van Knippenberg, A. (2010). Presentation and validation of the Radboud Faces Database. Cognition and Emotion, 24(8), 13771388.

Leal, S., \& Vrij, A. (2008). Blinking during and after lying. Journal of Nonverbal Behavior, 32(4), 187-194. doi: 10.1007/s10919-008-0051-0 
Leal, S., Vrij, A., Fisher, R. P., \& van Hooff, H. (2008). The time of the crime: Cognitively induced tonic arousal suppression when lying in a free recall context. Acta Psychologica, 129(1), 1-7. doi: 10.1016/j.actpsy.2008.03.015

Leary, M. R., \& Kowalski, R. M. (1990). Impression management: A literature review and two-component model. Psychological Bulletin, 107(1), 34.

Leins, D. A., Fisher, R. P., \& Ross, S. J. (2013). Exploring liars' strategies for creating deceptive reports. Legal and Criminological Psychology, 18(1), 141-151. doi: 10.1111/j.2044-8333.2011.02041.x

Lu, J., Whyte, M., McCarty, K., Aibara, D., Morison, C., \& Webster, M. (2010). RIBA guidance on designing for counter-terrorism. UK: RIBA in partnership with TPS Carillion.

Lucas, G. M., Gratch, J., King, A., \& Morency, L.-P. (2014). It's only a computer: Virtual humans increase willingness to disclose. Computers in Human Behavior, 37, 94-100.

Lykken, D., Rose, R., Luther, B., \& Maley, M. (1966). Correcting psychophysiological measures for individual differences in range. Psychological Bulletin, 66(6), 481-484. doi: http://dx.doi. org/10.1037/h0023922

Lykken, D. T., \& Venables, P. H. (1971). Direct measurement of skin conductance: A proposal for standardization. Psychophysiology, 8(5), 656-672.

Malle, B. F., Moses, L. J., \& Baldwin, D. A. (2001). Intentions and intentionality: Foundations of social cognition. Cambridge MA: MIT press.

Mauss, I., Wilhelm, F., \& Gross, J. (2004). Is there less to social anxiety than meets the eye? Emotion experience, expression, and bodily responding. Cognition and Emotion, 18(5), 631-642.

Mauss, I. B., Levenson, R. W., McCarter, L., Wilhelm, F. H., \& Gross, J. J. (2005). The tie that binds? Coherence among emotion experience, behavior, and physiology. Emotion, 5(2), 175.

McEwen, B. S., \& Sapolsky, R. M. (1995). Stress and cognitive function. Current opinion in neurobiology, 5(2), 205-216. doi: 10.1016/0959-4388(95)80028-X

Memon, A. A., Vrij, A., \& Bull, R. (2003). Psychology and Law: Truthfulness, Accuracy and Credibility. London: Jossey-Bass.

Milgram, S. (1992). Cyranoids In S. John \& S. Maury (Eds.), The individual in a social world: Essays and experiments (2nd edition) (pp. 337-345). New York: McGraw-Hill.

Miller, G. R., \& Stiff, J. B. (1993). Deceptive communication. Thousand Oaks, CA, US: Sage Publications, Inc.

Monsell, S. (2003). Task switching. Trends in Cognitive Sciences, 7(3), 134-140.

Morkes, J., Kernal, H. K., \& Nass, C. (1999). Effects of humor in task-oriented human-computer interaction and computer-mediated communication: A direct test of SRCT theory. HumanComputer Interaction, 14(4), 395-435.

Nourbakhsh, N., Wang, Y., Chen, F., \& Calvo, R. A. (2012). Using galvanic skin response for cognitive load measurement in arithmetic and reading tasks. Paper presented at the Proceedings of the 24th Australian Computer-Human Interaction Conference, Melbourne, VIC, Australia.

Nunamaker, J. F., Derrick, D., C, Elkins, A. C., Burgoon, J. K., \& Patton, M. W. (2011). Embodied conversational agent-based kiosk for automated interviewing. Journal of Management Information Systems, 28(1), 17-48.

Nunez, J. M., Casey, B., Egner, T., Hare, T., \& Hirsch, J. (2005). Intentional false responding shares neural substrates with response conflict and cognitive control. Neuroimage, 25(1), 267-277.

Page, M., \& Robson, R. C. A. (2007). Galvanic skin responses from asking stressful questions. British Journal of Nursing, 16(10), 622-627. 
Park, J., Waqar, S., Kersey, T., Modi, N., Ong, C., \& Sleep, T. (2011). Effect of distraction on simulated anterior segment surgical performance. Journal of Cataract \& Refractive Surgery, 37(8), 15171522.

Pecchinenda, A. (1996). The affective significance of skin conductance activity during a difficult problemsolving task. Cognition \& Emotion, 10(5), 481-504.

Pennebaker, J. W., \& Chew, C. H. (1985). Behavioral inhibition and electrodermal activity during deception. Journal of Personality and Social Psychology, 49(5), 1427. doi: 10.1037/0022-3514.49.5.1427

Peter Bankart, C., \& Elliott, R. (1974). Heart rate and skin conductance in anticipation of shocks with varying probability of occurrence. Psychophysiology, 11(2), 160-174. doi: 10.1111/j.14698986.1974.tb00836.x

Podlesny, J. A., \& Raskin, D. C. (1977). Physiological measures and the detection of deception. Psychological Bulletin, 84(4), 782. doi: 10.1037/0033-2909.84.4.782

Porter, S., \& Brinke, L. (2010). The truth about lies: What works in detecting high-stakes deception? Legal and criminological psychology, 15(1), 57-75.

Sexual relations (n.d.) In Merriam-Webster. Retrieved from http://www.merriam-webster.com

Roelofs, K., Hagenaars, M. A., \& Stins, J. (2010). Facing Freeze Social Threat Induces Bodily Freeze in Humans. Psychological Science, 1575-1581.

Roth, W. T., Dawson, M. E., \& Filion, D. L. (2012). Publication recommendations for electrodermal measurements. Psychophysiology, 49, 1017-1034.

Sackett, P. R., \& Dreher, G. F. (1982). Constructs and assessment center dimensions: Some troubling empirical findings. Journal of Applied Psychology, 67(4), 401-410. doi: http://dx.doi. org/10.1037/0021-9010.67.4.401

Schmeichel, B. J., Demaree, H. A., Robinson, J. L., \& Pu, J. (2006). Ego depletion by response exaggeration. Journal of experimental social psychology, 42(1), 95-102. doi: 10.1016/j.jesp.2005.02.005

Schroeder, R. (2011). Comparing Avatar and Video Representations. In A. Peachey \& M. Childs (Eds.), Reinventing Ourselves: Contemporary Concepts of Identity in Virtual Worlds (pp. 235-251). London: Springer.

Schuetzler, R., Grimes, M., Giboney, J., \& Buckman, J. (2014). Facilitating Natural Conversational Agent Interactions: Lessons from a Deception Experiment. Paper presented at the International Conference on Information Systems, Auckland, New Zealand

Schweitzer, M. E., Brodt, S. E., \& Croson, R. T. (2002). Seeing and believing: Visual access and the strategic use of deception. International Journal of Conflict Management, 13(3), 258-375.

Seitz, M., Daun, T. J., Zimmermann, A., \& Lienkamp, M. (2013). Measurement of Electrodermal Activity to Evaluate the Impact of Environmental Complexity on Driver Workload. Paper presented at the Proceedings of the FISITA 2012 World Automotive Congress.

Setz, C., Arnrich, B., Schumm, J., La Marca, R., Troster, G., \& Ehlert, U. (2010). Discriminating stress from cognitive load using a wearable EDA device. IEEE Transactions on information technology in biomedicine, 14(2), 410-417.

Shi, Y., Ruiz, N., Taib, R., Choi, E., \& Chen, F. (2007). Galvanic skin response (GSR) as an index of cognitive load. Paper presented at the $\mathrm{CHI}$ '07 extended abstracts on Human factors in computing systems, San Jose, CA, USA.

Sip, K. E., Roepstorff, A., McGregor, W., \& Frith, C. D. (2008). Detecting deception: the scope and limits. Trends in Cognitive Sciences, 12(2), 48-53. doi: 10.1016/j.tics.2007.11.008

Sokolov, E. N. (1963). Higher nervous functions: The orienting reflex. Annual Review of Physiology, 25(1), 545-580. 
Spence, S. A., Farrow, T. F., Herford, A. E., Wilkinson, I. D., Zheng, Y., \& Woodruff, P. W. (2001). Behavioural and functional anatomical correlates of deception in humans. Neuroreport, 12(13), 2849-2853.

Starr, K. (1998). The Starr Report:The Findings of Independent Counsel Kenneth W. Starr on President Clinton and the Lewinsky Affair New York: Public Affairs/Perseus Books Group.

Ströfer, S., Noordzij, M. L., Ufkes, E. G., \& Giebels, E. (2015). Deceptive intentions: Can cues to deception be measured before a lie is even stated? PlosOne, 1-17. doi: 10.1371/journal.pone.0125237

Strömwall, L. A., Hartwig, M., \& Granhag, P. A. (2006). To act truthfully: Nonverbal behaviour and strategies during a police interrogation. Psychology, Crime \& Law, 12(2), 207-219. doi: 10.1080/10683160512331331328

Strömwall, L. A., \& Willén, R. M. (2011). Inside criminal minds: Offenders' strategies when lying. Journal of Investigative Psychology and Offender Profiling, 8(3), 271-281. doi: 10.1002/jip.148

Tiersma, P. (2004). Did Clinton Lie: Defining Sexual Relations. Chicago-Kent Law Review, 79, 927-958.

Tombu, M., \& Jolicœur, P. (2003). A central capacity sharing model of dual-task performance. Journal of Experimental Psychology: Human Perception and Performance, 29(1), 3.

Turing, A. M. (1950). Computing machinery and intelligence. Mind, 59, 433-460.

Twyman, N. W., Lowry, P. B., Burgoon, J. K., \& Nunamaker Jr, J. F. (2014). Autonomous Scientifically Controlled Screening Systems for Detecting Information Purposely Concealed by Individuals. Journal of Management Information Systems, 31(3), 106-137.

Van Impe, A., Coxon, J., Goble, D., Wenderoth, N., \& Swinnen, S. (2011). Age-related changes in brain activation underlying single-and dual-task performance: visuomanual drawing and mental arithmetic. Neuropsychologia, 49(9), 2400-2409.

Verschuere, B., Crombez, G., De Clercq, A., \& Koster, E. H. (2004). Autonomic and behavioral responding to concealed information: Differentiating orienting and defensive responses. Psychophysiology, 41(3), 461-466.

Verschuere, B., Spruyt, A., Meijer, E. H., \& Otgaar, H. (2011). The ease of lying. Consciousness and Cognition, 20(3), 908-911. doi: 10.1016/j.concog.2010.10.023

Vincent, A., \& Furedy, J. J. (1992). Electrodermal differentiation of deception: Potentially confounding and influencing factors. International Journal of Psychophysiology, 13(2), 129-136. doi: 10.1016/01678760(92)90052-D

Volle, E., Gonen-Yaacovi, G., de Lacy Costello, A., Gilbert, S. J., \& Burgess, P. W. (2011). The role of rostral prefrontal cortex in prospective memory: A voxel-based lesion study. Neuropsychologia, 49(8), 2185-2198.

Vrij, A. (2000). Detecting Lies and Deceit: The Psychology of Lying and the Implications for Professional Practice. Chichester: John Wiley \& Sons Ltd.

Vrij, A. (2004a). Guidelines to catch a liar. In G. Davies, C. Holling \& R. Bull (Eds.), The detection of deception in forensic contexts (pp. 287-314). New York: Cambridge University Press.

Vrij, A. (2004b). Why professionals fail to catch liars and how they can improve. Legal and Criminological Psychology, 9(2), 159-181.

Vrij, A. (2008). Detecting Lies and Deceit: Pitfalls and Opportunities. Chichester: John Wiley \& Sons.

Vrij, A., Ennis, E., Farman, S., \& Mann, S. (2010). People's perceptions of their truthful and deceptive interactions in daily life. Open Access Journal of Forensic Psychology, 2, 6-49.

Vrij, A., Fisher, R., Mann, S., \& Leal, S. (2006). Detecting deception by manipulating cognitive load. Trends in Cognitive Sciences, 10(4), 141-142. doi: 10.1016/j.tics.2006.02.003 
Vrij, A., Granhag, P. A., Mann, S., \& Leal, S. (2011). Outsmarting the liars: Toward a cognitive lie detection approach. Current Directions in Psychological Science, 20(1), 28-32. doi: 10.1177/0963721410391245

Vrij, A., Leal, S., Mann, S., \& Fisher, R. (2012). Imposing cognitive load to elicit cues to deceit: Inducing the reverse order technique naturally. Psychology, Crime \& Law, 18(6), 579-594. doi: 10.1080/1068316X.2010.515987

Vrij, A., Mann, S., \& Fisher, R. P. (2006). Information-gathering vs accusatory interview style: Individual differences in respondents' experiences. Personality and Individual Differences, 41(4), 589-599. doi: 10.1016/j.paid.2006.02.014

Vrij, A., Mann, S., Kristen, S., \& Fisher, R. P. (2007). Cues to deception and ability to detect lies as a function of police interview styles. Law and Human Behavior, 31(5), 499-518.

Vrij, A., Mann, S., Leal, S., \& Fisher, R. (2010). 'Look into my eyes': can an instruction to maintain eye contact facilitate lie detection? Psychology, Crime \& Law, 16(4), 327-348.

Vrij, A., Mann, S. A., Fisher, R. P., Leal, S., Milne, R., \& Bull, R. (2008). Increasing cognitive load to facilitate lie detection: the benefit of recalling an event in reverse order. Law and Human Behavior, 32(3), 253-265. doi: http://dx.doi.org/10.1007/s10979-007-9103-y

Vrij, A., Semin, G. R., \& Bull, R. (1996). Insight Into Behavior Displayed During Deception. Human Communication Research, 22, 544-562. doi: 10.1111/j.1468-2958.1996.tb00378.x

Walczyk, J. J., Roper, K. S., Seemann, E., \& Humphrey, A. M. (2003). Cognitive mechanisms underlying lying to questions: Response time as a cue to deception. Applied Cognitive Psychology, 17(7), 755774. doi: $10.1002 /$ acp.914

Walczyk, J. J., Schwartz, J. P., Clifton, R., Adams, B., Wei, M., \& Zha, P. (2005). Lying person to person about life events: a cognitive framework for lie detection. Personnel Psychology, 58(1), 141-170. doi: 10.1111/j.1744-6570.2005.00484.x

Wallin, B. G. (1981). Sympathetic nerve activity underlying electrodermal and cardiovascular reactions in man. Psychophysiology, 18(4), 470-476. doi: 10.1111/j.1469-8986.1981.tb02483.x

Warmelink, L., Vrij, A., Mann, S., Jundi, S., \& Granhag, P. A. (2012). The effect of question expectedness and experience on lying about intentions. Acta psychologica, 141(2), 178-183.

Warmelink, L., Vrij, A., Mann, S., Leal, S., \& Poletiek, F. H. (2013). The effects of unexpected questions on detecting familiar and unfamiliar lies. Psychiatry, Psychology and Law, 20(1), 29-35. doi: 10.1080/13218719.2011.619058

Watson, D. C., \& Sinha, B. K. (1993). Individual differences, social arousal and the electrodermal detection of deception. Personality and Individual Differences, 15(1), 75-80. doi: 10.1016/01918869(93)90043-3

Wilson, G. F. (2002). An analysis of mental workload in pilots during flight using multiple psychophysiological measures. The International Journal of Aviation Psychology, 12(1), 3-18. doi: 10.1207/S15327108IJAP1201_2

Zuckerman, M., DePaulo, B. M., \& Rosenthal, R. (1981). Verbal and nonverbal communication of deception. Advances in Experimental Social Psychology, 14, 1-59. 

Summary 
102 | Summary 
This dissertation advanced the deception field by examining the psychological processes associated with deceptive intent. The crucial point of deception is to intentionally create in another a false belief (Vrij, 2000) and hence the intention to deceive forms the unifying factor underlying all deceptive attempts. Strikingly, deceivers usually stick to the truth as close as possible to reduce the chances of getting caught (Leins et al., 2013; Strömwall et al., 2006). Deceivers only deliberately and carefully diverge from truth telling to tell a believable but deceptive story. Hence truth telling with intention to deceive takes up a large part of the time and psychological efforts within a deceptive attempt. The main focus of this dissertation forms the intention to deceive and more specifically, whether cues to deception already can be measured at truth telling with the mere intention to lie at a later point in time.

The purpose for this dissertation is to deliver a theoretical as well as practical contribution to the deception field. Therefore, the 4 empirical studies surrounding the intention to deceive are conducted in different settings, ranging from controlled to more realistic experiments, varying in interpersonal context and stakes for the deceiver.

Certain psychological processes related to stress and cognitive load are more likely to occur during lying than truth telling, leading to an increase in the physiological response of the sympathetic nervous system (DePaulo et al., 2003; Zuckerman et al., 1981). In the present dissertation, we argue that in addition some processes such as impression management to appear sincere and honest are present during the whole attempt to deceive, including the truth telling parts. In order to test this prediction and 'capture' the mere intention to deceive, we examined truth telling with the intention to lie on a crucial aspect later on and compared this with 'sincere' truth telling and lying. The latter two, fully truthful and fully deceptive accounts, are traditionally compared in almost all paradigms in deception research (e.g., Vrij, Fisher, et al., 2006; Vrij et al., 2012; Watson \& Sinha, 1993).

Across all empirical studies we measured the physiological response by means of electrodermal activity (EDA), a direct indicator for SNS activity (Boucsein, 2012) and most frequently used physiological measure in the lie detection context (Vrij, 2008). An advantage of EDA is that is can be measured within one measurement (Dawson et al., 2007) which makes it a good measurement method for our studies.

In the first two empirical studies, we put the idea that the mere intention to lie could already increase the physiological response to a first test (Chapter 2). To this end, we focused on a controlled within-subject design to reduce inter-individual variance. Also, interpersonal contact and interactivity was kept low. Participants thought that an expert in lie detection would observe and judge them but they neither saw nor could communicate with him. Chapter 2 provided first empirical evidence that physiological cues to deception can already be measured during truth telling with the mere intention to lie (only Study 2.2). Lying however still evoked the highest EDA level (Study 2.1 and 2.2). 
In Chapter 3 and 4 we tested the three veracity conditions in a more realistic setting in which we interviewed participants about a transgression they committed within the study context. To gain more insight into the processes underlying deception we combined measurements of electrodermal activity (EDA) with self-reports of stress and cognitive load. Both studies were identical but differed in the interpersonal contact the participant had with the interviewer: In Study 3 the interview was conducted face-to-face by a human and in Study 4 by a virtual avatar on a screen. Study 4 additionally addressed the fast developments in technology by looking into how virtual avatars affect the deception process. Especially, we examined whether the 'belief' whether such an avatar is human or computer operated is a relevant factor in evoking physiological cues to deception.

We hypothesized that moving the deceptive attempt from a controlled setting (Chapter 2) to an interview setting (Chapter 3 and 4) would be beneficial for detecting cues to deception, since the conversation pattern is rather dynamic and difficult to anticipate (Berger \& Battista, 1993). In contrast to a more static setting (such as in Chapter 2), deceivers in an interview setting probably have to more intensively "attend to their conversation partner to find out whether they are still believed [...]" (Vrij, 2008, p. 48). Across both interview studies, EDA and self-reported cognitive load were highest in the lie condition whereas higher self-reports of stress only were associated with the lie and intention condition in Study 3.

Most interesting however, both studies differ with regard to the differentiation of the intention with the truth condition. Only in Study 4 when using the virtual avatar, EDA was higher in the intention condition. More specifically, this effect was moderated by the belief of the participants about how the virtual avatar was operated. EDA differences between the intention and truth-but also between the lie and truth-condition only could be detected when participants believed the virtual avatar was operated by a human. In first instance this is surprising, because both situations are almost identical. The only difference is that in Study 3 participants had direct contact with the human interviewer and in Study 4 indirectly via a virtual avatar.

Differences might be explained by the degree of interpersonal contact, especially the access the deceiver has to the other's reaction. In both Study 2.2 and Study 4 we found a difference between the intention and truth condition and in both, participants were deprived from 'seeing' the other person. In contrast, in Study 3, deceivers had full access to the facial reactions of the interviewer and we did not find a difference. Interpersonal deception theory says that deceiving face-to-face is initially difficult but that these difficulties typically dissipate over time as deceivers acquire more feedback from the target to deceive (Buller \& Burgoon, 1996). The non-access to reactions of the target to deceive in Chapter 2 and 4 could have made impression management therefore more difficult for the deceiver. It seems that in order to increase the chances of measuring cues to deception at the mere intention to deceive, withholding the deceiver from reactions on the part of the target to deceive can be beneficial. 
Across all studies the lie and truth condition could de differentiated. During lying, impression management is coupled with creating a story with fictional elements for the other person to believe in. The latter in itself is demanding, independent of the interpersonal context. The higher self-reports of cognitive load in Study 3 and 4 support this. During truth telling with the intention to lie, no counterfactual statements have to be made. However, deceivers are probably already busy with impression management, which does depend on the presence of the target to deceive. This argumentation could explain why the effect of the intention to deceive (for which only impression management is relevant) is more sensitive to the interpersonal contact between deceiver and target to deceive whereas lying and truth telling can be differentiated across all interpersonal contexts.

In the current dissertation we only identified one interpersonal context, where we measure no cues to deception at all: When participants believed they interacted with a virtual avatar operated by a computer instead of a human (Study 4). A reason might be that under such circumstances, deceivers perceive no need to engage in impression-management at all, since an unconscious computer cannot 'understand' the conversation such as human would (see e.g., Lucas et al., 2014). Together, the empirical chapters reveal that fully deceptive accounts can be reliably differentiated from fully truthful accounts. But deceptive accounts, which largely consist of truth telling, do not necessarily have to induce an increase in the physiological response. Rather, elevated EDA levels at the mere intention to deceive seem to depend highly on the degree of interpersonal contact. In this connection, withholding the deceiver reactions on the part of the target to deceive can be beneficial. An important conclusion is to always take into account the interpersonal context when studying deception related processes. 

Samenvatting 
108 | Samenvatting 
Dit proefschrift beschrijft psychologische processen die aan de intentie om te misleiden ten grondslag liggen. Het cruciale punt van misleiding is het bewust creëren van een misvatting bij iemand anders (Vrij, 2000) en daarom vormt de intentie om te misleiden de verbindende factor die bij alle pogingen tot misleiding een rol speelt. Opvallend is dat misleiders gewoonlijk zo dicht mogelijk bij de waarheid blijven om de kans te verminderen betrapt te worden (Leins et al., 2013; Strömwall et al., 2006). Misleiders wijken alleen maar bewust en bedachtzaam af van de waarheid om een geloofwaardig maar misleidend verhaal te vertellen. Daarom neemt het vertellen van de waarheid met de intentie om te misleiden een groot gedeelte van de tijd en mentale inspanning in tijdens een poging om te misleiden. Het belangrijkste onderwerp van dit proefschrift is de intentie om te misleiden en dan in het bijzonder of signalen die op misleiden wijzen gemeten kunnen worden tijdens het vertellen van de waarheid met enkel de intentie om te liegen.

Het doel van dit proefschrift is om zowel een theoretische en praktische bijdrage te leveren aan het onderzoeksgebied van misleiding. Daarom worden de 4 empirische studies rond de intentie om te misleiden op verschillende manieren uitgevoerd, variërend van meer gecontroleerde tot meer realistische experimenten en variërend in de intermenselijke context en keuze tot misleiden.

Bepaalde psychologische processen die gerelateerd zijn aan stress en cognitieve belasting treden vaker op tijdens het liegen dan het vertellen van de waarheid. Dit hangt samen met een toename in de fysiologische respons van het sympathische zenuwstelsel (DePaulo et al., 2003; Zuckerman et al., 1981). We stellen echter dat sommige processen zoals pogingen om een oprechte indruk te wekken, tijdens de gehele poging om te misleiden aanwezig zijn, ook in de gedeeltes wanneer de waarheid verteld wordt. Om dit te testen onderzoeken wij het vertellen van de waarheid met de intentie om op een later moment te liegen en vergelijken dit met het 'oprechte' vertellen van de waarheid en met liegen. De laatste twee, volledig waarheidsgetrouwe en volledig verzonnen verhalen worden in bijna alle paradigma's vergeleken die onderzoek doen naar misleiden (bijv., Vrij, Fisher, et al., 2006; Vrij et al., 2012; Watson \& Sinha, 1993).

Over alle empirische studies heen hebben wij de fysiologische respons gemeten via electrodermische activiteit (EDA), een directe indicator voor de activiteit van het sympathisch zenuwstelsel (Boucsein, 2012) en de meest gebruikte maat in het veld van leugendetectie (Vrij, 2008). Een voordeel van EDA is dat het binnen één meting (zonder herhaling) kan worden gedetecteerd (Dawson et al., 2007) wat het een geschikte meetmethode maakt voor onze studies.

In de eerste twee empirische studies hebben wij de hypothese dat enkel de intentie om te liegen tot een verhoging in activiteit van het sympathische zenuwstelsel leidt aan een eerste toets onderworpen (Hoofdstuk 2). Daartoe hebben we ons gericht op een gecontroleerde binnen -proefpersoon design om inter-individuele variatie te verminderen. Eveneens werd 
het intermenselijke contact en de interactiviteit laag gehouden. De deelnemers dachten dat een expert in leugendetectie hen zou observeren en beoordelen, maar ze konden deze persoon niet zien of met hem communiceren. Hoofdstuk 2 levert een eerste empirisch bewijs dat de fysiologische signalen die op misleiden duiden al gemeten kunnen worden tijdens het vertellen van de waarheid met enkel de intentie om te liegen (alleen Studie 2.2). Liegen veroorzaakt echter nog steeds het hoogste EDA niveau (Studie 2.1 en 2.2).

In Hoofdstuk 3 en 4 hebben wij onze drie oprechtheidscondities getest in een realistischer setting waarin wij deelnemers geïnterviewd hebben over een overtreding die zij binnen de studiecontext hebben gepleegd. Om meer inzicht te verkrijgen in de processen die aan misleiding ten grondslag liggen, hebben wij metingen van elektrodermische activiteit (EDA) gecombineerd met zelf gerapporteerde stress en cognitieve belasting. Beide studies waren identiek, maar verschilden in de mate van het intermenselijke contact die de deelnemer had met de interviewer: In Studie 3 werd het interview face-to-face uitgevoerd door een menselijke interviewer en in Studie 4 door een virtuele avatar op een scherm. Studie 4 is bovendien relevant voor de snelle ontwikkelingen in technologie rond virtuele avatars en de toepassing daarvan in een ondervragings of interview context. De nadruk werd in het bijzonder gelegd op of het 'geloof' of een dergelijke avatar door mens of computer bediend wordt, een relevante factor vormt voor het oproepen van aan misleiden gerelateerde fysiologische signalen.

We veronderstelden dat het verplaatsen van een poging tot misleiden van een gecontroleerde setting (Hoofdstuk 2) naar een interview setting (Hoofdstuk 3 en 4) gunstig zou zijn voor het detecteren van aan het misleiden gerelateerde fysiologische signalen, aangezien het gesprekspatroon vrij dynamisch en moeilijk te voorspellen is (Berger \& Battista, 1993). In tegenstelling tot in een meer statische setting (zoals in Hoofdstuk 2), moeten misleiders in een interviewsetting waarschijnlijk intensiever "hun conversatiepartner in de gaten houden om uit te vinden of zij nog geloofd worden [...]" (Vrij, 2008, p. 48). Over beide interviewstudies heen, waren EDA en zelfgerapporteerde cognitieve belasting het hoogst in de leugen conditie terwijl hogere zelfgerapporteerde stress alleen geassocieerd werd met de leugen en intentie conditie in Studie 3.

Echter, het meest interessante is dat beide studies verschillen met betrekking tot de differentiatie van de intentie en waarheid conditie. Alleen in Studie 4 waar gebruik werd gemaakt van de virtuele avatar was EDA hoger in de intentie conditie. Dit effect was afhankelijk van het geloof van de deelnemers over hoe de virtuele avatar werd bestuurd. EDA verschillen tussen de intentie en de waarheid-maar ook tussen de leugen en waarheidconditie konden alleen worden gedetecteerd wanneer de deelnemers geloofden dat de virtuele avatar bediend werd door een mens. In eerste instantie is dit verrassend, omdat beide situaties vrijwel identiek zijn. Het enige verschil is dat in Studie 3 deelnemers direct contact hadden met de menselijke interviewer en in Studie 4 indirect via een virtuele avatar. 
Verschillen zouden kunnen worden verklaard door de mate van intermenselijk contact, in het bijzonder de toegang die de misleider heeft tot de reactie van de ander. In zowel Studie 2.2 en Studie 4 hebben wij een verschil gevonden tussen de intentie en de waarheid conditie en in beide werd de deelnemers het 'zien' van de andere persoon onthouden. Echter in Studie 3 hadden misleiders volledig toegang tot de gezichtsuitdrukkingen van de interviewer en hier hebben wij geen verschil gevonden. De 'Interpersonal deception theory' zegt dat face-to-face misleiden aanvankelijk moeilijk is, maar dat deze moeilijkheden meestal verdwijnen met de tijd zodra misleiders meer feedback verkrijgen van degene die zij misleiden (Buller \& Burgoon, 1996). Het lijkt erop dat om de kansen te verhogen tekens van misleiden te meten tijdens enkel de intentie om te misleiden, het gunstig kan uitpakken om de misleider te onthouden van de reacties van diegene die mogelijk wordt misleid.

In alle studies kon de leugen en waarheid conditie van elkaar worden onderscheiden. Tijdens het liegen gaat impressie management gepaard met het creëren van een fictief verhaal voor de andere persoon om in te geloven. Dat laatste is op zich al veeleisend, onafhankelijk van de intermenselijke context. De hogere mate van zelf gerapporteerde cognitieve belasting in Studie 3 en 4 ondersteunt dit. Tijdens het vertellen van de waarheid met de intentie om te liegen hoeven echter geen onjuiste verklaringen worden gemaakt. Misleiders zijn daarentegen waarschijnlijk al bezig met impressie management dat in tegenstelling wel afhankelijk is van de aanwezigheid van de persoon die misleid wordt.

Deze redenering zou kunnen verklaren waarom het effect van de intentie om te misleiden (waarvoor alleen impressie management relevant is) sensitiever is voor het intermenselijke contact tussen misleider en degene die misleid wordt, terwijl liegen en waarheid vertellen onafhankelijk van het intermenselijke contact van elkaar kunnen worden onderscheiden.

In dit proefschrift hebben wij alleen één intermenselijke context geïdentificeerd waar wij helemaal geen fysiologische tekens van misleiden konden meten: Namelijk wanneer proefpersonen dachten dat ze met een virtuele avatar communiceerden die door een computer in plaats van een mens bestuurd werd (Studie 4). Een reden zou kunnen zijn dat onder dergelijke omstandigheden, misleiders geen noodzaak zien om zich bezig te houden met impressie management omdat een onbewuste computer het gesprek niet kan 'begrijpen' zoals een mens dit zou kunnen (zie bijv., Lucas et al., 2014). Samen laten de empirische hoofdstukken zien dat volledig waarheidsgetrouwe en volledig verzonnen verhalen betrouwbaar kunnen worden onderscheiden. Maar pogingen om te misleiden die grotendeels uit het vertellen van de waarheid bestaan, leiden niet noodzakelijkerwijs tot een verhoging in de fysiologische respons. Veel meer lijken hogere EDA niveaus tijdens enkel de intentie om te misleiden sterk afhankelijk van de mate van intermenselijk contact. In dit verband kan het onthouden van de misleider van de reacties van diegene die wordt misleidt voordelig zijn. Een belangrijke conclusie voor studies die misleiding onderzoeken is om altijd met de intermenselijke context rekening te houden. 

Acknowledgements 
114 | Acknowledgements 
Promoveren is net zoals een huidgeleidingssignaal - een stevig stijgende lijn doorgroeid met pieken en dalen. Ik wil graag een aantal mensen bedanken die ervoor gezorgd hebben dat mijn lijn steeds bleef stijgen, dat ik de pieken waardeerde, en in de dalen volhield: Zonder jullie zou dit proefschrift hier nu niet zijn en ik deze mijlpaal niet hebben bereikt.

Mijn directe dank gaat uit naar mijn begeleiders Matthijs Noordzij en Elze Ufkes en mijn promotor Ellen Giebels. Matthijs, de dag toen ik als studente bij je binnen liep voor het een of ander en de kamer verliet met het idee dat ik ging promoveren ben ik nooit vergeten- wat was ik blij en trots. Jij hebt vanaf dag één in mij geloofd en mij de wetenschap ingestuurd. Dank voor het vertrouwen dat je in mij had! Je nuchtere en analytische kijk op dingen heeft mij altijd geholpen, hetzij bij het analyseren van huidgeleiding of bij de kijk op de wereld en in het bijzonder de wetenschap.

Elze, zonder mij te kennen ben je dit project met mij aangegaan en heb ik ontzettend veel van je kunnen leren. Jouw deur stond altijd open voor mij en zonder jouw input zouden onze artikelen nooit zo leuk zijn geworden, ik denk dat we elkaar bijzonder goed konden aanvullen. Het laatste empirische hoofdstuk van dit proefschrift is hier heel kenmerkend voor. Je was altijd enorm betrokken bij dit project en hebt het beste uit mij kunnen halen. Dank voor je enthousiasme, inzet, ideeën, begeleiding en geduld (als ik weer voor de deur stond met de vraag of je "5 minuten" voor mij had)!

Ten slotte Ellen, bedankt dat jij mij de kans hebt gegeven om op dit onderwerp te promoveren. Er zijn drie dingen die mij heel erg bij zijn gebleven: je enthousiasme, je enorme betrokkenheid maar ook je vermogen om alles in zijn geheel te plaatsen. Door jou heb ik geleerd mij niet vast te bijten in (op het eerste oog) onoplosbare obstakels. Ik kan me nog goed herinneren dat ik een aantal keren radeloos een gesprek met je aanging en exact dit gesprek met een verbazend "aha momentje" verliet en opeens alle puzzelstukken samen pasten.

De diverse studies in dit proefschrift heb ik niet alleen gerealiseerd. Als eerste wil ik Marije Hoogeboom bedanken voor haar bijdrage aan de studies in hoofdstuk 2. Hoofdstuk 4 zou onmogelijk zijn geweest zonder de bijdrage van Merijn Bruijnes. Daarnaast wil ik graag een aantal studenten bedanken voor hun bijdrage aan de praktische realisatie van diverse studies: Niels Boele, Dirk Berentsen, Anna-Maria Bachmann, Ricarda Baumhof, Maren Bethke, Jaron Plochg, Laurèn Appelman en Theresa Angsmann. De maanden waarin wij samen experimenten draaiden waren bijzonder intensief en uitputtend, maar ook bijzonder grappig en gezellig! Dank voor jullie inzet! 
Dank ook aan mijn vakgroep PCRV voor de leuke tijd en in het bijzonder mijn kamergenoten Ilona van het Veer en Marian van Dijk. Met jullie was het bijzonder gezellig! Marian, wij deelden het grootste gedeelde van ons aio tijd een kamer en wat hebben wij samen gelachen, gediscussieerd, gemopperd, gedroomd, gezucht en als het weer eens niet zo lukte- chocola gegeten. Ik zal ons gezamenlijke tijd in onze "hok" missen!

Om productief te blijven werken moet je soms ook niet werken: Femke en Inga, bedankt voor de vele gezellige "koffiepauzes" en hilarische "pasta en wijn avonden". Miriam Oostinga bedankt, je was altijd een vrolijke reisgenoot: het Discovery Festival, waar je mij tot middernacht hielp met experimenteren, en de verjaardagsslingers op mijn hotelkamer tijdens de EAPL conferentie zal ik niet snel vergeten.

Ook wil ik graag avast Inken Gast en Marian van Dijk bedanken, zij zullen mij bijstaan als paranimfen tijdens mijn verdediging. Daarnaast wil ik Floor Bakker bedanken voor het ontwerpen van mijn proefschriftomslag.

Mijn dankwoord zou niet compleet zijn zonder diegenen te noemen die er altijd voor mij zijn, mijn ouders en Guus. Danke Mama und Papa, dass ihr bedingungslos hinter mir steht. Ohne eure große Unterstützung in meinem damaligen Vorhaben in die Niederlande zu gehen, wäre ich nicht so weit gekommen. Ten slotte Guus, ik kan alles met je delen, mijn dromen en zelfs mijn matlab scripts. Geen woorden kunnen beschrijven hoeveel je voor mij betekent. Bedankt voor je onvoorwaardelijke steun en liefde! 


\section{KLI Dissertation Series}


118 | KLI Dissertation Series 
The "Kurt Lewin Institute Dissertation Series" started in 1997. Since 2014 the following dissertations have been published in this series:

2014-01: $\quad$ Marijn Stok: Eating by the Norm: The Influence of Social Norms on Young People's Eating Behavior

2014-02: $\quad$ Michèlle Bal: Making Sense of Injustice: Benign and Derogatory Reactions to Innocent Victims

2014-03: Nicoletta Dimitrova: Rethinking errors: How error-handling strategy affects our thoughts and others' thoughts about us

2014-04: Namkje Koudenburg: Conversational Flow: The Emergence and Regulation of Solidarity through social interaction

2014-05: $\quad$ Thomas Sitser: Predicting sales performance: Strengthening the personalityjob performance linkage

2014-06: $\quad$ Goda Perlaviciute: Goal-driven evaluations of sustainable products

2014-07: $\quad$ Said Shafa: In the eyes of others: The role of honor concerns in explaining and preventing insult-elicited aggression

2014-08: $\quad$ Felice van Nunspeet: Neural correlates of the motivation to be moral

2014-09: $\quad$ Anne Fetsje Sluis: Towards a virtuous society: Virtues as potential instruments to enhance

2014-10: Gerdien de Vries: Pitfalls in the Communication about CO2 Capture and Storage

2014-11: Thecla Brakel: The effects of social comparison information on cancer survivors' quality of life: A field-experimental intervention approach

2014-12: Hans Marien: Understanding and Motivating Human Control: Outcome and Reward Information in Action

2014-13: $\quad$ Daniel Alink: Public Trust: Expectancies, Beliefs, and Behavior

2014-14: Linda Daphne Muusses: How Internet use may affect our relationships: Characteristics of Internet use and personal and relational wellbeing

2014-15: Hillie Aaldering: Parochial and universal cooperation in intergroup conflicts

2014-16: Martijn Keizer: Do norms matter? The role of normative considerations as predictors of pro-environmental behavior

2015-01: $\quad$ Maartje Elshout: Vengeance

2015-02: $\quad$ Seval Gündemir: The Minority Glass Ceiling Hypothesis: Exploring Reasons and Remedies for the Underrepresentation of Racial-ethnic Minorities in Leadership Positions

2015-03: Dagmar Beudeker: On regulatory focus and performance in organizational environments 
2015-04: Charlotte Koot: Making up your mind about a complex technology: An investigation into factors that help or hinder the achievement of cognitive closure about CCS

2015-05: Marco van Bommel: The Reputable Bystander: The Role of Reputation in Activating or Deactivating Bystanders

2015-06: Kira O. McCabe: The Role of Personality in the Pursuit of Context-Specific Goals

2015-07: Wiebren Jansen: Social inclusion in diverse work settings

2015-08: Xiaoqian Li: As time goes by: Studies on the subjective perception of the speed by which time passes

2015-09: Aukje Verhoeven: Facilitating food-related planning. Applying metacognition, cue-monitoring, and implementation intentions

2015-10: Jasper de Groot: Chemosignaling Emotions: What a Smell can Tell

2015-11: Hedy Greijdanus: Intragroup Communication in Intergroup Conflict: Influences on Social Perception and Cognition

2015-12: Bart de Vos: Communicating Anger and Contempt in Intergroup Conflict: Exploring their Relational Functions

2015-13: Gerdientje Danner: Psychological Availability. How work experiences spill over into daily family interactions

2015-14: Hannah Nohlen: Solving ambivalence in context. The experience and resolution of attitudinal ambivalence

2015-15: $\quad$ Stacey Sanders: Unearthing the Moral Emotive Compass: Exploring the Paths to (Un)Ethical Leadership

2015-16: Marc Heerdink: Regulating deviance with emotions: Emotional expressions as signals of acceptance and rejection

2015-17: Danny Taufik: "Can you feel it" The role of feelings in explaining proenvironmental behavior

2015-18: $\quad$ Sarah Elbert: Auditory information and its parameters in health persuasion. The development of a tailored smartphone application to support behavior change

2016-01: $\quad$ Anna van 't Veer: Effortless morality - cognitive and affective processes in deception and its detection

2016-02: Thijs Bouman: Threat by association: How distant events can affect local intergroup relations

2016-03: Tim Theeboom: Workplace coaching: Processes and effects

2016-04: Sabine Strofer: Deceptive intent: Physiological reactions in different interpersonal contexts 
